\title{
CRISTALIZAÇÃO INDUSTRIAL A PARTIR DE SOLUÇõES: SOBRE FUNDAMENTOS E APLICAÇÕES
}

Texto sistematizado apresentado ao Departamento de Engenharia Química da Escola Politécnica da Universidade de São Paulo para obtenção de título de Livre-Docente na especialidade "Separações Térmicas e Mecânicas"

Edital EP/Concursos - 040/2011

Marcelo Martins Seckler

São Paulo

2011 


\section{REITORIA}

Proc. USP no 09.1.3503.3.8

$\begin{array}{lll}\text { Portaria } & \mathrm{n}^{\circ} \quad 1240\end{array}$

2378

O REITOR DA UNIVERSIDADE DE SÃO PAULO, usando de suas atribuições legais, EX P E D E a presente Portaria para declarar que tendo MARCELO MARTINS SECKLER, Professor Doutor, ref. MS-3, do QDUSP-PG, em Regime de Dedicação Integral à Docência e à Pesquisa, lotado na Escola Politécnica (Departamento de Engenharia Química), obtido o título de Livre-Docente, conforme elementos constantes do Processo USP n⿳0 09.1.3503.3.8, fica, a contar de 21/12/2011, designado para exercer a função de Professor Associado, ref. MS-5, do mesmo Quadro, Parte, Regime e Lotação, nos termos do artigo 84 do Estatuto da Universidade de São Paulo.

Reitoria da Universidade de São Paulo, $04 \mathrm{~J} A \mathrm{~N}$ ?ก!?
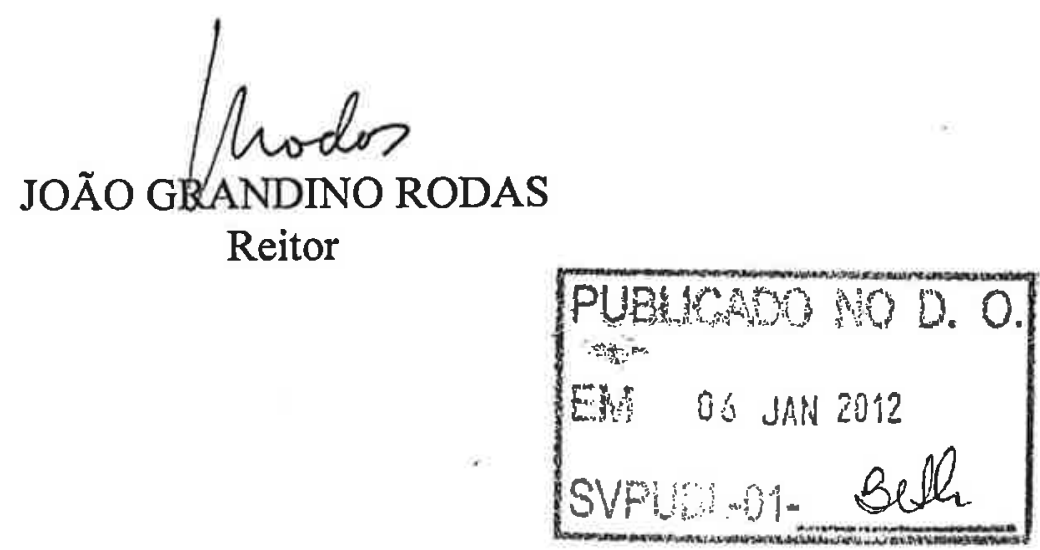


\section{UNIVERSIDADE DE SÃO PAULO}

PROCURADORIA GERAL

PG. P. 3822/11

GFCM/loduca

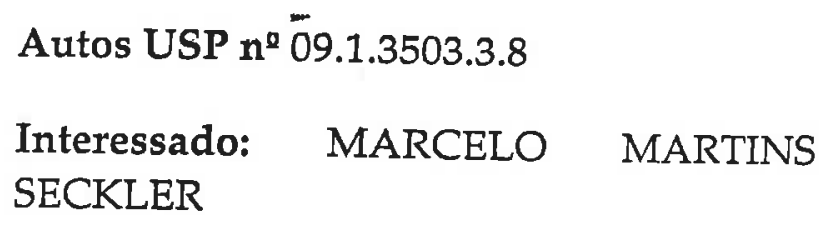

Assunto: Expedição de Título.

Tema: Concurso para a expedição de título de livre-docência Inexistência de irregularidades procedimentais que obstem seja expedido.

\section{PARECER}

Examinados os autos n.9 11.1.2053.3.1 de "concurso de livredocente", em particular as informações de fls. 81-85, e os autos n. ${ }^{2}$ 09.1.3503.3.8, conclui-se que o procedimento de concurso não apresenta irregularidades que obstem se ratifique a homologação do relatório final da comissão julgadora e se acolha a proposta de expedição do título.

Encaminhem-se os autos ao Gabinete do Magnífico Reitor.

Procuradoria Geral, 21 de dezembro de 2011

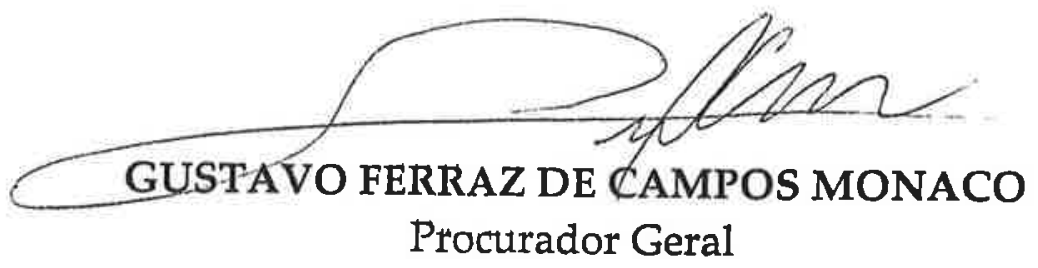


Aos queridos

Thais, Pedro e João 


\section{Resumo}

A cristalização a partir de soluções é uma operação unitária da indústria química destinada tanto à separação de componentes em sistemas homogêneos quanto à obtenção de produtos na forma de sólidos particulados. Apesar de ser empregado extensa e milenarmente, o processo de cristalização é ainda hoje insuficientemente conhecido, sobretudo no que diz respeito aos processos elementares que o constituem, a saber a nucleação primária, nucleação secundária e crescimento cristalino molecular, além de diversos fenômenos acessórios, tais como aglomeração, especiação nas soluções, micromistura, envelhecimento e polimorfismo. Se quantitativamente descritos, estes fenômenos elementares permitem explicar e prever aspectos industrialmente importantes relacionados ao processo - tais como rendimento e consumo energético - e ao produto particulado - tais como tamanho e forma dos cristais e grau de perfeição do retículo cristalino. Neste trabalho são reunidas diversas pesquisas relacionadas ao desenvolvimento e projeto de processos de cristalização a partir de uma abordagem fundamental. Na primeira destas pesquisas, um processo para obtenção de cloreto de sódio foi desenvolvido até a escala piloto. Foi também desenvolvida uma metodologia de projeto inovadora aplicável a processos de cristalização evaporativa. Na segunda pesquisa, os mecanismos de incrustação indesejável em um trocador de calor associado a um reator químico foram esclarecidos como sendo resultantes da cristalização de reagente, de produto e da deposição particulada de uma impureza. Com base nos mecanismos citados, foi sugerida uma modificação do processo - a redução da quantidade de produto recirculado na batelada - que foi implementada industrialmente com sucesso. $\mathrm{Na}$ terceira pesquisa, os fundamentos da cristalização foram utilizados para melhorar um processo de fabricação de um pigmento à base de óxidos de ferro. Foram identificadas as condições - temperatura e taxa de aeração - que favorecem a formação do produto com as características desejadas, isto é, partículas de pequenas dimensões do polimorfo goethita. A quarta pesquisa versou sobre a fluidodinâmica em sistemas sólido-liquido. A partir de estudos computacionais, foram desenvolvidas correlações para o projeto de tanques agitados visando garantir uma qualidade de suspensão especificada. No seu conjunto, as pesquisas contribuem para uma melhoria do entendimento de aspectos fundamentais selecionados dos processos de cristalização e para o emprego deste conhecimento em situações de interesse prático. 


\section{Abstract}

The crystallization from solutions is a unit operation of the chemical industry which is used both for the separation of components from a homogeneous mixture and for the synthesis of particulate products. Despite being millenary and extensively applied, the crystallization process is still nowadays insufficiently known, particularly with respect to its constitutive elementary processes, namely primary nucleation, secondary nucleation and molecular crystal growth, as well as several accessory phenomena such as agglomeration, speciation in solution, micromixing, aging and polymorphism. If quantitatively described, these elementary phenomena explain and predict industrially relevant aspects of the industrial processes - such as yield and energy consumption - and of the particulate product - such as particle shape, particle size and regularity of the crystalline lattice. In this work a number of researches are presented, which are related to the development and design of crystallization processes from a fundamental perspective. In the first research, a process for production of food grade sodium chloride has been developed to the pilot scale. An innovative methodology for the design of evaporative crystallization has been developed as well. In the second research, the mechanisms of the undesirable scaling in a heat exchanger associated to a chemical reactor have been elucidated as being derived from the reactant crystallization, the product crystallization and from the particulate deposition of an impurity. Based on the cited mechanisms, a process modification has been suggested - the reduction in the recirculation product in each batch - and successfully implemented industrially. In the third research, the fundamentals of crystallization have been applied to improve a process for the production of an iron oxide pigment. The conditions have been identified - temperature and aeration rate - that favor the formation of a product with the desired characteristics, i.e., small particles of the polymorph goethite. The fourth research concerned the fluid dynamics in solid-liquid systems. Based on computational studies, design correlations for agitated tanks have been developed aimed at assurance of a specified suspension quality. Altogether, the researches contribute to a better understanding of selected fundamental aspects of the crystallization processes and to the application of such knowledge to situations of practical interest. 


\section{SUMÁRIO}

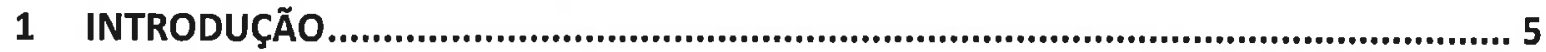

1.1 IMPORTÂNCIA DA CRISTALIZAÇÃO E PRECIPITAÇÃO A PARTIR DE SOLUÇõES ....................................... 5

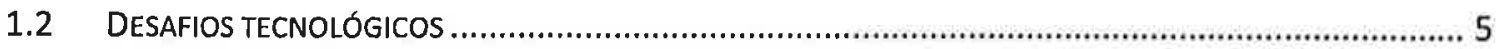

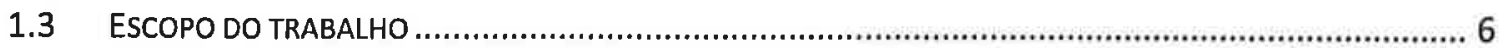

2 CRISTALIZAÇÃO DE CLORETO DE SÓDIO NA ESCALA DE $1 \mathrm{M}^{3}$ : DO PROJETO HIERÁRQUICO À OPERAÇÃO DA UNIDADE PILOTO .................................................... 10

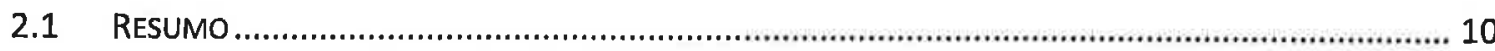

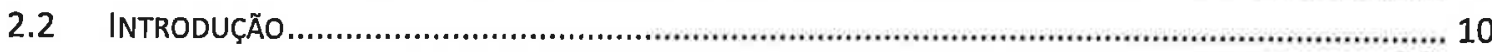

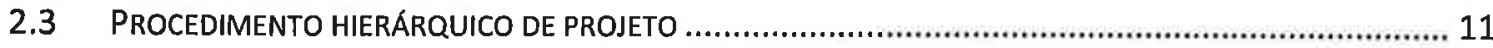

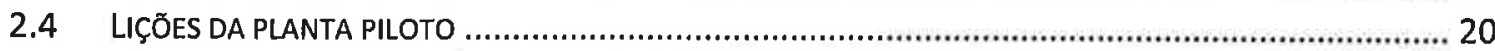

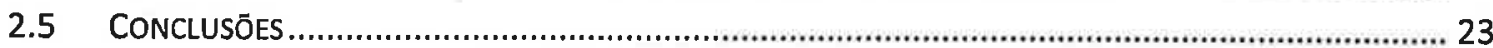

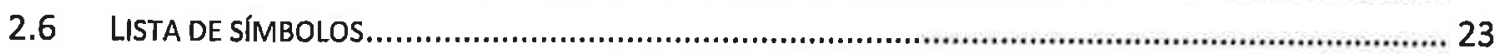

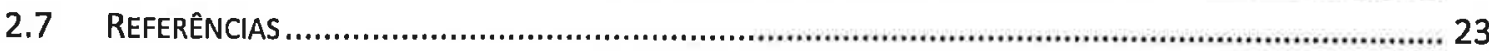

3 IDENTIFICAÇÃO DO MECANISMO DE INCRUSTAÇÃO EM UM TROCADOR DE CALOR CASCO-TUBOS

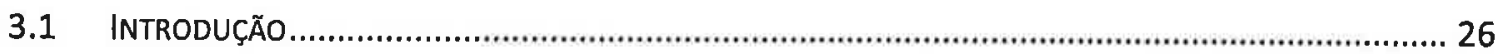

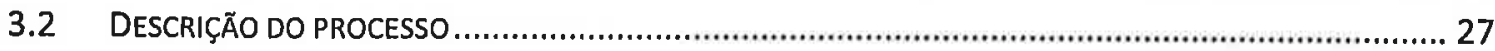

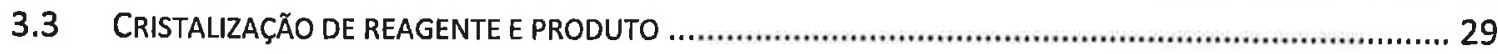

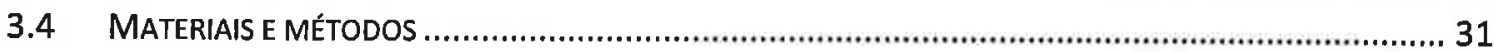

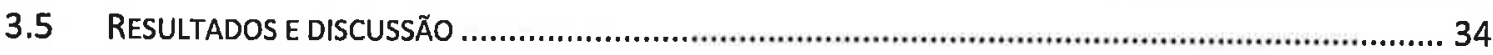

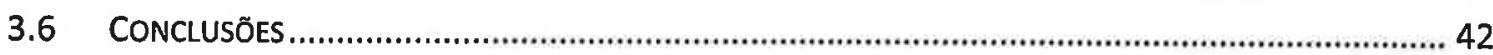

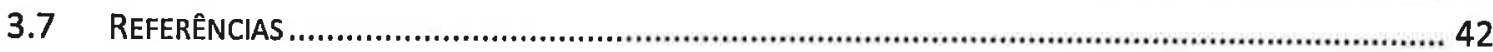

4 EFEITO DA TEMPERATURA E DA TAXA DE OXIDAÇÃO SOBRE OS POLIMORFOS E A MORFOLOGIA DAS PARTÍCULAS DE ÓXIDOS AMARELOS SINTÉTICOS DE FERRO........... 44

4.1 INTRODUÇÃO

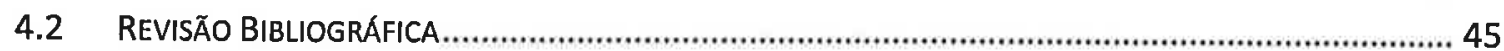

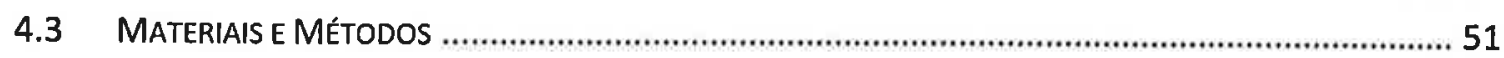

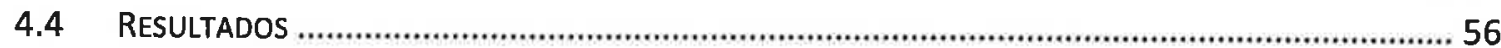

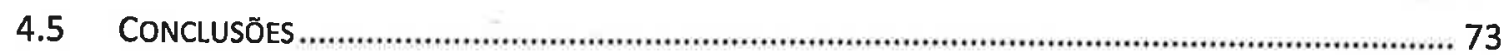

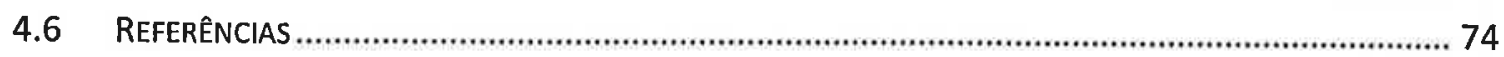

5 QUALIDADE DA SUSPENSÃO EM TANQUES AGITADOS.......................................... 78

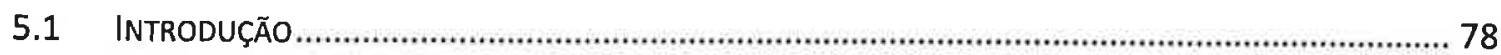


5.2 PROCEDIMENTO

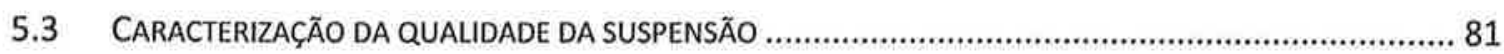

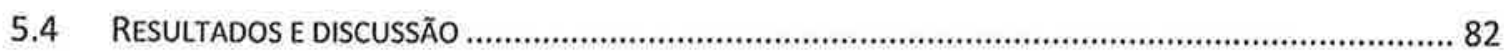

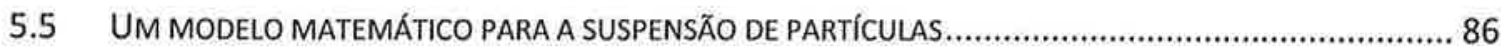

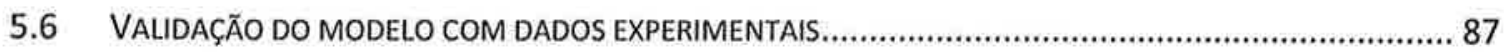

5.7 PROJETO DE MISTURADORES SÓLIDO-LÍQUIDO COM BASE NA QUALIDADE DA SUSPENSÄO. ................... 88

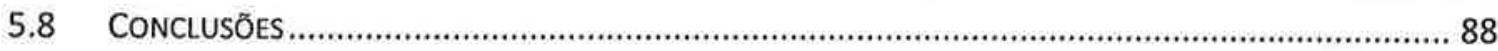

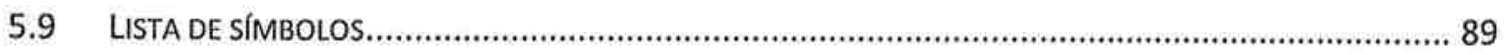

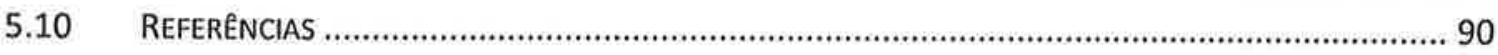




\section{INTRODUÇÃo}

\subsection{Importância da cristalização e precipitação a partir de soluções}

Cerca de $70 \%$ dos produtos da indústria química são apresentados na forma de sólida. Muitos deles são obtidos por cristalização, os quais abrangem "commodities", intermediários, produtos da química fina, fármacos, aditivos de alimentos, pigmentos, produtos biotecnológicos, produtos na nanoescala, entre outros. Além disso, a cristalização é muito empregada como processo de separação em sistemas homogêneos líquidos, por exemplo, no tratamento de efluentes domésticos e da indústria de galvanoplastia, na purificação de água visando seu reuso, na purificação de fármacos, de intermediários orgânicos, entre outros. Assim sendo, seja pelo seu uso na síntese de produtos na forma particulada, seja como operação unitária de purificação, a cristalização encontra expressivo emprego na indústria química, sendo a operação unitária mais comumente empregada depois da destilação.

Quando o produto sendo cristalizado apresenta uma baixa solubilidade, o processo de cristalização é usualmente chamado de precipitação. Processos de precipitação são freqüentes em aplicações de alto valor agregado (como medicamentos, pigmentos, etc.) e no tratamento de efluentes. Em anos recentes, tem crescido a demanda para se desenvolver, por precipitação, novos produtos e processos, explorando as propriedades da matéria na nanoescala. As possibilidades de expansão neste campo são imensas, pois os métodos de precipitação são excelentes para sintetizar partículas na faixa de tamanhos nanométrica: são flexiveis quanto à variedade de características das partículas obtidas, de baixo custo e, freqüentemente, têm baixo impacto ambiental.

\subsection{Desafios tecnológicos}

Apesar da cristalização ser empregada extensa e milenarmente, há ainda grandes dificuldades no projeto, operação e controle do processo de cristalização, bem como na obtenção de produtos com a qualidade desejada. Para que se entendam estas dificuldades, é importante reconhecer que a cristalização, assim como outros processos de separação homogênea, é entendida a partir da termodinâmica e dos fenômenos de transporte.

A termodinâmica estabelece as condições para equilíbrio nos sistemas sólido-líquido. Ela freqüentemente permite que se determine o rendimento mássico, a temperatura e o consumo energético dos processos de cristalização.

Quando o sistema é afastado de sua condição de equilíbrio por meio de uma ação externa (por exemplo, adição de calor ou de um anti-solvente), o processo de cristalização se estabelece. Este abrange um conjunto de processos elementares que ocorrem mais ou menos concomitantemente, tais como nucleação primária, nucleação secundária, crescimento molecular e aglomeração. Além destes, diversos outros fenômenos acessórios podem também estar presentes, tais como reação química, especiação das soluções, micromistura, envelhecimento e 
polimorfismo. Se quantitativamente descritos, estes fenômenos elementares permitem explicar não apenas a taxa da cristalização, mas também as características do material particulado, tais como tamanho, forma, grau de perfeição do retículo cristalino. No entanto, as teorias de cristalização são limitadas, pois não permitem prever quais os processos ativos numa situação particular. Elas permitem apenas identificar as quais variáveis afetam cada um destes processos. $\mathrm{E}$ mesmo quando os fenômenos ativos e suas taxas são determinados experimentalmente, os resultados são difíceis de traduzir para outras escalas, pois os processos elementares são sensiveis à fluidodinâmica, ou regimes de operação, pois eles são dependentes da supersaturação.

Assim sendo, o conhecimento completo de sistemas de cristalização depende não apenas de informações sobre o equilíbrio termodinâmico, mas também informações experimentais sobre cada processo elementar da cristalização, obtidas em condições próximas às condições de interesse. Como estas premissas raramente são atendidas, é importante dominar dos fundamentos dos processos de cristalização, para assim explorar ao máximo os conhecimentos fragmentares disponiveis para se otimizar, projetar e controlar processos de cristalização. Além disso, são desejáveis desenvolvimentos que permitam ampliar a abrangência das teorias de cristalização. Vejamos a seguir como isso pode ser feito.

No caso de otimização, o sistema de cristalização na escala real pode fornecer os subsídios experimentais, por exemplo, pela simples caracterização de amostras de cristais, que possibilitem identificar os processos elementares relevantes. Este conhecimento é freqüentemente suficiente para se propor modificações no processo que levem à melhoria do processo ou produto. Para projeto, experimentos em escala piloto ou em unidades industriais similares podem ser necessários. Para o controle do processo de cristalização, modelos matemáticos aplicáveis na escala industriais são desejáveis, pois a cristalização é um processo não-linear, o que resulta freqüentemente em sistemas instáveis e difíceis de controlar.

A abrangência das teorias de cristalização existentes pode ser ampliada a partir de uma caracterização fluidodinâmica adequada. No caso de cristalização de produtos solúveis, que normalmente envolve partículas na escala de tamanhos milimétrica, a suspensão de sólidos e sua distribuição no cristalizador são relevantes.

\subsection{Escopo do trabalho}

Neste trabalho são reunidas diversas pesquisas relacionadas ao projeto e otimização de processos de cristalização a partir de uma abordagem fundamental. Além disso, é apresentado um estudo sobre a fluidodinâmica de sistemas solido-liquido em tanques agitados, que usualmente são encontrados em cristalizadores. Os trabalhos foram conduzidos através de uma variedade de projetos independentes, que exploram os aspectos relacionados na seção anterior. 


\subsubsection{Desenvolvimento DE PROCesso de CRISTalização DE CloReto DE Sódio grau ALIMENTAR $^{1}$}

Nesta pesquisa os fundamentos da cristalização são utilizados para propor um procedimento para o projeto de cristalizadores, baseado em informações termodinâmicas e em informações cinéticas fragmentares.

Processos de cristalização na escala industrial são freqüentemente conduzidos em condições subótimas com respeito à qualidade dos produtos. Os dois principais motivos para esta situação estão ligados à presença da fase sólida, cujo comportamento é difícil de prever teoricamente. Por isso, o projeto freqüentemente é baseado em dados obtidos em escala de laboratório, mas mesmo neste caso há dificuldades, pois os fenômenos da cristalização são fortemente dependentes de escala.

Visando minimizar as dificuldades citadas, neste trabalho, foi desenvolvida uma metodologia hierárquica para o projeto de processos de cristalização, construída a partir de considerações de produto, da caracterização físico-química da tarefa da cristalização, dos fluxos do processo e do projeto detalhado dos estágios da cristalização. No procedimento procurou-se aliar a teoria da cristalização aos conhecimentos experimentais fragmentares prévios do comportamento do sistema de interesse frente à cristalização. A metodologia de projeto foi desenvolvida para a cristalização de cloreto de sódio na escala de $1.000 \mathrm{~kg} / \mathrm{h}$ de produto sólido. A unidade piloto foi construída segundo este projeto, ela contou com dois cristalizadores de $1.1 \mathrm{~m}^{3}$ cada. Durante a partida da unidade piloto, foram coletados dados que permitiram formular melhorias para a metodologia de projeto.

\subsubsection{IDENTIFICAÇÃO DO MECANISMO DE INCRUSTAÇÃO EM UM TROCADOR DE CALOR CASCO-TUBOS 2}

Neste trabalho os fundamentos da cristalização são utilizados para otimizar um processo na escala industrial, para o qual apenas informações termodinâmicas (curva de solubilidade) são conhecidas.

Incrustação é um fenômeno indesejável freqüentemente encontrado na indústria química, que muitas vezes pode ser minimizado, se suas causas forem conhecidas. No caso em pauta, um composto orgânico é sintetizado na forma solúvel em um reator acoplado a um trocador de calor casco-tubos em escala real. A incrustação nos tubos dificulta a remoção do calor gerado na reação. A partir da curva de solubilidade do produto, da inspeção realizada nos tubos do trocador e de caracterização físico-química dos depósitos, foram investigadas as causas da incrustação e

\footnotetext{
${ }^{1}$ Uma versao simplificada deste capítulo foi aceita como trabalho completo para publicação no BIWIC 2011$18^{\text {th }}$ International Worshop on Industrial Crystallization. Co-autores M. Giulietti (UFSCar), A. Bernardo (UFSCar), S. Derenzo (IPT), E. Cekinski (IPT), A. L. Nunis (USP, IPT), H.J.M. Kramer (TUDelft), Max Bosch (Refinaria Nacional de Sal).

2 Andréia Virgínia Pepe Ambrozin, Melhoria da troca térmica pelo controle do processo de incrustação, Dissertação de Mestrado, IPT, 2006. Orientador Marcelo Seckler. Trabalho completo publicado no III ENBTEQ e I TECNIQ, Seminário sobre Tecnologia na Indústria Química, São Paulo, 2006, São Paulo. p.310 313.
} 
identificados os principais fatores operacionais que as controlam. Uma das medidas sugeridas foi implementada industrialmente, tendo resultado numa diminuição efetiva da incrustação nos trocadores.

\subsubsection{EFEITO DA TEMPERATURA E DA TAXA DE OXIDAÇ̃̃o SOBRE OS POLIMORFOS E A MORFOLOGIA DAS PARTÍCULAS DE ÓXIDOS AMARELOS SINTÉTICOS DE FERRO ${ }^{3}$}

Nesta pesquisa os fundamentos da cristalização são utilizados para otimizar um processo na escala de bancada, para o qual apenas informações fragmentares de equilíbrio e cinética são conhecidas.

Quando a cristalização é empregada como método de síntese de partículas, o produto obtido freqüentemente deve cumprir funções específicas, as quais podem em geral ser realizadas se o produto for constituído da fase cristalina (polimorfo) adequada e na forma de um particulado com morfologia e tamanho desejados. Os pigmentos à base de óxidos de ferro são casos típicos de compostos que apresentam polimorfismo e cuja funcionalidade, no caso a qualidade da cor produzida, depende tanto do polimorfo formado quanto do tamanho da partícula.

Muito embora não seja possível prever a existência de polimorfos, teorias de cristalização auxiliam a identificar condições que favorecem a formação de um ou outro polimorfo e das características morfológicas das partículas. Neste trabalho, os polimorfos de óxidos de ferro produzidos a partir de soluções de ferro (II) foram identificados em diferentes condições de temperatura e taxa de aeração. Foram identificadas as condições que favorecem a formação de partículas de goethita de pequenas dimensões, que são as condições preferenciais para emprego como pigmento amarelo.

\subsubsection{QUALIDADE DA SUSPENSÃO EM TANQUES AGITADOS 4}

Neste trabalho é abordada a fluidodinâmica em sistemas sólido-liquido. O estudo oferece subsídios para estender a aplicabilidade das teorias de cristalização.

A cristalização a partir de soluções é freqüentemente conduzida industrialmente em tanques agitados, os quais homogeinizam o líquido e o material particulado e promovem um contato íntimo das partículas sendo formadas entre si e com a solução.

O projeto de tanques agitados é comumente baseado no critério de suspensão mínima, condição suficiente para evitar que os sólidos se depositem no fundo do tanque. No entanto, em processos de cristalização, é desejável garantir que os sólidos estejam uniformemente distribuídos no interior do tanque. Para esta situação, os estudos existentes ainda não são suficientes para

\footnotetext{
${ }^{3}$ Nelson Pedro Baptista, Investigaçăo das características cristalográficas de óxidos amarelos sintéticos de ferro produzidos por nucleações primárias heterogêneas, Dissertação de mestrado, IPT 2010. Orientador Marcelo Seckler. $O$ aluno é engenheiro da empresa produtora de pigmentos Lanxess.

${ }^{4}$ Publicado como Cekinski E, Giulietti M, Seckler MM. A new approach to characterize suspensions in stirred vessels based on computational fluid dynamics. Brazilian Journal of Chemical Engineering, Vol. 27, No. 02, pp. 265 - 273, April - June, 2010.
} 
garantir a homogeneidade em tanques agitados em escala real. Neste trabalho, a agitação em tanques de diferentes escalas é estudada por meio de simulações de fluidodinâmica. Com base nestes estudos, correlações empíricas são propostas para o projeto de tanques agitados visando garantir uma qualidade de suspensão pré-especificada. A metodologia é aplicável para desenvolver correlações de projetos para tanques de quaisquer geometrias. 


\section{Cristalização de cloreto de sódio na escala de $1 \mathbf{~ m}^{3}$ : do projeto hierárquico à operação da unidade piloto ${ }^{5}$}

\subsection{Resumo}

Um processo para produção de cloreto de sódio por cristalização foi desenvolvido até a escala piloto. O projeto conceitual do processo foi desenvolvido de forma hierárquica segundo a metodologia de Bermingham (2003), que adota a seguintes etapas: considerações de produto, caracterização físico-química da tarefa da cristalização, projeto do processo de cristalização e projeto detalhado dos estágios de cristalização. O método selecionado foi a cristalização evaporativa contínua em dois estágios em cristalizadores do tipo circulação forçada (FC). As respostas do processo foram interpretadas em termos dos processos elementares da cristalização. A maior dificuldade durante a posta em marcha da operação foi a forte tendência a incrustação de sólidos sobre as paredes do cristalizador e das linhas de circulação. Ela foi fortemente reduzida por melhorias no sistema de controle da unidade, pelo aumento do teor de sólidos no cristalizador e por restrições à elevação da temperatura da suspensão no circuito de recirculação. Estes achados formam regras heurísticas de projeto que foram incorporadas ao método de projeto de cristalizadores.

\subsection{Introdução}

A síntese de processos químicos é uma tarefa complexa que requer muitas hipóteses e tem soluções múltiplas. Por isso, é desejável que se disponha de procedimentos sistemáticos que permitam desenvolver processos: (i) com alta qualidade; (ii) rapidamente, com um mínimo de esforço experimental; (iii) reprodutíveis, isto é, com argumentos e decisões de projeto rastreáveis. Esta necessidade já é conhecida há tempo, mas a grande diversidade dos processos químicos dificulta a construção de uma sistemática geral. Por isso, diversos procedimentos têm sido propostos para sistemas específicos. No caso de processos de cristalização a partir de soluções, metodologias foram propostas para sistemas que produzem soluções sólidas (Lin et al., 2008), sistemas multicomponente que requerem cristalização fracionada (Cisternas et al., 2006) e sistemas polimórficos (Lin et al., 2007). Além disso, procedimentos foram desenvolvidos para o projeto integrado da cristalização e do processamento a jusante dos cristais, como filtração, lavagem, desaguamento, recristalização e secagem (Wibowo et al., 2001). Apenas recentemente uma abordagem genérica para síntese de projetos foi proposta. Ela é baseada na decomposição do processo em tarefas que representam os eventos físicos fundamentais (Lakerveld et al., 2009; Menon et al., 2007) e é adequada para a intensificação de processos (Lakerveld et al., 2010). No

\footnotetext{
${ }^{5}$ Uma versao simplificada deste capítulo foi aceita como trabalho completo para publicação no BIWIC 2011- $18^{\text {th }}$ International Worshop on Industrial Crystallization. Co-autores M. Giulietti (UFSCar), A. Bernardo (UFSCar), S. Derenzo (IPT), E. Cekinski (IPT), A. L. Nunis (USP, IPT), H.J.M. Kramer (TUDelft), Max Bosch (Refinaria Nacional de Sal).
} 
entanto, esta metodologia requer desenvolvimentos adicionais antes de poder ser aplicada pelo projetista.

Para atingir uma melhor previsão da qualidade do produto final, procedimentos de projeto empregando modelos matemáticos precisos dos fenômenos da cristalização têm sido propostos (Bermingham et al., 1998; Gerstlauter et al., 2006; Kramer et al., 1999), mas a dificuldade de obter dados experimentais de qualidade limita a utilidade desta abordagem. Outra forma de melhorar a qualidade do produto é pela incorporação de controle de processos já na etapa de projeto (Grosch et al., 2008). Esta linha baseia-se no fato da cristalização envolver etapas altamente não-lineares e estar inserida num processo que normalmente envolve varias operações unitárias ou estágios e reciclos.

Douglas propôs um procedimento hierárquico de projeto que subdivide o projeto em etapas, sendo que em cada etapa um número limitado de aspectos é analisado, simplificando assim o processo de formulação de hipóteses e de tomada de decisões. Esta abordagem foi proposta inicialmente para sistemas líquido-vapor (Douglas, 1985) e depois foi adaptada para sistemas sólido-líquido-vapor por Rajagopal e colaboradores (Rajagopal et al., 1992). Posteriormente, Bermingham e colaboradores (2000) propuseram um procedimento análogo para cristalização a partir de soluções, com ênfase no emprego de modelos preditivos. Propõe-se aqui empregar este procedimento hierárquico, mas sem a ênfase para modelos preditivos. Desta forma, a abordagem torna-se menos restritiva, pois se torna aplicável a sistemas para os quais uma quantidade limitada de informações seja disponível. A aplicabilidade do procedimento será demonstrada pela sua aplicação ao projeto e implementação de uma unidade piloto para fabricação de cloreto de sódio. As lições aprendidas durante a posta em marcha da unidade piloto serão usadas para melhorar a metodologia e a base de conhecimento para o projeto de unidades de cloreto de sódio.

\subsection{Procedimento hierárquico de projeto}

O procedimento adotado é similar ao proposto por Bermingham e colaboradores (2000) e melhorada posteriormente (Bermingham, 2003). Ele é constituído por niveis de projeto relacionados hierarquicamente. Em cada nível de projeto as mesmas tarefas são realizadas. 0 ponto de partida são as especificações de projeto daquele nível. A partir delas, são identificadas as variáveis de projeto pertinentes. Em seguida, são coletados os conhecimentos necessários para correlacionar as variáveis com as especificações. Estes conhecimentos podem ser regras heurísticas, dados experimentais ou modelos fenomenológicos pertinentes. Se os conhecimentos forem considerados insuficientes, dados experimentais adicionais ou novos modelos podem ser requeridos. Em seguida, é realizada a etapa de síntese do projeto, onde alternativas são geradas e comparadas, sendo selecionada a alternativa que atinja as especificações referentes ao nível de projeto correspondente. A alternativa selecionada é desenvolvida até se determinar valores para as variáveis de projeto. As variáveis de projeto realizadas em cada nível são consideradas especificações de projeto no nível seguinte. 
O procedimento constitui-se de um nível de projeto no qual as especificações iniciais do projeto são formuladas e por quatro níveis de projeto em hierarquia decrescente, mostrados na Tabela 2-1. O nivel I concerne o projeto do produto, os níveis II e III o projeto do processo e o nível IV o projeto do cristalizador. Esta hierarquia pode ser aplicada a qualquer processo de cristalização a partir de soluções.

Tabela 2-1. Níveis de projeto propostos por Bermingham (2003).

\begin{tabular}{|l|l|}
\hline Nivel de projeto & Descrição \\
\hline 0 & Especificações de projeto iniciais \\
\hline I & Projeto do produto cristalino \\
\hline II & Projeto físico-químico da tarefa de cristalização \\
\hline III & Projeto do processo de cristalização \\
\hline IV & Projeto de um estágio de cristalizaçăo \\
\hline
\end{tabular}

Nos itens a seguir, os conteúdos de cada nível de projeto são apresentados e aplicados para o caso estudado, o desenvolvimento de um processo para produção de sal em escala piloto.

\subsubsection{NíVEL DE PROJETO 0 - ESPECIFICAÇÕES INICIAIS}

Neste nivel são identificadas as especificações iniciais do projeto, subdivididas em três categorias: especificações do produto, do processo e do projeto.

\section{Especificações do produto}

Trata-se das especificações relativas ao desempenho do produto, tanto para o seu processamento a jusante da unidade de cristalização na própria unidade industrial (filtrabilidade, geração de pó, etc.) quanto para a sua aplicação como produto particulado (cor, sabor, aparência, etc.). No caso em pauta há dois produtos, o cloreto de sódio grau alimentar e o cloreto de sódio grau P.A. Em ambos os casos, o produto deve ser facilmente separável do licor-mãe, conter teores de impurezas especificados (Tabela 2-1) e, no caso do sal grau alimentar, ter distribuição granulométrica similar à apresentada na Figura 2-1.

\section{Especificações de processo}

Trata-se de especificações como a capacidade da unidade industrial, o consumo energético, a controlabilidade, a disponibilidade, considerações de segurança, saúde e ambiente, etc. No caso em pauta a capacidade especificada para a unidade piloto é de $1 \mathrm{~m}^{3} / \mathrm{h}$. A matéria prima para o sal grau alimentar é uma salmoura concentrada derivada da evaporação de água do mar. Para o grau P.A., a matéria prima é uma salmoura mais pura. Os teores de impurezas destas matérias primas são mostrados na Tabela 2-2. As utilidades disponíveis são vapor a $225 \mathrm{kPa}$, energia elétrica e água marinha a $25^{\circ} \mathrm{C}$. Um tema considerado importante no projeto são as paradas da unidade para remover incrustações. 


\section{Especificações de projeto}

Estas especificações referem-se ao processo do projeto, e incluem o orçamento disponível para o projeto, o tempo para comercialização, experiência dos projetistas, etc. No caso em pauta a principal especificação do projeto é o desenvolvimento de tecnologia pela própria empresa.

Tabela 2-2. Algumas especificações do nível 0 . (*) estimado

\begin{tabular}{|l|l|l|l|l|l|}
\hline Variável & Unidade & Matéria prima & Matéria prima & Produto & Produto \\
\hline & $\begin{array}{l}\text { Salmoura para } \\
\text { sal P.A. }\end{array}$ & $\begin{array}{l}\text { Salmoura para } \\
\text { sal alimentar }\end{array}$ & P.A. & Grau alimentar \\
\hline Pureza & \%massa base seca & - & - & $>99.9$ & $>99.2$ \\
\hline $\mathrm{Ca}$ & \%massa & 0.03 & $0.27\left(^{*}\right)$ & $<0.001$ & $<0.02$ \\
\hline $\mathrm{Mg}$ & \%massa & 0.1 & 0.9 & $<0.002$ & $<0.08$ \\
\hline $\begin{array}{l}\text { Tamanho da } \\
\text { partícula }\end{array}$ & - & $\begin{array}{l}\text { Não } \\
\text { especificado }\end{array}$ & & $\begin{array}{l}\text { Não } \\
\text { especificado }\end{array}$ & Ver Figura 2-1 \\
\hline
\end{tabular}

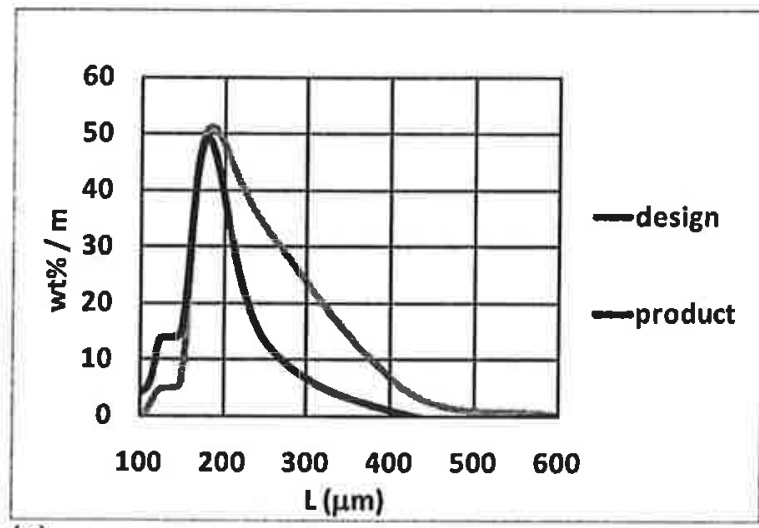

(a)

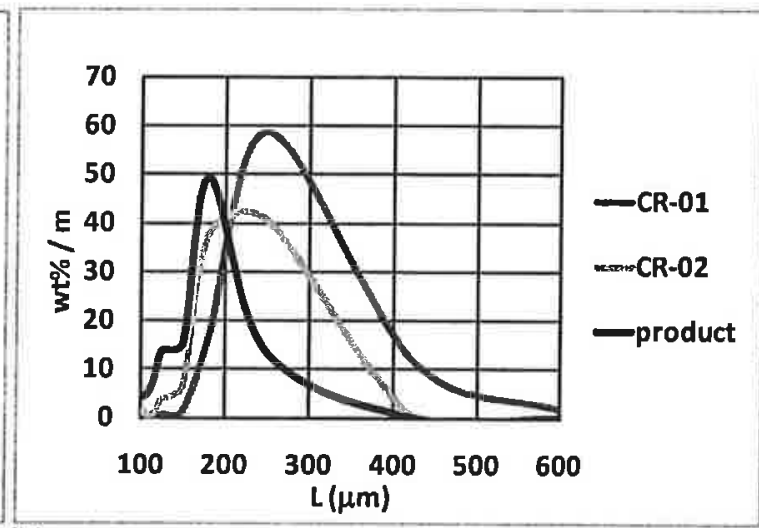

(b)

Figura 2-1. Distribuição de tamanho de partícula: (a) especificação de projeto e produto típico obtido na unidade piloto (o produto refere-se ao material obtido após centrifugação e secagem); (b) cristais obtidos no $1^{\circ}$ cristalizador, $2^{\circ}$ cristalizador e produto.

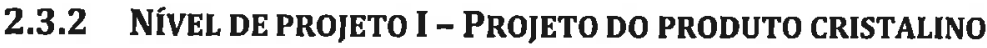

Neste nível procura-se identificar as propriedades físicas e químicas do produto necessárias para que ele apresente o desempenho especificado no nivel anterior. Por exemplo, para que um produto seja facilmente filtrável, as partículas devem ser grandes, de tamanho uniforme e não devem ter formato tabular. Se o desejado for conferir um sabor intenso ao produto, as partículas devem ser pequenas para que se dissolvam rapidamente. No caso em pauta, os produtos já são comercialmente disponiveis, as propriedades desejadas já são conhecidas, em termos de pureza e tamanho de partícula, e já foram especificadas no nível de projeto 0 (Tabela 2-2 e Figura 2-1).

\subsubsection{Nível de PROJETo II - ProjeTo físico-Químico da TAREFA DE CRISTALIZAÇÃo}

Neste nível é identificada a rota tecnológica que fornece o produto especificado no nível anterior da forma mais econômica e sustentável. Os conhecimentos necessários são principalmente o equilíbrio termodinâmico do sistema na região sólido-líquido e alguns conceitos elementares da teoria da cristalização que permitem relacionar processo com características físico-químicas do produto. 


\section{Seleção do solvente}

O solvente influencia características do produto. Produtos solúveis num dado solvente tendem a formar partículas na faixa milimétrica $\left(10^{-4}\right.$ a $\left.10^{-3} \mathrm{~m}\right)$ e de alta pureza, enquanto produtos pouco solúveis formam, em geral, partículas na faixa micrométrica $\left(10^{-6}\right.$ a $\left.10^{-5} \mathrm{~m}\right)$ e impuras. Compostos pouco solúveis são também mais sujeitos a apresentar polimorfismo. O solvente também influencia o processo. Por exemplo, se o composto tem alto valor comercial, um solvente no qual o produto seja pouco solúvel pode ser escolhido para promover uma alta recuperação do composto. Caso seja necessário usar um solvente misto, o processo deve contemplar a purificação e reciclo dos solventes.

No caso do sal, o solvente mais conveniente é a água, por dissolver o sal até uma alta concentração, favorecendo assim a formação de cristais grandes e puros, que são características desejáveis tanto para facilitar a separação do licor-mãe quanto para facilitar a lavagem dos cristais, necessária para se obter cristais puros. Além disso, a água é abundante e barata.

\section{Método de cristalização}

A cristalização é promovida por uma ação externa, que pode ser a adição de calor, a remoção de calor, a adição de um anti-solvente ou de um reagente químico. A natureza da ação externa define o método de cristalização economicamente mais favorável (Kramer et al., 1999), respectivamente cristalização evaporativa, por resfriamento, por anti-solvente e precipitação. Para compostos solúveis, cristalização evaporativa ou por resfriamento são os métodos mais adequados. Se adicionalmente a solubilidade variar pouco com a temperatura, apenas cristalização evaporativa pode ser usada. Para compostos pouco solúveis, a cristalização por antisolventes ou a precipitação podem ser aplicados. Assim sendo, a seleção de métodos de cristalização é determinada a partir do diagrama de fases do sistema. Em geral, apenas uma região do diagrama de fases é relevante, aquela que contém as regiões de líquido e sólido-líquido para o composto de interesse (o soluto), comumente expressa na forma da curva de solubilidade do composto.

No caso em pauta, o sal é altamente solúvel em água, e a solubilidade praticamente não varia com a temperatura (Mullin, 2001), de modo que a cristalização evaporativa é a única escolha (Kramer et al., 1999).

\section{Materiais de construção}

Materiais de construção são relevantes, pois salmouras são corrosivos para metais, especialmente a altas temperaturas. Se temperaturas abaixo de $100{ }^{\circ} \mathrm{C}$ forem usadas, é possível empregar materiais poliméricos (p.ex. PVC) para tubulações e compósitos de polímeros com fibra de vidro para o corpo do cristalizador. 


\section{Número de etapas de cristalização}

A cristalização em apenas uma etapa ${ }^{6}$ normalmente é suficiente para que o produto atinja a pureza requerida, já que a grande maioria das aplicações industriais trata de sistemas eutéticos. No entanto, quando a solução contém impurezas similares ao composto sendo cristalizado, estas substituem isomorficamente parte das moléculas do composto principal no retículo cristalino, gerando produtos impuros e conseqüentemente implicando na necessidade de uma ou mais recristalizações.

Outras duas formas de incorporação de impurezas no produto são originadas do próprio licormãe. Na primeira delas, o licor-mãe contendo impurezas é incorporado aos cristais na forma de inclusões fluidas, um fenômeno comum quando a cristalização é conduzida sob alta supersaturação. A segunda é trazida pelo licor-mãe aderido sobre a superfície dos cristais que deixam o cristalizador. Nestes dois casos mais de uma etapa de cristalização pode ser necessária.

Outro motivo para se empregar uma ou mais recristalizações é obter partículas diferenciadas. Como nas etapas finais de cristalização a solução é mais pura, resultam em geral cristais maiores e, em alguns casos, com morfologia diferenciada.

Para a cristalização de sal grau alimentar, as principais impurezas são o magnésio e, secundariamente, o cálcio e o sulfato. Estes íns diferem substancialmente dos íons sódio e cloro que compõem o retículo cristalino do sal, tanto no que diz respeito ao raio dos íons quanto às suas cargas elétricas. Por isso, é provável que substituição isomórfica não seja importante. Inclusões fluidas e incorporação superficial podem ocorrer dependendo respectivamente da supersaturação no cristalizador e da eficiência da lavagem dos cristais. Por outro lado, a prática industrial mostra que tanto cristalizadores evaporativos quanto lagos solares são capazes, em uma única etapa, de gerar um sal grau alimentar dentro da especificação. Assim sendo, propõe-se neste projeto a cristalização em uma etapa, mas tomando-se precauções para minimizar a incorporação de impurezas pelos mecanismos mencionados (ver nivel de projeto IV). Para o sal P.A., uma segunda etapa seria necessária. Na planta piloto, propõe-se empregar uma salmoura mais pura como matéria prima.

\section{Temperatura e pressāo}

Temperaturas mais elevadas são preferidas porque normalmente levam a cristais maiores e mais puros. No entanto, o limite máximo para a temperatura do cristalizador é determinado pela temperatura da fonte quente, que fornece o calor necessário para a evaporação. Nesse caso, a fonte quente é o vapor de exaustão de uma turbina a gás, disponível a $225 \mathrm{kPa}$ (temperatura de saturação de $124^{\circ} \mathrm{C}$ ). Uma temperatura de cristalização de $100^{\circ} \mathrm{C}$ é escolhida para permitir uma troca térmica eficiente entre o vapor vivo e o meio de cristalização, bem como para permitir o emprego de materiais poliméricos e compósitos na construção da unidade. 0 cristalizador opera

\footnotetext{
${ }^{6}$ Na cristalização evaporativa o número de "etapas de cristalização" refere-se ao número de vezes que o sólido é dissolvido e recristalizado. Ele é distinto do número de estágios de evaporação, que se refere ao número de vezes que o vapor gerado na cristalização é reaproveitado.
} 
na pressão de saturação da salmoura a $100^{\circ} \mathrm{C}$, neste caso $75,2 \mathrm{kPa}$. A concentração da suspensão pode ser estimada como sendo a de uma solução saturada, isto é, $39,1 \mathrm{~g}$ sal / $100 \mathrm{~g} \mathrm{H}_{2} \mathrm{O}$.

\subsubsection{Nível DE PROJETo III - ProjeTo do PROCESSO de CRISTALIZAÇÃo}

Neste nivel a rota tecnológica especificada no nivel anterior norteia o desenvolvimento do processo de cristalização. Nesta etapa define-se o modo de operação (contínuo ou em bateladas), métodos para conservação de energia, configurações para a alimentação, reciclo e purga. Nesta etapa são gerados os fluxogramas de processo. Balanços de massa e energia possibilitam definir composições, temperaturas e pressões das principais correntes do processo.

\section{Modo de operação}

As vantagens de cada modo de operação, contínuo ou em bateladas, foram abordadas por diversos autores, sendo que Nyvlt e colaboradores (2001) apresentam de forma didática os pontos relevantes, alguns dos quais são descritos a seguir. A cristalização contínua é vantajosa quanto ao consumo de matéria prima, de energia e ao investimento requerido, além de proporcionar variações pequenas na qualidade do produto. As desvantagens do regime contínuo são a operação e equipamentos complexos. O regime em bateladas tem como vantagens a simplicidade de operação e a facilidade para contornar problemas de incrustação. A cristalização contínua é em geral preferida nas seguintes condições: elevada capacidade de produção, pequeno número de produtos a serem processados na mesma unidade, produto com pequeno valor agregado e pouca restrição quanto ao tempo para colocação no mercado.

A unidade piloto em pauta tem dupla finalidade: servir de base para a ampliação de escala para uma unidade industrial de $25 \mathrm{t} / \mathrm{h}$ sal e servir como unidade em escala real para produção de sal P.A.. Como a capacidade (da unidade industrial) é elevada, o número de produtos é pequeno, os produtos têm baixo valor agregado e o tempo para colocação no mercado não é critico, o modo de operação contínuo é selecionado.

\section{Método para minimizar o consumo de energia}

Na cristalização evaporativa, o consumo de energia pode ser minimizado de três diferentes maneiras: evaporação em múltiplos estágios, recompressão mecânica do vapor e recompressão térmica do vapor. Na evaporação em múltiplos efeitos, vapor vivo fornece a energia necessária para evaporação do solvente no primeiro efeito. $O$ vapor vegetal ali gerado é empregado em um estágio subseqüente e assim sucessivamente. A recompressão mecânica do vapor permite o emprego de apenas um evaporador, e utiliza energia elétrica para recomprimir o vapor gerado. A recompressão térmica é similar, mas a principal fonte de energia é o vapor.

A escolha do método para economizar energia depende da disponibilidade e do custo da energia elétrica e do vapor no local de implantação da unidade. No caso em pauta, estes fatores apontaram que a evaporação em múltiplos estágios é a mais indicada. Se $N$ estágios de evaporação são empregados, o consumo energético é $1 / N$ vezes o consumo energético de um sistema com um único efeito. 0 número máximo de estágios depende da temperatura disponível do vapor vivo, que define a temperatura do primeiro estágio, e da temperatura de ebulição 
proporcionada pelo sistema de vácuo, na qual o último estágio opera. Estágios sucessivos operam em temperaturas e pressões mais baixas que o primeiro, não apenas devido à diferença de temperatura requerida, mas também devido à elevação do ponto de ebulição da salmoura em cada estágio.

No caso em pauta, a fonte de calor é vapor vivo saturado a $124^{\circ} \mathrm{C}$ e o sistema de vácuo é capaz de gerar uma pressão de $7,3 \mathrm{kPa}$, a qual proporciona uma temperatura de ebulição da salmoura de $45^{\circ} \mathrm{C}$. Se admitirmos uma força motriz para a troca de calor de $10^{\circ} \mathrm{C}$ e uma elevação de ponto de ebulição de $8{ }^{\circ} \mathrm{C}$, seria possível colocar até 4 estágios de evaporação. Na unidade industrial, uma fonte de calor mais quente possibilitaria colocar 5 ou 6 estágios de evaporação, sendo que 5 estágios é recomendado como um valor ótimo (Jongema, 1983). Para a planta piloto, é desejada uma operação simples, mas com possibilidade de avaliar as interações dinâmicas entre estágios. Por isso, é definida uma unidade com dois estágios de evaporação. Uma temperatura relativamente baixa de $60^{\circ} \mathrm{C}$ (e uma pressão de $15 \mathrm{kPa}$ ) é escolhida para o segundo estágio, de forma que ele represente o quarto cristalizador de uma unidade industrial com cinco estágios.

\section{Configuração da alimentação}

A alimentação é adicionada em paralelo para cada cristalizador. Operação em série com respeito à alimentação poderia ser aplicada se fosse requerida uma distribuição de tamanhos de cristais estreita (Mullin, 2001).

\section{Estrutura do reciclo}

A solução saturada que deixa os cristalizadores deve ser reciclada para minimizar a perda do seu conteúdo energético e do sal nela contidos. As suspensões que deixam cada cristalizador têm temperaturas diferentes $\left(100\right.$ e $50{ }^{\circ} \mathrm{C}$ ) e composições similares (já que a solubilidade do sal praticamente independe da temperatura). A solução mais simples é misturar as suspensões que deixam cada estágio, separar os cristais e recircular a solução para o tanque de alimentação.

\section{Purga}

A purga tem a função de evitar o acúmulo de impurezas na solução. A purga deve ser realizada preferencialmente a partir de uma corrente com um alto teor de impurezas (para minimizar a vazão de purga) e uma baixa temperatura (para conservação de energia). Uma vez que as alimentações de salmoura aos cristalizadores são em paralelo, o nível de impurezas nos estágios é similar. Por isso, decidiu-se por realizar uma só purga na corrente de reciclo. Uma possivel otimização da política de purga (taxa e localização) poderá ser feita após coleta de dados experimentais na escala piloto. Por exemplo, se cristais mais puros e conseqüentemente soluções mais impuras se formarem em temperaturas mais altas, pode se considerar efetuar purgas individuais em cada cristalizador.

\section{Tempo de residência}

A cinética de cristalização do cloreto de sódio pode ser expressa pela seguinte relação: 
$B_{0} \propto G^{i} S S^{j}$

Onde $B_{0}$ é a taxa de nucleação secundária $\left(\# \mathrm{~m}^{-3} \mathrm{~s}^{-1}\right), G$ é a taxa de crescimento molecular dos cristais ( $\mathrm{m} \mathrm{s}^{-1}$ ), SS é o teor de sólidos ( $\mathrm{kg}$ sólidos / $\mathrm{kg}$ suspensão), $i$ e $j$ são constantes empíricas que para o cloreto de sódio valem respectivamente 2 e 1 (Jancic and Grootscholten, 1984). Para cristalizadores contínuos ideais (MSMPR) pode ser mostrado (Mullin, 2001) que:

$\frac{L_{m 2}}{L_{m 1}}=\left(\frac{\tau_{2}}{\tau_{1}}\right)^{(i-1) /(i+3)}$

Onde $L_{m 1}$ e $L_{m 2}$ são os tamanhos dominantes dos cristais obtidos em cristalizadores que operam com tempos de residência $\tau_{I}$ e $\tau_{2}$. Como para o sal $i=2$, o expoente na relação acima vale $1 / 5$, de forma que o tempo de residência tem pequena influência sobre o tamanho das partículas. Foi assumido um valor conservador (pequeno) de $2.5 \times 10^{-8} \mathrm{~m} / \mathrm{s}$ para a taxa crescimento molecular a partir de dados de Mullin (2001) e Mersmann e Kind (1988), para calcular um tempo de residência de $37 \mathrm{~min}$.

\section{Outras variáveis contínuas}

As especificações de projeto feitas até aqui permitem calcular diversas variáveis continuas, tais como a taxa de reciclo, a pressão e a temperatura em cada estágio de cristalização, as cargas térmicas para resfriamento e aquecimento. Essas variáveis são calculadas a partir de balanços de massa e de energia, da solubilidade do sal e da pressão de vapor da salmoura em função da temperatura.

\subsubsection{NívEL DE PROJETO IV - ESTÁGIO DE CRISTALIZAÇÃo}

\section{Tipo de cristalizador}

Para compostos altamente solúveis como o cloreto de sódio, os tipos de cristalizador mais convenientes são o de circulação forcada ou "forced circulation" (FC), o "draft tube baffle (DTB) e - leito fluidizado (OSLO). Tamanhos de partícula típicos produzidos nestes equipamentos são respectivamente $0.5, \sim 1.0$ e $1.5 \mathrm{~mm}$ e tempos de residência típicos são $1 \mathrm{~h}, 3 \mathrm{~h}$ e $6 \mathrm{~h}$ (Mersmann, 2001). O cristalizador de circulação forçada é o mais simples dos três (e, portanto o mais simples para realizar a ampliação de escala) e o mais barato. Suas desvantagens são a falta de opções para controle de supersaturação e a abrasão relativamente elevada dos cristais, causada pela alta turbulência requerida no interior do cristalizador (já que a própria circulação da salmoura deve promover a homogeneização da suspensão). No presente caso cristais maiores que $0,5 \mathrm{~mm}$ não são requeridos, por isso foi escolhido o cristalizador tipo FC.

\section{Classificação de finos e de produto}

A teoria dos cristalizadores contínuos ideais revela que as maneiras mais eficientes para se influenciar o tamanho das partículas são pela remoção de finos e classificação do produto. No primeiro caso, o cristalizador é provido de um sistema para remoção seletiva de uma suspensão 
rica nas partículas finas do cristalizador. As partículas finas são dissolvidas e a solução resultante é recirculada ao cristalizador. $O$ efeito desse recurso é uma taxa de nucleação efetiva menor que sem o uso deste recurso, resultando em partículas maiores. No segundo caso, o cristalizador é provido de um dispositivo que retira preferencialmente os maiores cristais. Como os cristais menores permanecem no cristalizador, o efeito líquido desta medida é uma redução no tamanho médio das partículas. Tanto a remoção de finos quanto a classificação de produtos produzem partículas com tamanhos mais uniformes que na ausência destes dispositivos.

O cristalizador de circulação forçada não admite um separador de finos em seu corpo, já que a suspensão em seu interior é fortemente agitada. Por outro lado, a classificação de produto pode ser realizada por meio de uma perna elutriadora. Este dispositivo permite ainda a lavagem do produto com solução de alimentação fresca, levando a um produto mais puro. A classificação de produto e sua lavagem por meio de uma perna elutriadora foram previstas no projeto da unidade piloto.

\section{Dimensōes do cristalizador}

Os cálculos para um cristalizador são simples. O volume da suspensão é calculado a partir do tempo de residência. $O$ diâmetro do cristalizador e a altura da sua cabeça são calculados para evitar o arraste de gotículas de solução pelo vapor ascendente (Billet, 1989). O arraste, para uma dada vazão mássica de vapor, é maior para menores pressões. Assim, os últimos estágios de cristalização, que operam sob pressões menores, resultam maiores que os primeiros. No caso da planta piloto, por simplicidade foram propostos dois cristalizadores com as mesmas dimensões, cada um com uma capacidade útil de $1 \mathrm{~m}^{3}$ de suspensão, sendo o diâmetro de $1.2 \mathrm{~m}$, a altura da suspensão de $1.42 \mathrm{~m}$ inclusive o fundo cônico e a cabeça de vapor de $2.0 \mathrm{~m}$ de altura inclusive o eliminador de névoa e o topo cônico.

\section{Concentração de sólidos (SS)}

Um valor elevado de SS é desejável porque ele contribui para uma baixa supersaturação, que por sua vez reduz inclusões fluidas (aumenta a pureza do produto) minimiza a chance de ocorrer nucleação primária (que instabiliza o processo) e reduz incrustações. O teor de sólidos também pode afetar o tamanho das partículas, mas para o cloreto de sódio a influencia é desprezível, já que $i$ e $j$ são 2 e 1 na equação abaixo.

$\frac{n_{o 2}}{n_{o 1}}=\left(\frac{S S_{2}}{S S_{1}}\right)^{(i-j) /(i+3)}$

Onde $n_{o}$ é a densidade populacional de núcleos $\left(\# / \mathrm{m} \mathrm{m}^{3}\right)$. Um valor de projeto para SS de $0,25 \mathrm{~kg}$ sólidos / kg de suspensão é escolhido para garantir facilidade de bombeamento da suspensão.

\section{Circulação da suspensão}

A circulação é realizada com uma bomba de fluxo axial para minimizar nucleação secundária. A vazão é tal que a elevação de temperatura da suspensão no aquecedor na linha de circulação 
evite a ebulição da suspensão dentro do trocador. Portanto, a elevação de temperatura deve ser inferior à elevação da temperatura de ebulição promovida pela coluna de liquido acima do trocador de calor. A corrente de circulação também deve promover turbulência suficiente no cristalizador para suspender os cristais e promover a homogeneização do líquido dentro do cristalizador (Mersmann, 2001; Nyvlt et al., 2001). Na unidade piloto, foi calculada uma taxa de circulação de $230 \mathrm{~m}^{3} / \mathrm{h}$ e uma elevação da temperatura da suspensão na circulação máxima de $4.5^{\circ} \mathrm{C}$.

\subsection{Lições da planta piloto}

A Figura 2-2 apresenta esquematicamente o processo de cristalização implementado. Salmoura quase saturada, depois de misturada à solução recirculada, alimenta em paralelo os dois cristalizadores. A suspensão em cada cristalizador circula pelos aquecedores respectivos. A suspensão que deixa os cristalizadores é centrifugada. Os sólidos são secos e a solução é recirculada. O fluido de aquecimento no primeiro aquecedor é vapor vivo e no segundo aquecedor é o próprio vapor vegetal gerado no primeiro cristalizador. O vapor gerado no segundo cristalizador vai para um sistema de vácuo (condensador barométrico). Uma corrente de purga é ligada à linha de circulação de solução. O vapor vivo e o vapor vegetal do primeiro cristalizador, após trocarem calor, formam correntes de condensado que são aproveitadas fora da unidade piloto. O vapor do segundo cristalizador mistura-se à água marinha usada no resfriamento do condensador barométrico, que é descartada.

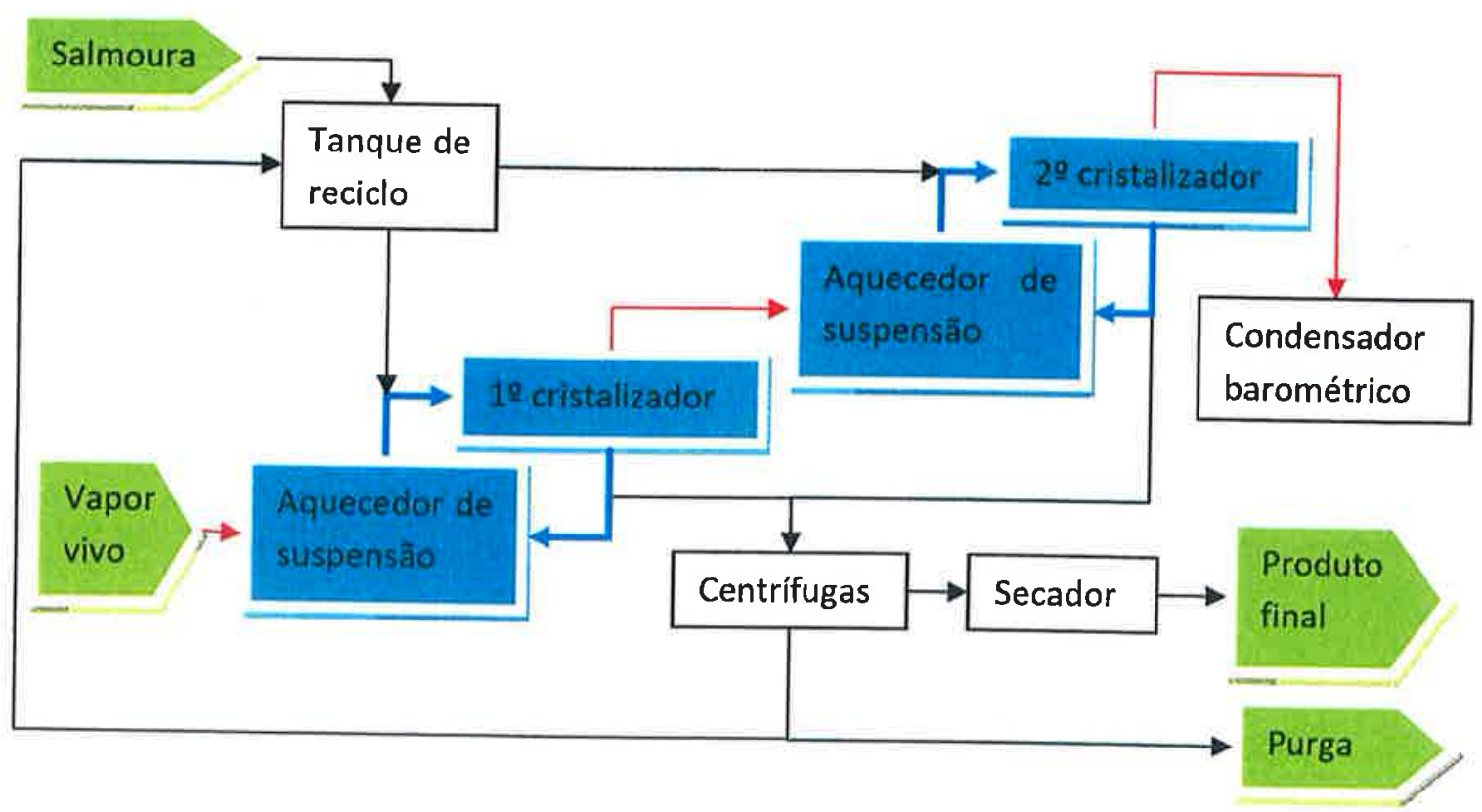

Figura 2-2. Diagrama esquemático do processo desenvolvido e implementado em escala piloto.

São apresentadas a seguir lições aprendidas durante a operação da unidade piloto. Projetistas, engenheiros de processo e de produção reuniam-se regularmente para diagnosticar o desempenho da unidade e propor melhorias. A capacidade de produção e a eficiência energética 
nos estágios iniciais da operação eram respectivamente $60 \%$ e $160 \%$ dos valores de projeto, principalmente devido a uma pressão do vapor vivo baixa, vazões de alimentação altas e uma baixa troca de calor no aquecedor do segundo cristalizador, em relação aos valores de projeto. $A$ alta vazão de alimentação induzia um baixo teor de sólidos nos cristalizadores os quais por sua vez promovia incrustação nas paredes do cristalizador e na linha de circulação. Incrustações desenvolviam-se tão rapidamente que a operação tinha que ser descontinuada após algumas horas de operação. Outra dificuldade nestes primeiros dias de operação era um controle deficiente da dinâmica da planta, com altas variações nas vazões e taxas de circulação. A Figura 2-3 mostra um experimento no qual a incrustação dificulta a circulação da suspensão, causando um aumento na diferença de temperatura da suspensão através do aquecedor.

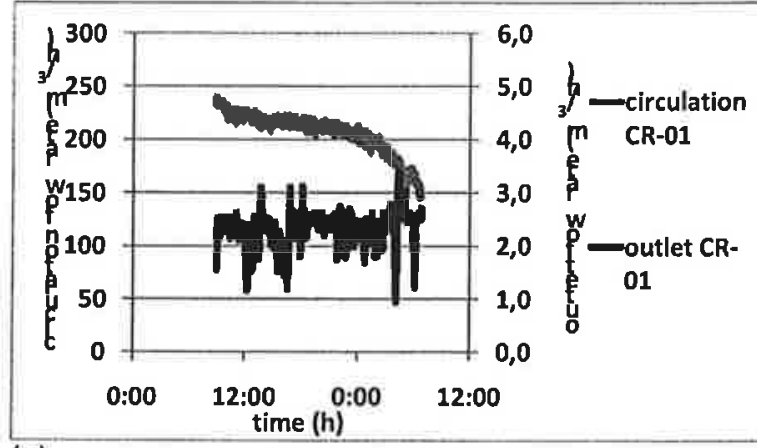

(a)

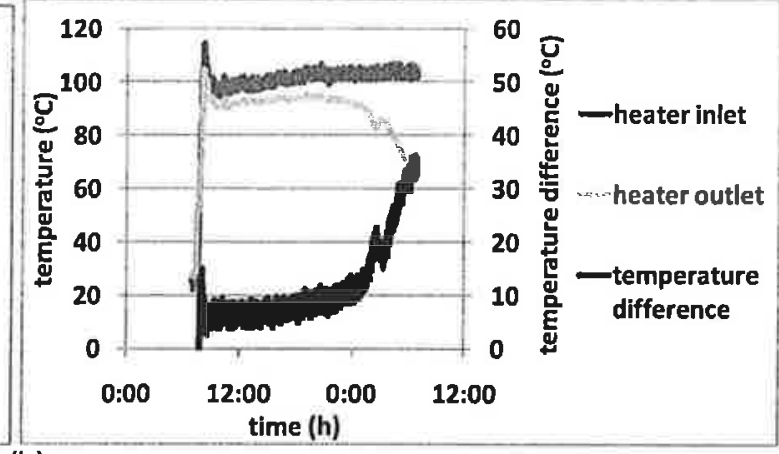

(b)

Figura 2-3. Experimento na unidade piloto com desenvolvimento de incrustação. (a) vazões da suspensão na linha de circulacao e nas saídas dos cristalizadores; (b) temperaturas da suspensão no aquecedor da circulaçāo.

Uma operação mais favorável foi alcançada após implementação de uma série de medidas. Primeiro, o sistema de controle foi melhorado pelo ajuste dos instrumentos e da política de controle. É provável que se o controle integrado da planta fosse considerado, melhorias mais significativas fossem atingidas (Ward et al., 2007; Ward et al., 2010). Em segundo lugar, a vazão de alimentação foi reduzida, o que permitiu aumentar o teor de sólidos no cristalizador para o valor de projeto, um fator decisivo na redução da incrustação. Em terceiro, medidas práticas foram tomadas para reduzir as incrustações, tais como trocar o ponto de adição de salmoura fresca subsaturada para uma região da linha de circulação onde a incrustação era particularmente importante. Em conjunto, estas medidas levaram a um aumento da eficiência energética para $1100 \mathrm{kcal} / \mathrm{kg}$ sal seco, que é próximo ao valor teórico para cristalização evaporativa em dois estágios, calculada a partir dos balanços de massa e energia da unidade piloto. A capacidade da planta não aumentou devido à baixa qualidade do vapor vivo e à área de troca limitada no segundo aquecedor.

Um experimento típico para estas condições favoráveis é mostrado na Figura 2-4. Vapor vivo supersaturado e com uma temperatura de $104{ }^{\circ} \mathrm{C}$ (Figura 2-4 a) aquece a suspensão circulante no primeiro cristalizador. $\mathrm{O}$ vapor gerado, que está a $102{ }^{\circ} \mathrm{C}$ e $80 \mathrm{kPa}$ e tem uma temperatura de saturação de $94^{\circ} \mathrm{C}$, aquece a suspensão do segundo cristalizador. Uma alta vazão de circulação de $235 \mathrm{~m}^{3} / \mathrm{h}$ (Figura 2-4 b) limita a elevação da temperatura da suspensão ao atravessar o aquecedor $(\Delta \mathrm{T})$. No 10 cristalizador $\Delta \mathrm{T}$ é cerca de $2.5^{\circ} \mathrm{C}$, enquanto no segundo o valor é $5.5^{\circ} \mathrm{C}$ (Figura 2-4 c e 
d). Os teores de sólidos no 1 e e 20 cristalizadores são respectivamente 17 e $30 \%$ em massa. Nestas condições, a planta opera sem perturbações por pelo menos uma semana (a operação foi interrompida após este período por motivos alheios ao processo de cristalização).
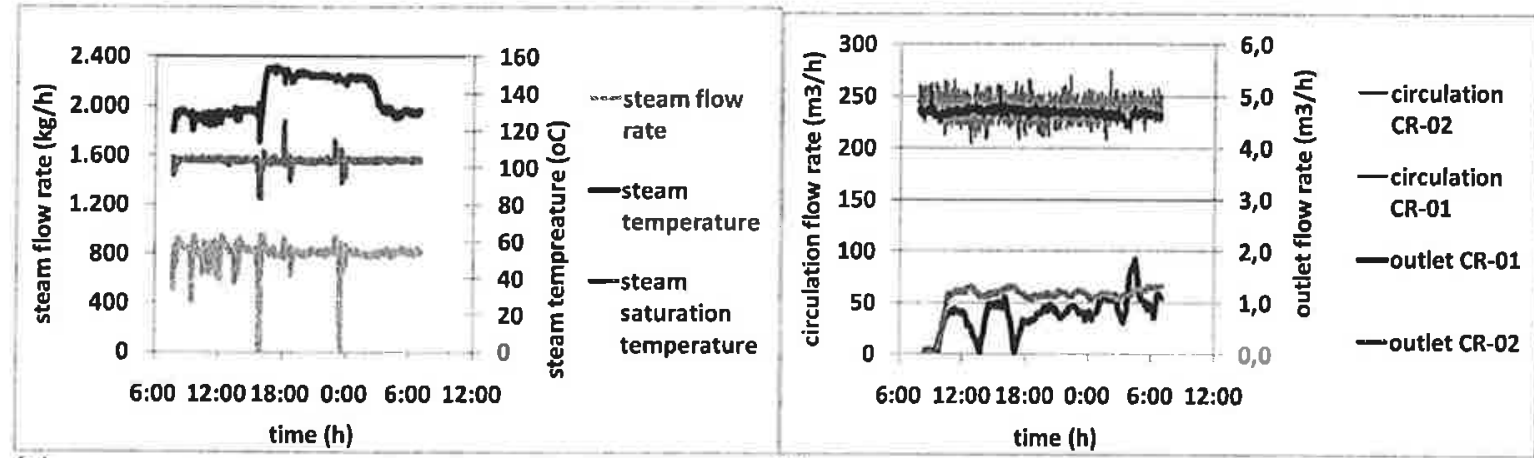

(a)

(b)

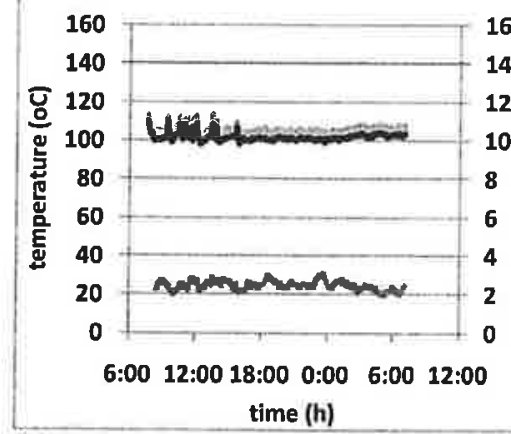

(c)

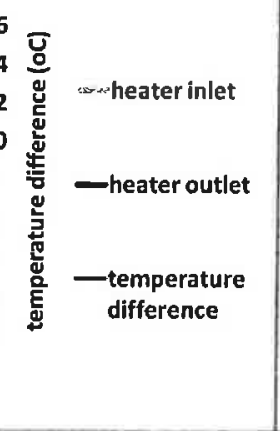

(d)

d)

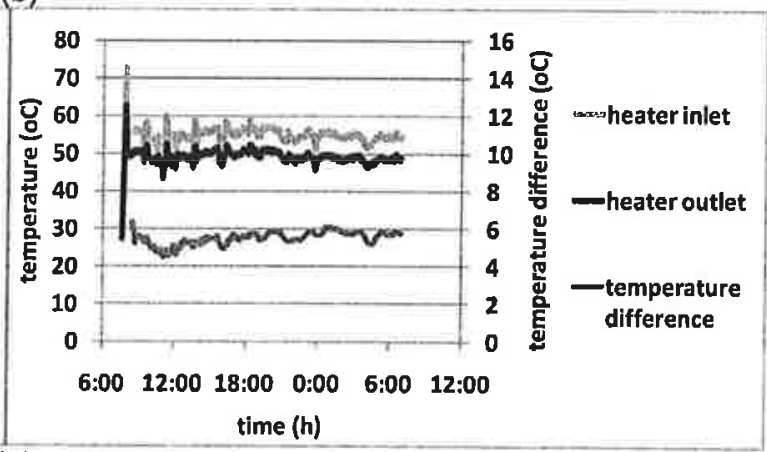

Figura 2-4. Experimento na unidade piloto com operação estável. (a) temperatura e vazao de vapor alimentado ao $1^{\circ}$ cristalizador; (b) vazoes da suspensão em circulação e das saidas de suspensão de cada cristalizador; (c) temperaturas da suspensão em torno do aquecedor do $1^{\circ}$ cristalizador; (d) temperaturas da suspensão em torno do aquecedor do $2^{\circ}$ cristalizador.

A distribuição de tamanhos de partículas no cristalizador foi similar ao valor projetado, mas abrasão dos cristais durante a centrifugação e secagem promoveu a formação excessiva de finos, conforme mostra a Figura 2-1.

A principal impureza no sal é o magnésio. Num experimento no qual a salmoura continha 0.9 \%massa de magnésio, o teor de magnésio no produto seco foi de $0.15 \%$ massa (superior ao valor especificado de $0.08 \%$ ) na ausência de lavagem dos cristais no cristalizador e na centrífuga. Testes em laboratório revelam que $97 \%$ do magnésio no produto podem ser removido pela simples lavagem, logo a pureza do sal pode ser facilmente atingida.

A Figura 2-1 também revela que os cristais obtidos no 10 cristalizador são maiores que os obtidos no 29, provavelmente devido à maior temperatura do primeiro $\left(94{ }^{\circ} \mathrm{C}\right.$ no primeiro e $50{ }^{\circ} \mathrm{C}$ no segundo), conforme já havia sido previsto. Além disso, há excesso de finos no segundo cristalizador. Esta presença de finos se deve a nucleação secundária excessiva, resultado de alta supersaturação, por sua vez associada a uma elevação de temperatura da suspensão excessiva $\left(\Delta T=5.5^{\circ} \mathrm{C}\right.$, ver Figura $2-4 \mathrm{~d}$ ), um valor superior ao valor de projeto de $4.5^{\circ} \mathrm{C}$. Valores menores de $\Delta T$, e, portanto menor formação de finos, podem ser obtidos com uma maior taxa de circulação 
da salmoura (não mostrado). Conclui-se que o tamanho das partículas pode ser controlado pela temperatura do cristalizador e pela taxa de circulação da suspensão.

\subsection{Conclusões}

O procedimento hierárquico de projeto proposto por Bermingham (2003) foi aplicado para uma unidade piloto de cristalização de cloreto de sódio. A unidade piloto implementada de acordo com o projeto forneceu um produto dentro de especificacoes de granulometria e pureza e um processo dentro da meta de consumo energético. A capacidade de projeto da planta não foi atingida devido a limitações na qualidade do vapor e na taxa de troca térmica. Análise da operação da unidade piloto permitir identificar critérios de projeto melhores: (i) o controle do processo é importante para melhoria do consumo energético, da capacidade e para minimizar incrustações; (ii) a elevação de temperatura da suspensão circulante não deve exceder $4.5^{\circ} \mathrm{C}$; (iii) a separação sólido-líquido deve permitir a lavagem efetiva dos cristais, uma vez que a incorporação de impurezas no produto está associada ao licor mãe impuro aderido aos cristais; (iv)a distribuição de tamanhos de partículas de produto final pode ser ajustada pela temperatura do cristalizador e pela taxa de circulação de suspensão; (v) o projeto da centrífuga e do secador devem levar em conta que os cristais de cloreto de sódio são sensíveis à abrasão.

\subsection{Lista de símbolos}

$$
\begin{aligned}
& B_{0} \quad \text { taxa de nucleação secundária, } \# \mathrm{~s}^{-1} \mathrm{~m}^{-3} \\
& G \quad \text { taxa de crescimento cristalino, } \mathrm{m} \mathrm{s}^{-1} \\
& i, j \quad \text { parâmetros cinéticos para cristalização, - } \\
& L_{m} \quad \text { tamanho dominante de partícula, } \mathrm{m} \\
& n_{0} \quad \text { densidade de núcleos no cristalizador, \# } \mathrm{m}^{-1} \mathrm{~m}^{-3} \\
& S S \quad \text { fração mássica de sólidos na suspensão, - } \\
& \tau \quad \text { tempo de residência no cristalizador, } \mathrm{s}
\end{aligned}
$$

\subsection{Referências}

Bermingham, S.K., H.J.M. Kramer and G.M. van Rosmalen, Towards on-scale crystalliser design using compartmental models. Computers \& Chemical Engineering, 1998. 22: p. S355-S362.

Bermingham, S.K. et al., A design procedure and predictive models for solution crystallisation processes. Fifth International Conference on Foundations of Computer-Aided Process Design, 2000. 96(323): p. 250-264. 
Bermingham, S.K., A design procedure and predictive models for solution crystallization processes. 2003, Delft University of Technology: Delft. p. 266.

Billet, R., Evaporation Technology: Principles, Applications, Economics. 1989, Weinheim: VCH Verlagsgesellschaft $\mathrm{GmbH}$.

Cisternas, L.A., C.M. Vasquez and R.E. Swaney, On the design of crystallization-based separation processes: Review and extension. Aiche Journal, 2006. 52(5): p. 1754-1769.

Douglas, J.M., A hierarchical decision procedure for process synthesis. AlChE Journal, 1985. 31(3): p. 9.

Gerstlauer, A. et al., Application of population balances in the chemical industry - current status and future needs. Chemical Engineering Science, 2006. 61(1): p. 205-217.

Grosch, R., M. Monnigmann and W. Marquardt, Integrated design and control for robust performance: Application to an MSMPR crystallizer. Journal of Process Control, 2008. 18(2): p. 173-188.

Jancic, S.J. and Grootscholten, P.A.M., Industrial Crystallization. 1984, Delft: Delft University Press. Jongema, P., Optimization of the Fuel Consumption of an Evaporation Salt Plant with the Aid of the Exergy Concept. in Sixth Intern. Symp. on Salt. 1983. Toronto, Canada.

Kramer, H.J.M., S.K. Bermingham and G.M. van Rosmalen, Design of industrial crystallisers for a given product quality. Journal of Crystal Growth, 1999. 198: p. 729-737.

Lakerveld, R. et al., The application of a task-based concept for the design of innovative industrial crystallizers. Computers \& Chemical Engineering, 2009. 33(10): p. 1692-1700.

Lakerveld, R. et al., Application of generic principles of process intensification to solution crystallization enabled by a task-based design approach. Chemical Engineering and Processing, 2010. 49(9): p. 979-991.

Lin, S.W., K.M. Ng and C. Wibowo, Integrative approach for polymorphic crystallization process synthesis. Industrial \& Engineering Chemistry Research, 2007. 46(2): p. 518-529.

Lin, S.W., K.M. Ng and C. Wibowo, Synthesis of crystallization processes for systems involving solid solutions. Computers \& Chemical Engineering, 2008. 32(4-5): p. 956-970.

Menon, A.R. et al., A task-based synthesis approach toward the design of industrial crystallization process units. Industrial \& Engineering Chemistry Research, 2007. 46(12): p. 3979-3996.

Mersmann, A., Crystallization Technology Handbook. $2^{\text {nd }}$ ed. 2001, New York: Marcel Dekker. Mullin, J.W., Crystallization. 2001, Boston: Butterworth-Heinemann.

Nyvlt, J., J. Hostomsky and M. Giulietti, Cristalização. 2001, São Carlos, Brazil: EdUFSCar/IPT. 
Rajagopal, S., K.M. Ng and J.M. Douglas, A hierarchical procedure for the conceptual design of solids processes. Computers \& Chemical Engineering, 1992. 16(7): p. 14.

Ward, J.D., C.C. Yu and M.F. Doherty, Plantwide operation of processes with crystallization. Aiche Journal, 2007. 53(11): p. 2885-2896.

Ward, J.D., C.C. Yu and M.F. Doherty, Plantwide dynamics and control of processes with crystallization. Computers \& Chemical Engineering, 2010. 34(1): p. 112-121.

Wibowo, C., W.C. Chang and K.M. Ng, Design of integrated crystallization systems. Aiche Journal, 2001. 47(11): p. 2474-2492. 


\section{IDENTIFICAÇÃO DO MECANISMO DE INCRUSTAÇÃO EM UM TROCADOR DE CALOR CASCO-TUBOS7}

\subsection{Introdução}

Incrustação é um fenômeno indesejável freqüentemente encontrado na indústria química, causando grandes prejuizos. Apesar de ser um fenômeno estudado há mais de 40 anos, o projeto de trocadores de calor não mudou, simplesmente é incluído um coeficiente de resistência térmica adicional devido à incrustação (Butterworth, 2004). Não é incomum projetar esta resistência de tal forma a provocar um aumento de $35 \%$ na área de troca térmica (Garret-Price et al., 1985), implicando em aumento do investimento necessário para realizar uma dada tarefa. Durante a operação do trocador de calor, a incrustação provoca paradas freqüentes da unidade para limpeza, as quais ocasionam perda de produtividade (Steinhagen et al., 1993).

A incrustação é um processo transiente. Há um período inicial de indução, quando o trocador de calor permanece limpo, seguido de um periodo quando a incrustação se desenvolve. Este período é percebido pela diminuição do coeficiente global de troca térmica e pelo aumento da perda de carga ao longo do trocado de calor (Mai et al., 1999). No limite, a perda de carga pode levar ao entupimento do equipamento. Tal entupimento pode ocorrer muito rapidamente.

Tem havido um esforço considerável em diminuir os efeitos indesejados causados pela incrustação em trocadores de calor. Pode-se, por exemplo, ajustar empiricamente parâmetros operacionais, como a velocidade do fluido e a temperatura da superfície de troca térmica (Zubair et al., 2000; Sahin et al., 2000). Além destes, parâmetros mecânicos de projeto, tais como material de construção, rugosidade e geometria da superfície de troca também podem afetar significativamente a ocorrência de incrustação. Também têm sido utilizados aditivos químicos antiencrustantes, mas seu uso encontra certas limitações (Sahin et al., 2000, apud Somerscales et al., 1991). Há algumas experiências com a adição de micropartículas inertes ao escoamento, para remover a incrustação mecanicamente ou para diminuir a resistência mecânica do depósito (Bansal et al., 2003).

A incrustação muitas vezes pode ser minimizada, se suas causas forem conhecidas. Entre as possiveis causas da incrustação, estão: (i) a cristalização a partir de soluções supersaturadas; (ii) a formação de produtos de corrosão; (iii) o depósito de biofilmes; (iv) agregação de particulado sobre a superfícies; (v) reação química; (iv) congelamento.

Para sistemas complexos, quando é difícil identificar a causa da incrustação, uma abordagem freqüentemente encontrada é a de simplesmente monitorar a incrustação em linha, para detectar

\footnotetext{
${ }^{7}$ Andréia Virgínia Pepe Ambrozin, Melhoria da troca térmica pelo controle do processo de incrustação, Dissertação de Mestrado, IPT, 2006. Orientador Marcelo Seckler. Trabalho completo publicado no III ENBTEQ e I TECNIQ, Seminário sobre Tecnologia na Indústria Química, São Paulo, 2006, São Paulo. p.310 313.
} 
- melhor momento de se realizar uma intervenção no processo. Jeronimo et al. (1997) desenvolveram uma metodologia de monitoramento baseada na eficiência térmica e a aplicaram a diversos trocadores de calor de uma refinaria de petróleo. Eles concluíram que não havia correlação entre as propriedades físicas das correntes e a ocorrência de incrustação. Mai et al. (1999) também desenvolveu um método de monitoramento baseado em eficiência térmica quando o fluido era submetido a variações dinâmicas de vazão. Zubair e colaboradores (2000) apresentaram um procedimento simples para caracterizar vários modelos probabilísticos para a taxa de crescimento da incrustação, tendo o aplicado para trocadores de calor casco-tubo operando com óleo cru. Os modelos randômicos utilizados foram: linear, exponencial, de taxa decrescente e assintótico. Os autores enfatizam que os modelos auxiliam na tomada de decisão de quando efetuar paradas para limpeza e/ou manutenção preventiva. 0 modelo permite que se estabeleçam custos mínimos com base na confiabilidade dos equipamentos.

Há relativamente poucos trabalhos sobre incrustação por cristalização, sendo a maior parte deles dedicada à formação de carbonato de cálcio e sulfato de cálcio. No primeiro caso, a incrustação parece ocorrer por cristalização apenas, mas no segundo ocorre uma combinação com incrustação particulada (Bramson, 1996). Herz et al. (2008) concluem que a rugosidade da superfície é importante por afetar a taxa de nucleação heterogênea e a taxa de remoção através da exposição da superfície à camada limite do escoamento. Sheikholeslami (2000) propõe um modelo para incrustação de sulfato de cálcio que leva em conta a química da solução, a cristalização, bem como a incrustação por particulados. Mwaba e colaboradores (2006) propõem uma correlação semi-empírica para prever a incrustação por cristalização de sulfato de cálcio.

O início do processo de incrustação por cristalização foi abordado por Vendel e Rasmusson (1997), que concluíram que o impacto de cristais sobre a superfície metálica pode provocar nucleação secundária sob valores de supersaturação menores do que na ausência de colisões. Bansal e colaboradores (2003) também verificaram que ao adicionar cristais à suspensão há um aumento na taxa de incrustação.

Sheikholeslami e Zhou (2000) estudaram a incrustação de água contendo sílica sobre membranas de osmose reversa. Eles notaram que os depósitos são formados predominantemente por sílica, que íons cálcio e magnésio catalisam a deposição, mas não participam do depósito.

Neste trabalho, a incrustação foi estudada num trocador de calor em escala real. A partir da analise do processo e da caracterização físico-química do deposito, foram propostos mecanismos para formação da incrustação. Uma vez conhecidos os mecanismos, foi possível propor alternativas para minimizar a incrustação industrialmente.

\subsection{Descrição do processo}

As composições não são reveladas por tratar-se de segredo industrial. A matéria prima $A$, na forma solúvel, é oxidada em bateladas ao produto B na presença de água, oxigênio e um catalisador particulado (carvão ativo) num reator de mistura em regime de batelada. Como a reação é exotérmica, todo o conteúdo do reator é recirculado através de um trocador de calor 
durante a reação (Figura 3-1). No trocador do tipo casco-tubo, o meio reacional é recirculado no interior dos tubos. Durante a carga dos reagentes, circula-se vapor no casco para aquecimento e durante a reação água de torre para controlar a temperatura constante. $O$ catalisador é filtrado e redirecionado ao reator após cada batelada.

Devido à pequena capacidade do filtro, há uma limitação quanto à quantidade de catalisador que pode ser processada em cada batelada. Para minimizar esta limitação, o regime de operação do reator foi modificado da seguinte maneira. Ao final da batelada, uma parte do conteúdo do reator não é removida. Assim sendo, na batelada seguinte, catalisador está presente desde o início, viabilizando conduzir a reação na presença de maior quantidade de catalisador. A desvantagem é que este regime resulta num maior teor de glifosato ao longo da batelada, o que aumenta a tendência a incrustação.

Há formação de subprodutos indesejáveis em temperaturas elevadas. Por outro lado, a temperatura tem que ser alta o suficiente para permitir a completa solubilização do produto $B$ no meio reacional, evitando assim a sua incrustação.

O controle da temperatura do reator, o "mestre", envia o "set point" para o controlador de temperatura do trocador de calor, o "escravo", que atua na válvula de controle de vazão da água da torre. As temperaturas e vazões de todas as correntes relevantes são medidas: temperatura do meio reacional no interior do reator e na saída do trocador de calor, temperatura da água de resfriamento na entrada e saída do trocador de calor. A vazão de recirculação não é medida.

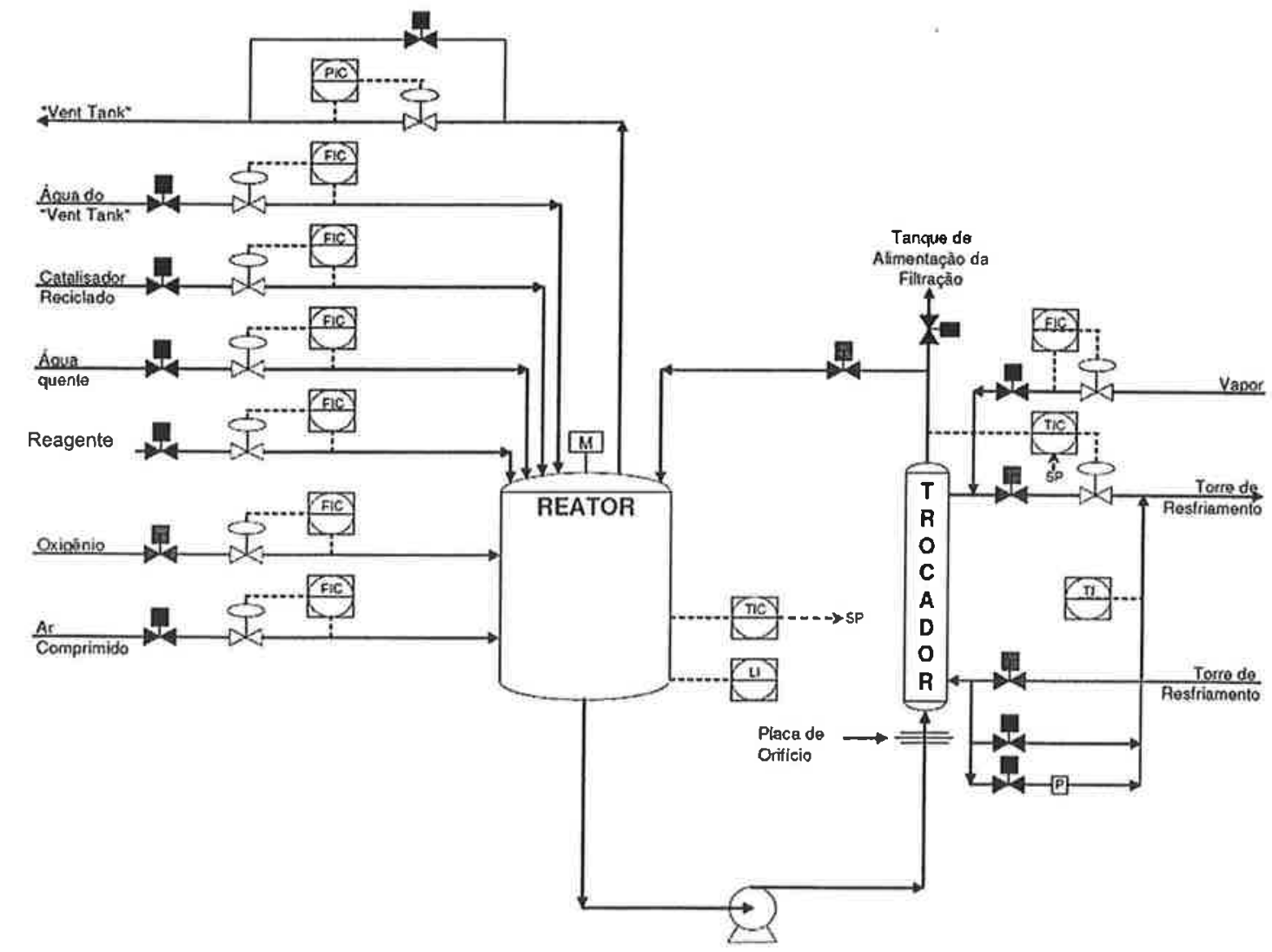

Figura 3-1. Diagrama de fluxos do sistema em bateladas de reação e troca de calor. 
Quando a reação atinge o grau de conversão desejado, o reator é despressurizado e a batelada é transferida para a etapa de filtração, onde o catalisador é separado e redirecionado ao reator.

\subsection{Cristalização de reagente e produto}

Uma solução que está em equilibrio com a fase sólida está saturada com respeito a este sólido. Quando uma solução contém mais soluto do que o que representa a saturação, diz-se que tal solução esta supersaturada com relação ao soluto. O estado da supersaturação é pré-requisito para a cristalização ocorrer.

Embora a força motriz fundamental para os processos de cristalização seja a diferença de potencial químico entre a sustância cristalizante no cristal e em solução, é prática comum usar concentração como indicativo da supersaturação do processo. A supersaturação do sistema pode ser expressa em diferentes formas. Para cristalização por resfriamento é adequado expressar a supersaturação pelo subresfriamento, definido como:

$$
\Delta T^{*}=T^{*}-T
$$

onde T e T* são as temperaturas do sistema e de saturação em oC, respectivamente.

Se a concentração de uma solução pode ser medida nas condições operacionais, o valor de $T^{*}$ é obtido pela curva de solubilidade, e o subresfriamento pode ser calculado pela expressão acima.

Os conceitos de supersaturação e de zona metaestável são úteis para entender um sistema de cristalização. O gráfico representado na Figura 3-2 é dividido em 3 zonas: (i) a região subsaturada, onde há dissolução; (ii) a linha de saturação, onde o sólido e o líquido estão em equilíbrio; (iii) a região metaestável, onde não ocorre não ocorre nucleação primária, mas na presença de cristais ocorre crescimento cristalino e nucleação secundária; (iv) a região lábil, onde ocorre nucleação primária.

Há duas situações relevantes do ponto de vista da cristalização. Uma refere-se ao início do processo de incrustação, que ocorre por nucleação primária heterogênea sobre a superfície metálica. Esta situação ocorre quando a supersaturação corresponde ao limite metaestável, isto é, sobre a linha 4 na figura ou acima dela. Como o processo inicia-se sobre a superfície metálica, é importante conhecer a supersaturação local, e não a supersaturação calculada nas condições médias do escoamento.

A outra situação é quando já existe um depósito de cristais sobre a parede. 0 depósito aumenta de espessura por meio do crescimento molecular dos cristais existentes. Esta situação ocorre quando o sistema encontra-se na região metaestável (região 3 na figura), isto é, em condições mais brandas que as necessárias para iniciar o processo. Novamente, a análise da supersaturação deve ser baseada na temperatura estimada na superfície do depósito e não nas condições no seio do fluido. 


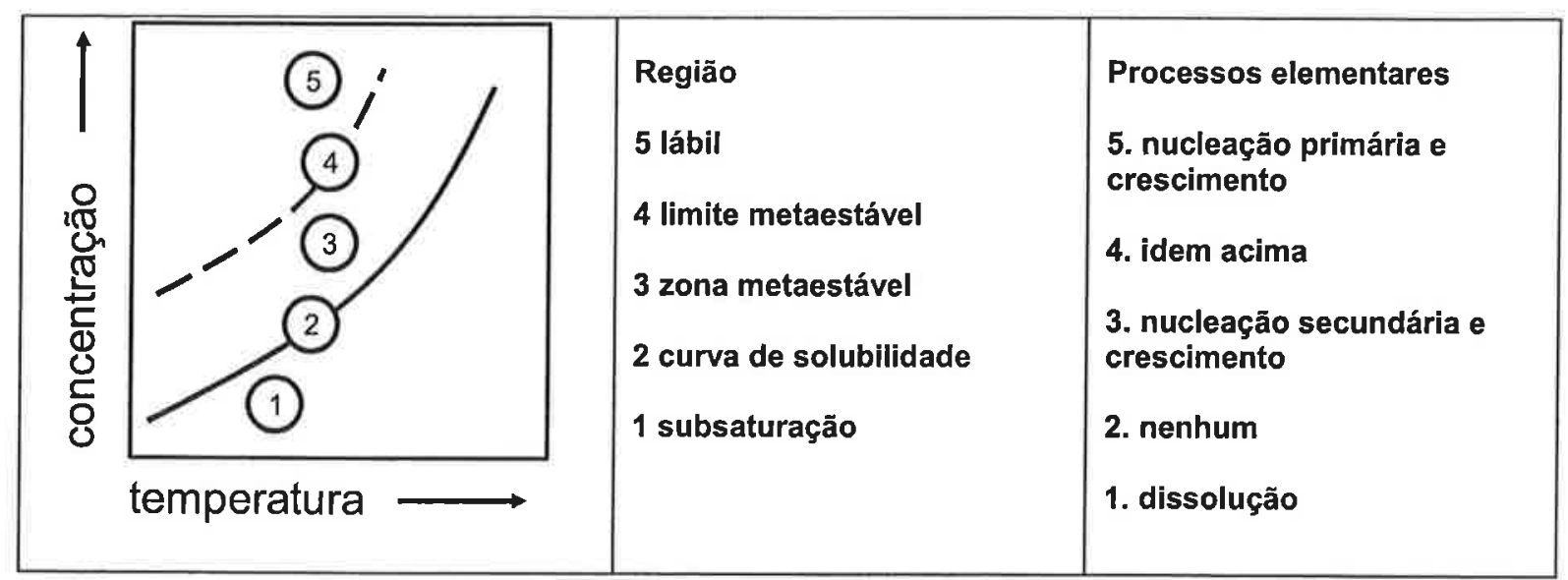

Figura 3-2. Diagrama de equilíbrio sólido-líquido típico.

Representada n Figura 3-3 encontra-se a curva de solubilidade para o reagente A. Esta curva foi determinada em laboratório, utilizando-se amostras de produto puro. Na Figura 3-4 é apresentada a solubilidade do produto de reação B. Infelizmente, as curvas de limite metaestável para estes sistemas não são conhecidos.

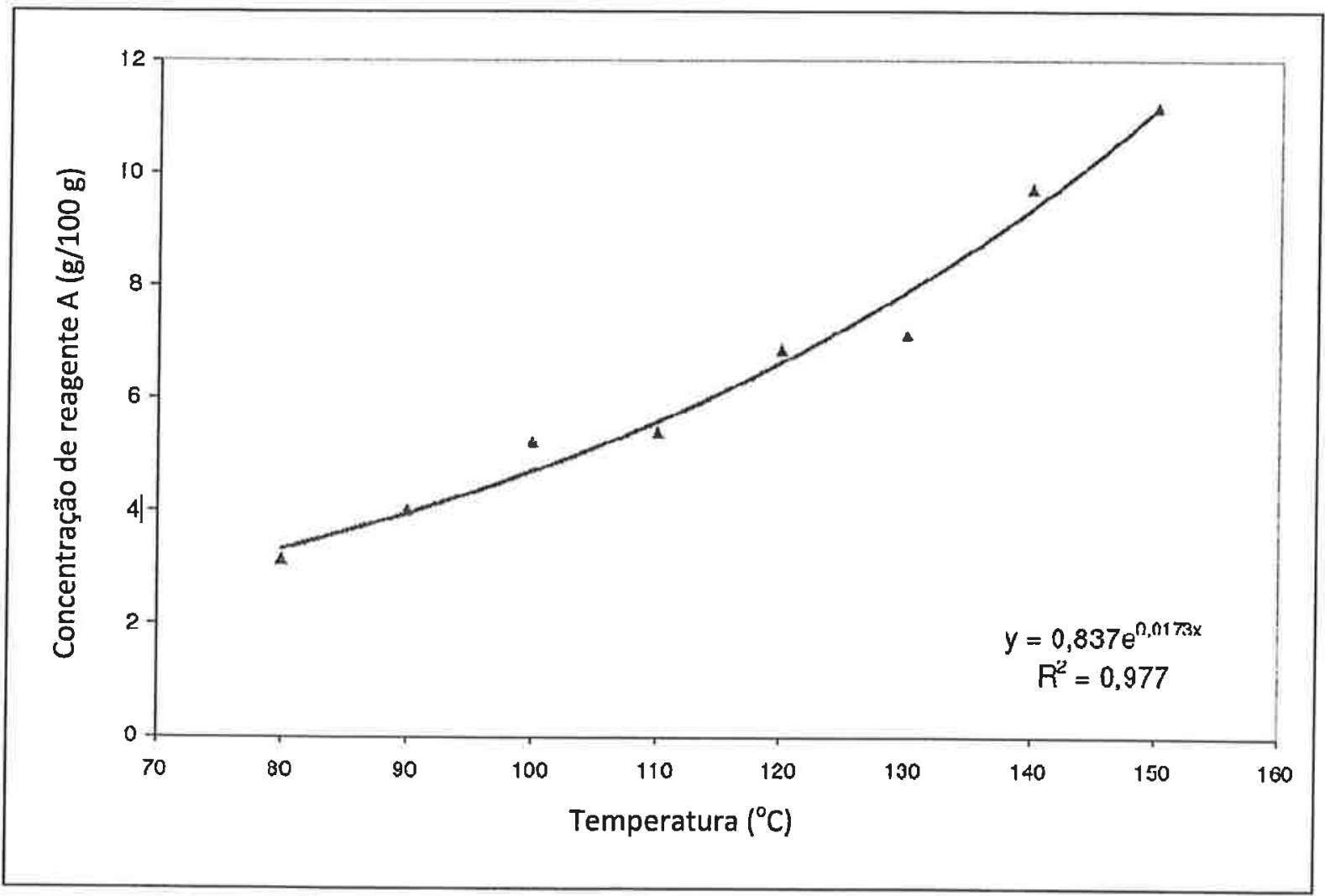

Figura 3-3. Curva de solubilidade do reagente A.

A abordagem a ser adotada neste trabalho será a seguinte. Parte-se da hipótese de que a incrustação seja ocasionada pela cristalização do reagente ou do produto sobre as paredes do trocador de calor. Para confirmar esta hipótese, utilizando-se dados de processo da instalação industrial, será calculada a temperatura da superfície de troca térmica. A concentração de 
produto será medida para, junto com a temperatura, calcular a razão de supersaturação (S) local. O deposito será também amostrado e analisado quanto a sua composição cristalográfica. Uma vez feito o diagnóstico dos mecanismos de incrustação, poderão ser propostas medidas para minimizar a incrustação.

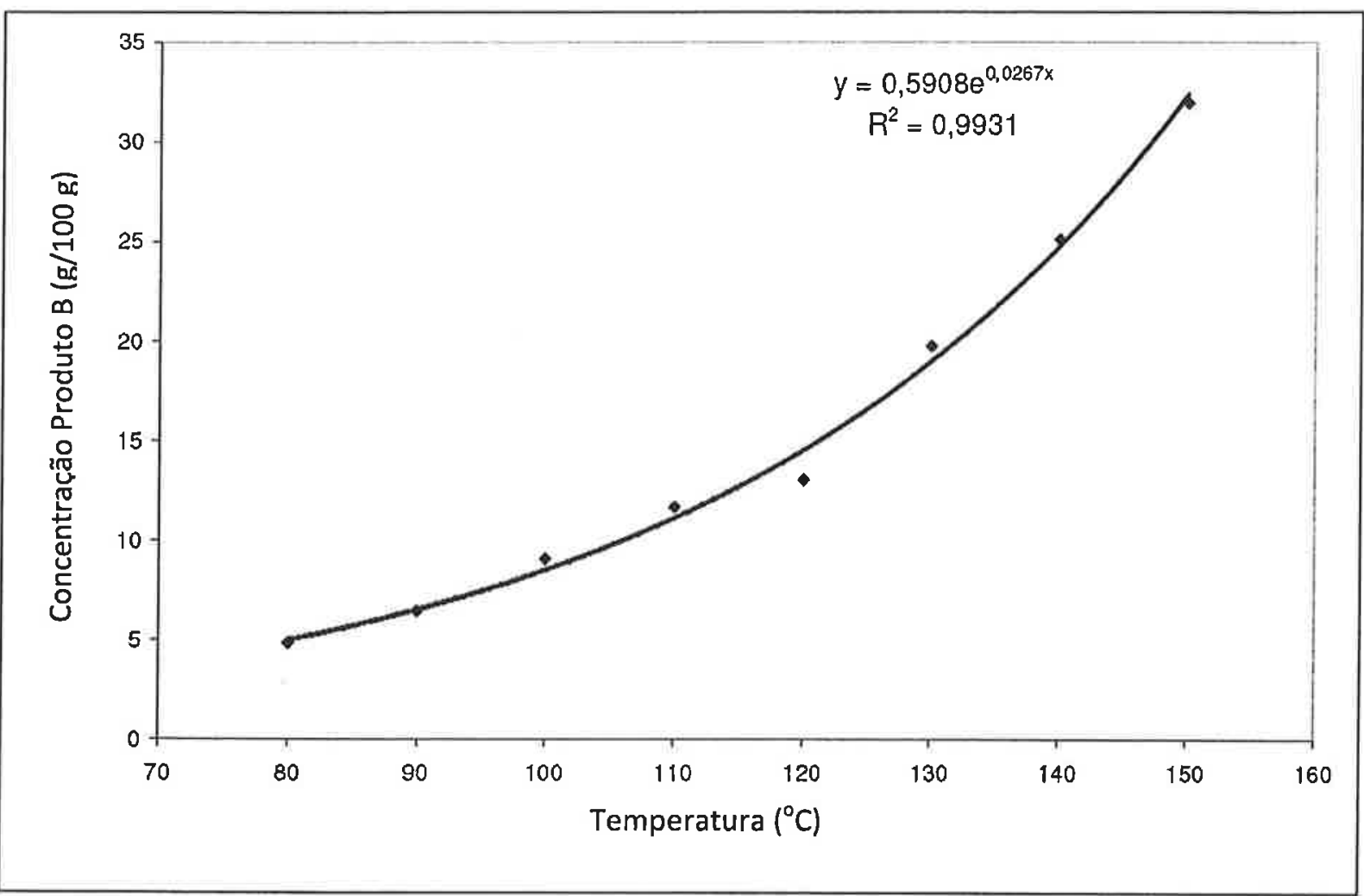

Figura 3-4. Curva de solubilidade do produto B.

\subsection{Materiais e métodos}

\subsubsection{EXTENSÃo DA INCRUSTAÇÃo}

Para avaliar a incrustação do interior dos tubos, o cabeçote superior do trocador de calor foi removido e inspecionado visualmente, durante paradas para manutenção e limpeza da unidade realizadas em agosto de 2005, fevereiro de 2006 e agosto de 2006. Cada parada ocorreu após um período de operação de aproximadamente 6 meses.

Os tubos foram preenchidos com água, de forma a avaliar a quantidade da incrustação nos tubos. A localização dos depósitos com maior dureza, tanto em relação ao diâmetro do equipamento, quanto em relação ao seu comprimento, foi determinada durante o processo de remoção mecânica desta incrustação.

A localização dos depósitos com maior dureza, tanto em relação à posição axial quanto radial nos tubos do trocador, foi identificada pelo tempo necessário para a sua remoção mecânica. 


\subsubsection{COMPOSIÇÃO DO DEPÓSITO}

Amostras do material incrustado foram coletadas dos tubos de forma a mapear uniformemente a incrustação (Figura 3-5). Foram determinados os teores do reagente $\mathrm{A}$ e do produto $\mathrm{B}$ por cromatografia líquida de alta eficiência. O material insolúvel foi analisado por espectrometria de fluorescência de raios $X$. $O$ espectro de elementos cobriu desde o flúor até $O$ urânio, com limite mínimo de deteç̧ão de aproximadamente $0,01 \%$ como óxidos.

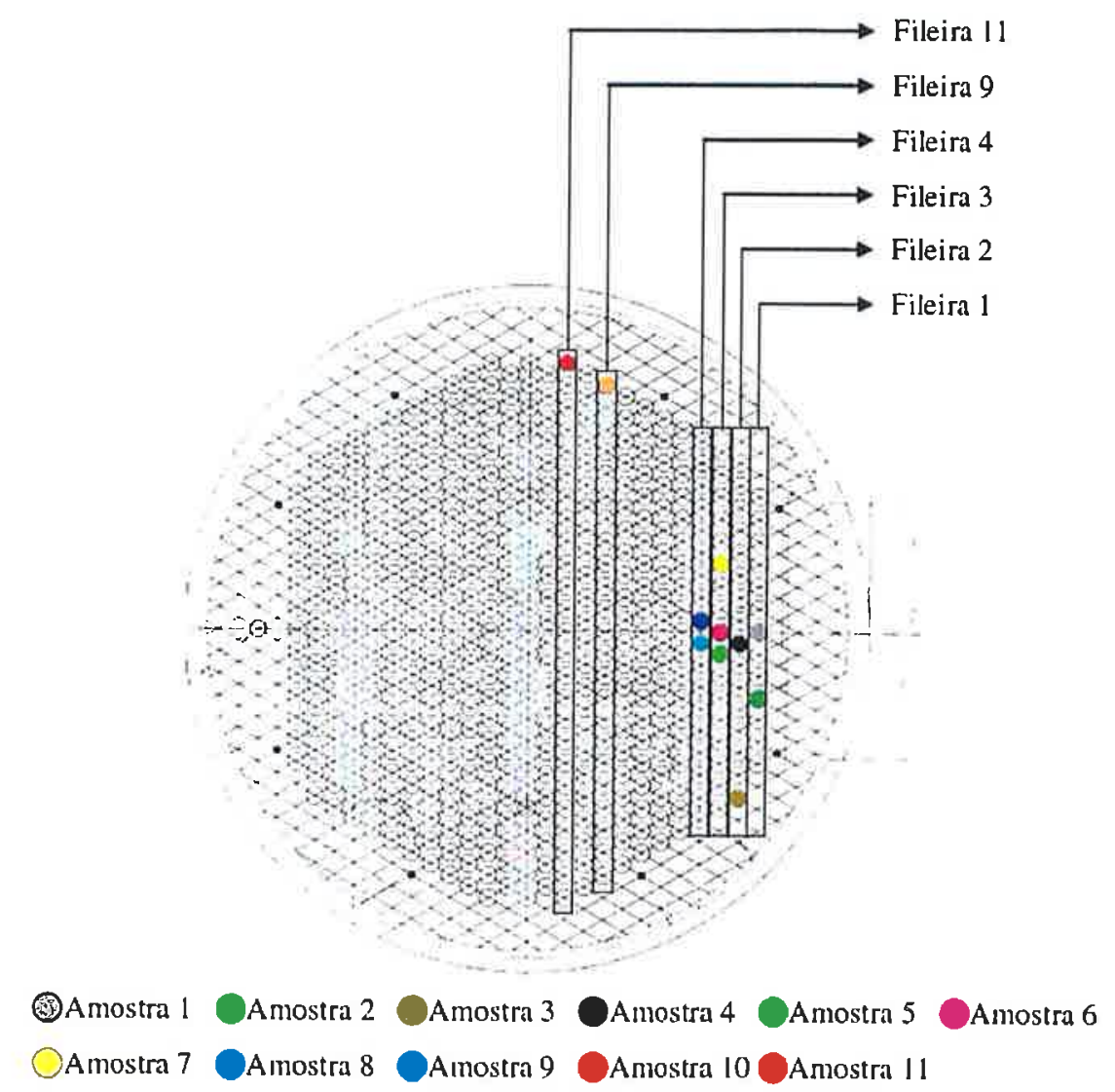

Figura 3-5. Pontos de amostragem para determinação da composição química do deposito de fevereiro de 2006.

\subsubsection{AVAliaÇÃo TÉrmica do Trocador DE CALOR}

O trocador existente é um trocador casco-tubos 1-1, instalado verticalmente, onde o produto escoa no lado dos tubos e água de resfriamento no casco. As dimensões do trocador são mostradas na Tabela 3-1, as propriedades físicas e condições de operação encontram-se na Tabela 3-2.

Utilizaram-se dados da água, como simplificação, para representar as propriedades físicoquímicas do produto, considerando-se as médias aritméticas entre as temperaturas de entrada e saída dos fluidos quente (Tc) e frio (tc).

Para assegurar que a resistência a troca térmica não incluisse a incrustação, as medidas foram feitas imediatamente após as paradas para limpeza dos trocadores. Antes da coleta de dados, 
observou-se cuidadosamente que o regime de operação normal estivesse estabelecido. Para cada situação, foram coletados dados de oito bateladas.

Tabela 3-1. Dimensões do trocador de calor

\begin{tabular}{|c|c|c|c|}
\hline ITEM & & Unidade & Dimensão \\
\hline Diámetro interno dos tubos & $\mathrm{D}_{\mathrm{i}}$ & $m$ & $2,8 E-02$ \\
\hline Dianmetro externo dos tutros & $D_{0}$ & m & $3,2 \mathrm{E}-02$ \\
\hline Número de Tubos & $N_{1}$ & & 500 \\
\hline Comprimento dos tubos & L. & min & 4.26 \\
\hline Diârnetro inteno cla cärcalça & $\mathrm{D}_{\mathrm{s}}$ & $m$ & 1.14 \\
\hline Diâmerro exteno do feixe (envolioria) de fubos & $D_{\text {otl }}$ & $m$ & 0.98 \\
\hline Passo & $j^{\prime}$ & m & $3,0 \mathrm{E}-02$ \\
\hline Passo paralelo & $P_{p}$ & $\mathrm{~m}$ & $3,4 \mathrm{E}-02$ \\
\hline Espaçamento entre as chicanils & $1_{s}$ & m & 0.51 \\
\hline Espaçamento da primeira chicana em relação :oo espello & $I_{\mathrm{si}}$ & $\mathrm{m}$ & 0,46 \\
\hline Espaçannento da última chicana em rêaçâa ao espelho & $I_{\mathrm{so}}$ & $\mathrm{m}$ & 0.46 \\
\hline Corte das chicanas & $I_{c}$ & $\mathrm{~m}$ & 0,31 \\
\hline Distancia entre o casco e a chicana & $\hat{v}_{\mathrm{sh}}$ & $m$ & $6,4 E-03$ \\
\hline Distância entre o tulro a a chicanal & $0_{1 \mathrm{~b}}$ & $m$ & 7.9E-04 \\
\hline Numero de liras selantes & $\mathrm{N}_{\mathrm{s} s}$ & & 3 \\
\hline
\end{tabular}

Tabela 3-2. Condições de operação e propriedades físicas no trocador de calor.

\begin{tabular}{|c|c|c|c|c|c|c|c|}
\hline & \multirow{2}{*}{\multicolumn{2}{|c|}{ Elapas de Reaçẵo }} & \multicolumn{2}{|c|}{ Infcio Oxidaçio } & \multicolumn{3}{|c|}{ Final Oxidaçào } \\
\hline & & & Janejro/2005 & Agos1o/2005 & Janciro/2005 & Agosto $/ 2005$ & Fevereird2006 \\
\hline \multirow{9}{*}{ Tubos } & $\mathrm{Ti}_{\text {posdute }}$ & ${ }^{a} \mathrm{C}$ & 96.2 & 93,3 & 1126 & 109,3 & 113.8 \\
\hline & To proturo & ${ }^{\circ} \mathrm{C}$ & 96.0 & 93,2 & 111.7 & 108.3 & 112,9 \\
\hline & $T c_{\text {prealuto }}$ & ${ }^{\circ} \mathrm{C}$ & 96.1 & 93.2 & $11 \geq .2$ & 108,8 & 113.3 \\
\hline & $\rho$ & $\mathrm{kg} / \mathrm{m}^{3}$ & 960.9 & 962,9 & 948.8 & $95 ! .4$ & 947.9 \\
\hline & $\mu$ & $\mathrm{kg} / \mathrm{m} * \mathrm{~s}$ & 2.92E-04 & $3,02 \mathrm{E}-044$ & $2,48 \mathrm{E}-(04$ & $2,56 \mathrm{E}-04$ & $2.45 \mathrm{E}-0.4$ \\
\hline & $k$ & $\mathrm{~W} / \mathrm{m} *{ }^{\circ} \mathrm{C}$ & 0,676 & 0,674 & 0.681 & 0,680 & 0.681 \\
\hline & $c_{p}$ & $\mathrm{cal} / \mathrm{g} *{ }^{n} \mathrm{C}$ & 1,006 & 1,005 & 1.011 & 1,010 & 1.012 \\
\hline & $w$ & $\mathrm{~kg} / \mathrm{h}$ & 1.508 .426 & 1.508 .426 & $1.50) \times .426$ & 1.508 .426 & 1.508 .426 \\
\hline & v & $\mathrm{m} / \mathrm{s}$ & 1.3 & 1.3 & 1.4 & 1.4 & 1.4 \\
\hline \multirow{10}{*}{ Casco } & $\dot{t}_{\text {agyม }}$ & ${ }^{\circ} \mathrm{C}$ & 32.1 & 33.8 & 32.1 & .34 .0 & 31,0 \\
\hline & $10)_{3.4011}$ & ${ }^{n} \mathrm{C}$ & 8.5 .1 & 801,8 & 69.4 & 63,9 & 70.8 \\
\hline & $I c_{\text {iectit }}$ & ${ }^{\circ} \mathrm{C}$ & 58,6 & .57 .3 & 50,8 & 48.9 & 50,9 \\
\hline & $\Gamma_{\mathrm{w}}$ & ${ }^{\circ} \mathrm{C}$ & 88.4 & 89.6 & 104,8 & 100,3 & 106.2 \\
\hline & $\rho$ & $\mathrm{kg} / \mathrm{m}^{3}$ & 983.7 & 984.4 & 987.6 & 988.5 & 987.6 \\
\hline & $\mu_{\mathrm{b}}$ & $\mathrm{kg} / \mathrm{m}^{*} \mathrm{~s}$ & $4,871 \mathrm{E}-(144$ & $4,89 E_{-}-04$ & $5.40 \mathrm{E}-(04$ & $5.58 \mathrm{E}-04$ & $5.39 \mathrm{E}-(1) 4$ \\
\hline & $\mu_{\psi}$ & $\mathrm{kg} / \mathrm{m}^{*} \mathrm{~s}$ & $3,198-(04$ & $3,1.5 \mathrm{E}-() 4$ & 2.66E-(04 & $2.78 E-04$ & 2,62E-(14 \\
\hline & $k$ & $\mathrm{~W} / \mathrm{m}^{* 4} \mathrm{C}$ & 0.649 & 0,648 & $0,6+11$ & 0.639 & $0.0-11$ \\
\hline & $c_{p}$ & $\mathrm{call} / \mathrm{g}{ }^{\circ} \mathrm{C}$ & 1,000 & 0.990 & 0.990 & 0.909 & 0.909 \\
\hline & W & $\mathrm{kg} / \mathrm{l}$ & 6,837 & $2 .(x) 5$ & 38.728 & 52.326 & 35.851 \\
\hline
\end{tabular}

A partir das dimensões do equipamento, bem como das vazões e temperaturas de entrada e saída dos fluidos, calculou-se a temperatura da parede (tw). Utilizaram-se métodos disponíveis na literatura aberta para cálculo dos coeficientes de transferência de calor. Para determinação dos coeficientes de transmissão de calor do lado dos tubos (hio) e do casco (hs), informações necessárias para cálculo da temperatura da parede, foram utilizados, respectivamente, os métodos de Kern e de Bell-Delaware (Araújo, 2002).

As temperaturas de entrada e saída para os fluidos quente e frio foram coletadas para 16 diferentes bateladas, durante um dia de operação. 
Para cálculo da temperatura da parede (tw), foi utilizada a seguinte equação:

$$
t_{w}=t_{c}+\frac{h_{i o}}{h_{i o}+h_{s}}\left(T_{c}-t_{c}\right)
$$

\subsubsection{TEOR DE Produto nas DifERENTES ETAPAS DE REAÇÃo}

As amostras da solução foram coletadas ao final das bateladas, uma vez por semana, ao longo de um mês. Durante o período de coleta, a capacidade de produção foi constante. A determinação do teor de produto na solução foi realizada por cromatografia líquida de alta eficiência (HPLC).

\subsection{Resultados e discussão}

\subsubsection{EXTENSÃO DA INCRUSTAÇÃO}

A Figura 3-6 apresenta um esquema dos tubos em vista de topo e das chicanas do trocador em corte longitudinal, bem como a localização das entradas e saídas dos fluidos quente e frio. As áreas coloridas das figuras indicam onde a incidência de incrustações foi maior. As Figura 3-7 e Figura 3-8 são fotografias das inspeções antes do hidrojateamento. Os tubos com incidência de incrustação mais severa estão na região indicada em vermelho nessas figuras. O número de tubos com incrustações diminuiu ao longo do tempo, como mostra a Tabela 3-3.

Tabela 3-3. Número de tubos com incrustação

\begin{tabular}{|l|l|}
\hline Mês e ano da inspeção & Número de tubos com incrustação \\
\hline Agosto / 2005 & 339 \\
\hline Fevereiro / 2006 & 73 \\
\hline Agosto / 2006 & 10 \\
\hline
\end{tabular}

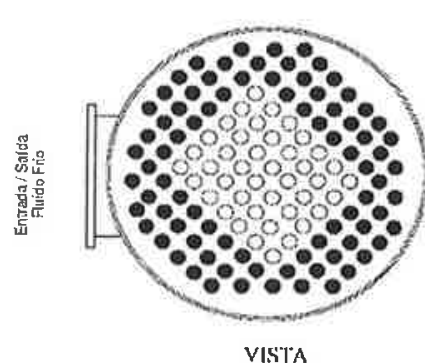

VISTA
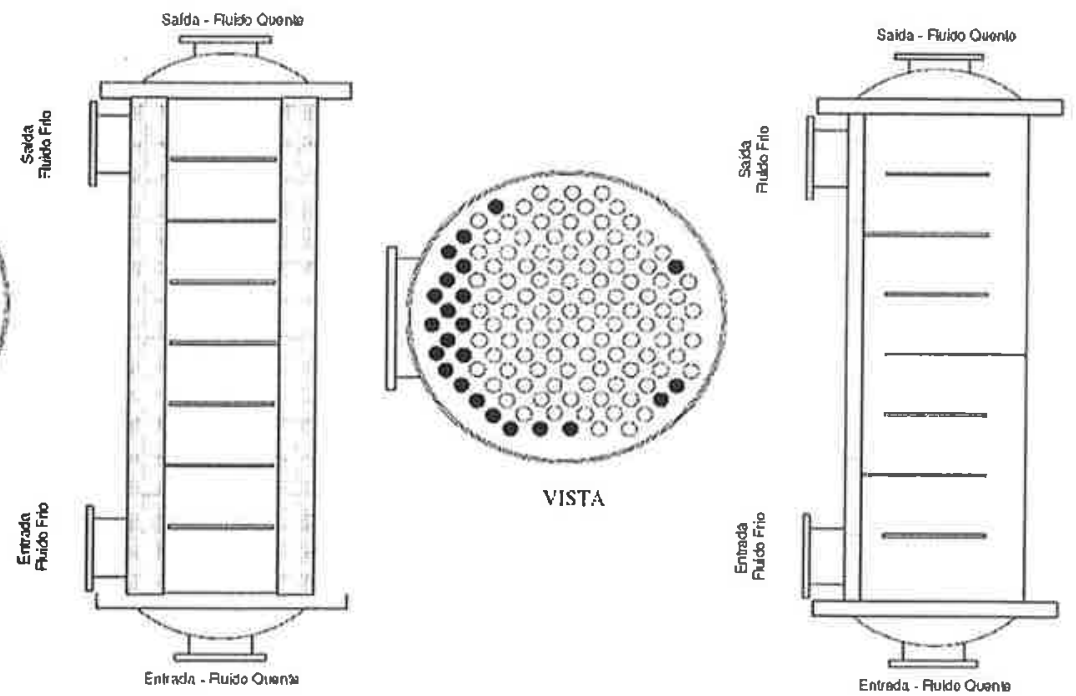

Figura 3-6. Vistas lateral e de topo do trocador de calor. As regiões coloridas indicam a presença de incrustação em agosto de 2005 (esquerda) e fevereiro de 2006 (direita). 

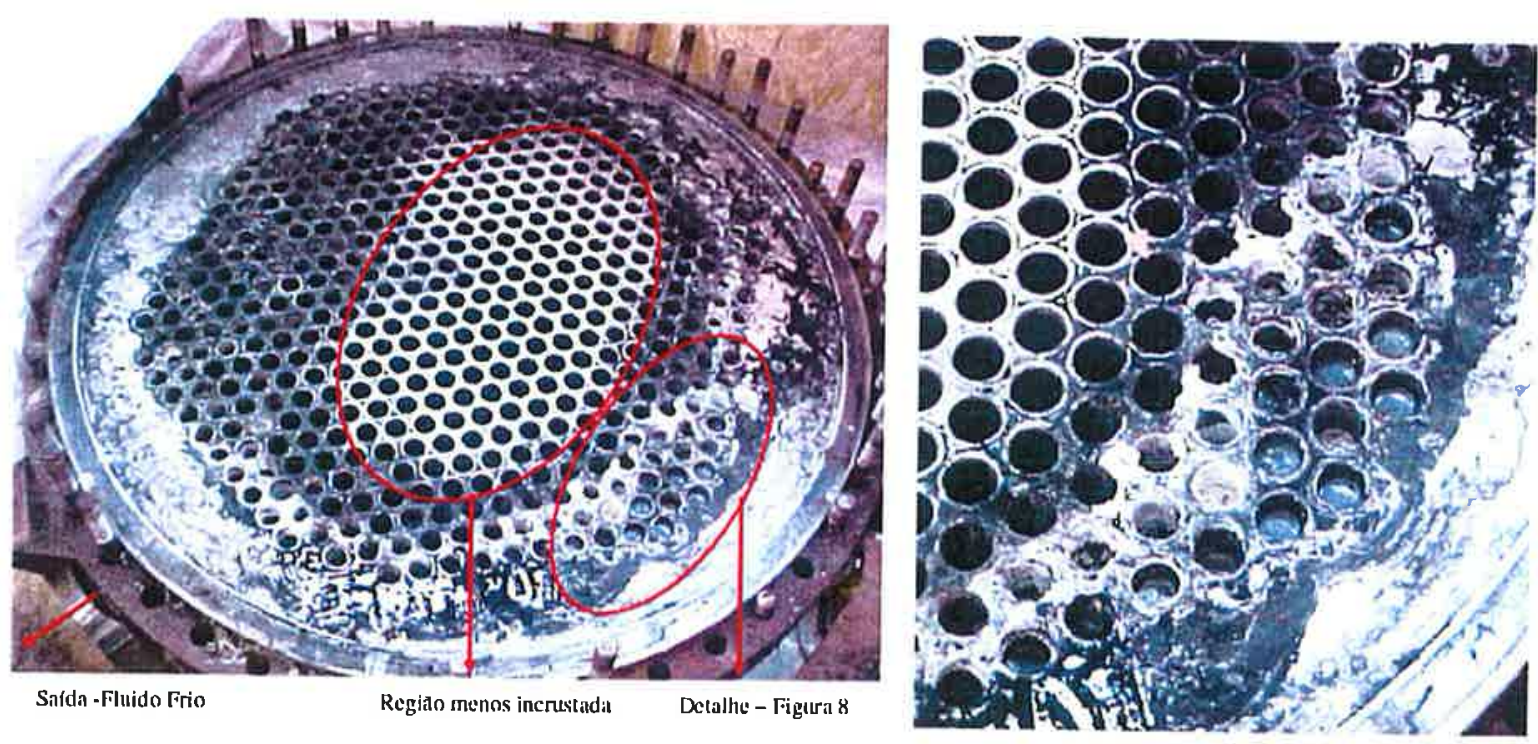

Figura 3-7. Fotos de topo do trocador de calor em inspeção realizada em agosto de 2005. Maior incidência de incrustação no interior dos círculos em vermelho.

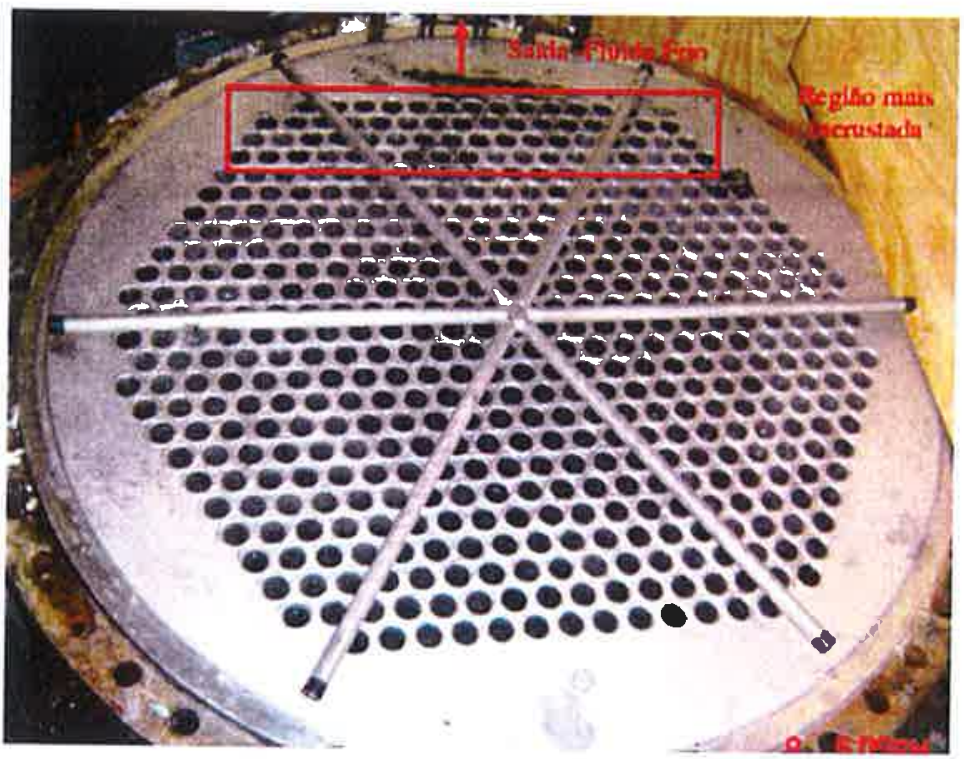

Figura 3-8. Foto de topo do trocador de calor em inspeção realizada em fevereiro de 2006. Maior incidência de incrustação no interior da área em vermelho.

Durante a operação de remoção da incrustação, detectou-se que os cristais mais dificilmente removíveis estavam nos tubos mais próximos à entrada e saída da corrente de água. Além disto, outra importante constatação foi que o material com maior dureza estava localizado próximo aos espelhos.

A menor incrustação na região central dos tubos do trocador pode ser explicada pelas maiores velocidades do fluido de processo nessa região, uma vez que há uma placa de orifício posicionada na entrada dos tubos do trocador, provavelmente contribuindo para intensificar este efeito. Assim sendo, uma redução da incrustação poderia ser obtida pelo aumento da velocidade média do fluido de processo e por sua melhor distribuição ao longo da seção transversal do trocador. 


\subsubsection{COMPOSIÇÃO DO DEPóSITO}

A Figura 3-9 mostra que o depósito é constituído predominantemente ou pelo reagente ou pelo produto, sendo apenas cerca de $25 \%$ constituído por insolúveis. Não foram encontradas amostras nas quais o único depósito era o material orgânico. Estes são compostos predominantemente por sílica (Tabela 3-4). A partir destes resultados, infere-se que os mecanismos de incrustação são provavelmente a cristalização de reagente, de produto (a ser confirmado pelo cálculo da supersaturação) e a deposição de particulado associados. A figura mostra ainda que o produto deposita-se principalmente nas proximidades da entrada de água de resfriamento. A matéria prima distribui-se aleatoriamente no trocador.

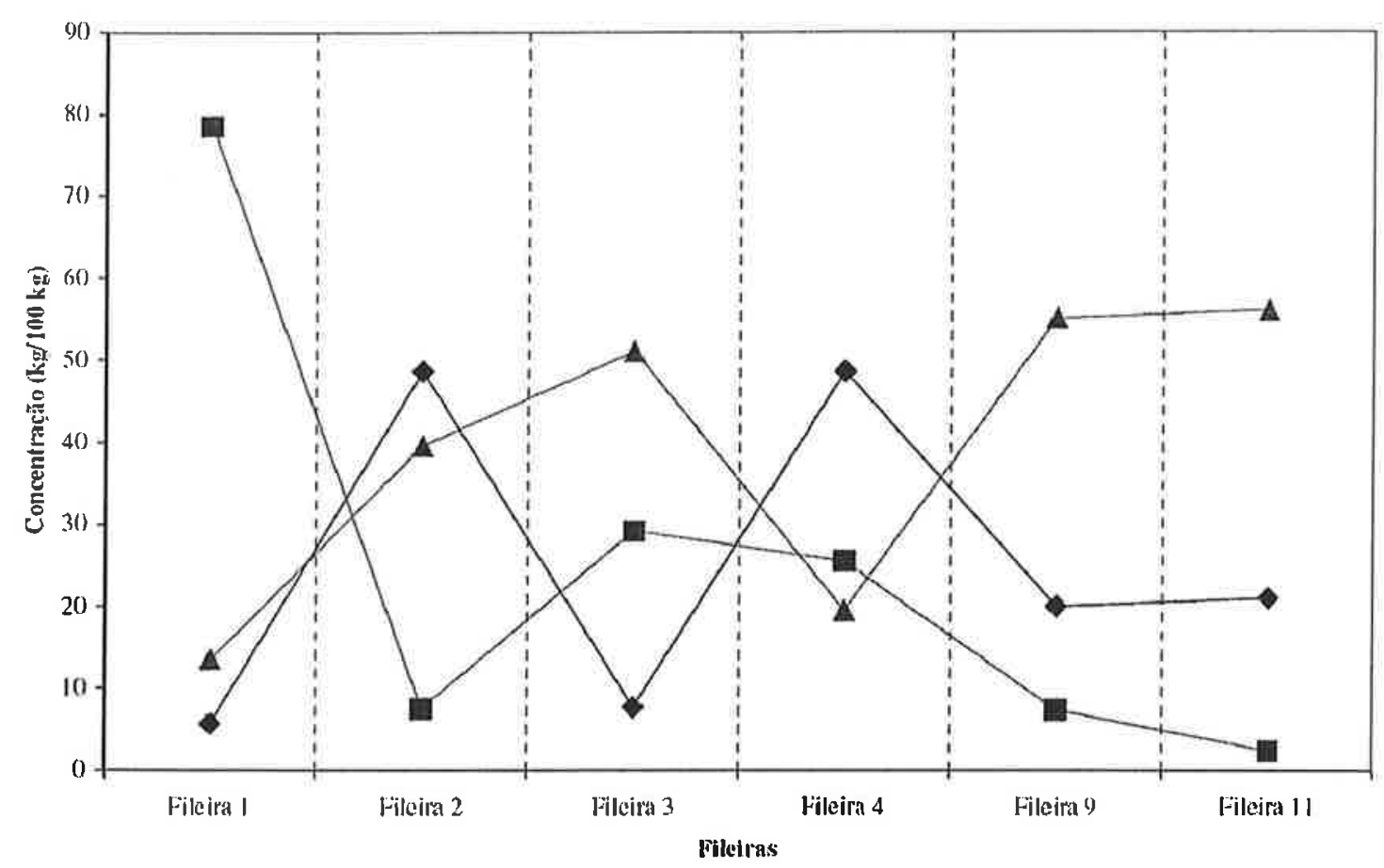

Figura 3-9. Composição do material incrustado em fevereiro de 2006 nos diversos pontos de amostragem. Quadrados representam a concentração de produto $B$, triângulos representam o reagente $A$ e diamantes são insolúveis. 
Tabela 3-4. Composição dos insolúveis na incrustação (fevereiro de 2006).

\begin{tabular}{c|c}
\hline Elemento & $\begin{array}{c}\text { Composição } \\
\text { (\%) }\end{array}$ \\
\hline $\mathrm{SiO}_{2}$ & $95,50 \%$ \\
$\mathrm{Al}_{2} \mathrm{O}_{3}$ & $1,49 \%$ \\
$\mathrm{WO}_{3}$ & $0,67 \%$ \\
$\mathrm{Fe}_{2} \mathrm{O}_{3}$ & $0,40 \%$ \\
$\mathrm{Na}_{2} \mathrm{O}$ & $0,40 \%$ \\
$\mathrm{~K}_{2} \mathrm{O}$ & $0,31 \%$ \\
$\mathrm{TiO} 2$ & $0,31 \%$ \\
$\mathrm{CaO}$ & $0,27 \%$ \\
$\mathrm{Co} \mathrm{O}_{4}$ & $0,24 \%$ \\
$\mathrm{P}_{2} \mathrm{O}_{5}$ & $0,09 \%$ \\
$\mathrm{MgO}$ & $0,08 \%$ \\
$\mathrm{Cr}_{2} \mathrm{O} 5$ & $0,06 \%$ \\
$\mathrm{PtO}_{2}$ & $0,04 \%$ \\
$\mathrm{SO}_{3}$ & $0,04 \%$ \\
$\mathrm{MnO}_{2}$ & $0,02 \%$ \\
$\mathrm{ZrO}_{2}$ & $0,02 \%$ \\
\hline
\end{tabular}

\subsubsection{AValiação Térmica do Trocador de Calor}

Para a análise térmica do equipamento, baseando-se na metodologia descrita anteriormente, foram utilizadas as seguintes premissas:

1. não há incrustação no trocador.

2. a resistência da parede metálica à troca de calor é desprezível;

3. a parede tem uma temperatura uniforme (tw) em toda a seção transversal;

4. $\quad$ os fluidos quente e frio escoam com as vazões de projeto;

As medidas foram tomadas logo após as paradas da unidade, a hipótese 1 é razoável. Com estas considerações, pode-se verificar que a velocidade do fluido reacional $(1,4 \mathrm{~m} / \mathrm{s})$, apresenta-se ligeiramente maior que o valor mínimo recomendado para projeto de fluidos incrustantes de 1,0 $\mathrm{m} / \mathrm{s}$ (Araújo, 2002).

A temperatura Tabela 3-5 mostra temperaturas típicas em torno do cristalizado no início e final da oxidação $(\mathrm{Ti}=\mathrm{To})$. A temperatura do meio reacional é praticamente constante em cada passe. Ao longo da batelada, no entanto, a temperatura aumenta gradativamente. A temperatura da água de resfriamento, ao contrário, varia bastante entre a entrada e a saída do trocador, tendo sido encontrados. valores de (to - ti) entre 30 e $50{ }^{\circ} \mathrm{C}$. 
Tabela 3-5. Temperaturas típicas no início da oxidação (acima) e no seu final (abaixo).

\begin{tabular}{l|ccccc}
\hline Mess & $\mathrm{T}_{\mathrm{i}}$ & $\mathrm{T}_{\mathrm{o}}$ & $\mathrm{t}_{\mathrm{i}}$ & $\mathrm{t}_{\mathrm{o}}$ & \\
\hline Janeiro / 2005 & 96 & 96 & 32 & 85 & $(\mathrm{)})$ \\
Agosto / 2005 & 93 & 93 & 34 & 81 & \\
\hline
\end{tabular}

(*) Temperatura calculada (não disponível no mes de coleta dos dados)

\begin{tabular}{l|ccccc}
\hline Mês & $\mathrm{T}_{\mathrm{i}}$ & $\mathrm{T}_{\mathrm{o}}$ & $\mathrm{t}_{\mathrm{i}}$ & $\mathrm{t}_{\mathrm{o}}$ & \\
\hline Janeiro / 2005 & 113 & 112 & 32 & 69 & $(*)$ \\
Agosio / 2005 & 109 & 108 & 34 & 64 & \\
Fevereiro / 2006 & 114 & 113 & 31 & 71 & \\
\hline
\end{tabular}

A avaliação térmica dos trocadores de calor, feita pelo método de Bel-Delaware para o lado do casco, é mostrada na Tabela 3-6 para o início da oxidação e na Tabela 3-7 para o seu final. Os coeficientes $J_{C}, J_{L} J_{b}, J_{r}, J_{s}$, respectivamente os fatores de correção do coeficiente de troca térmica do lado do casco devido a efeitos de chicana, vazamento na chicana, contorno de feixe, gradiente adverso de temperatura e espaçamento desigual de chicanas na entrada e saída, são compatíveis com valores encontrados na literatura.

Tabela 3-6. Avaliação térmica do trocador de calor no início da oxidação.

\begin{tabular}{|c|c|c|c|c|}
\hline \multicolumn{3}{|c|}{ Dados de processo } & Janeiro/2005 & Agosto/2005 \\
\hline \multirow{6}{*}{ Tubos } & $T i_{\text {produto }}$ & ${ }^{\circ} \mathrm{C}$ & $96 ; 2$ & $93 ; 3$ \\
\hline & To produto & ${ }^{\mathrm{B}} \mathrm{C}$ & 96,0 & 93,2 \\
\hline & $\mathrm{Tc} \mathrm{c}_{\text {produto }}$ & ${ }^{\circ} \mathrm{C}$ & 96.1 & 93.2 \\
\hline & $w$ & $\mathrm{~kg} / \mathrm{h}$ & 1.508 .426 & 1.508 .426 \\
\hline & $h_{i}$ & $\mathrm{~W} / \mathrm{m}^{2} *{ }^{\circ} \mathrm{C}$ & $9,31 E+03$ & $9,22 \mathrm{E}+03$ \\
\hline & $\mathrm{h}_{\mathrm{io}}$ & $\mathrm{W} / \mathrm{m}^{2} *{ }^{\circ} \mathrm{C}$ & $8,35 \mathrm{E}+03$ & $8,26 \mathrm{E}+03$ \\
\hline \multirow{13}{*}{ Casco } & $\mathrm{ti}_{\mathrm{igua}}$ & ${ }^{\circ} \mathrm{C}$ & 32,1 & 33,8 \\
\hline & $\mathrm{to}_{\text {agua }}$ & ${ }^{\circ} \mathrm{C}$ & 85.1 & 80,8 \\
\hline & $\mathrm{tc}_{\text {águi }}$ & ${ }^{\circ} \mathrm{C}$ & 58,6 & 57,3 \\
\hline & $T_{w}$ & ${ }^{\circ} \mathrm{C}$ & 88,4 & 89,6 \\
\hline & W & $\mathrm{kg} / \mathrm{h}$ & 6.837 & 2.695 \\
\hline & $\mathrm{h}_{\text {ideal }}$ & $W / m^{2} *{ }^{\circ} \mathrm{C}$ & 1.192 & 694 \\
\hline & $\mathrm{J}_{\mathrm{C}}$ & & 1.02 & 1.02 \\
\hline & $\mathrm{J}_{\mathrm{L}}$ & & 0,58 & 0,58 \\
\hline & $\mathrm{J}_{\mathrm{b}}$ & & 0,62 & 0,62 \\
\hline & $\mathrm{J}_{\mathrm{r}}$ & & 1,00 & 1,00 \\
\hline & $\mathrm{J}_{\mathrm{s}}$ & & 1,01 & 1,01 \\
\hline & $h_{s}$ & $\mathrm{~W} / \mathrm{m}^{2} *{ }^{\circ} \mathrm{C}$ & $4,45 E+02$ & $2,59 \mathrm{E}+02$ \\
\hline & $T_{w}$ & ${ }^{\circ} \mathrm{C}$ & 94.2 & 92,1 \\
\hline
\end{tabular}


Tabela 3-7. Avaliação térmica do trocador de calor no final da oxidação.

\begin{tabular}{|c|c|c|c|c|c|}
\hline \multicolumn{3}{|c|}{ Dados de processo } & Janeiro/2005 & Agos:o/2005 & Fevereiro/2006 \\
\hline \multirow{6}{*}{ Tubos } & $\mathrm{Ti}_{\text {protulo }}$ & ${ }^{\circ} \mathrm{C}$ & 112.6 & 109,3 & 113,8 \\
\hline & $\mathrm{To}_{\text {preduto }}$ & ${ }^{3} \mathrm{C}$ & 111.7 & 108,3 & 112,9 \\
\hline & $\mathrm{Tc}_{\text {precluus }}$ & ${ }^{\mathrm{D}} \mathrm{C}$ & 112.2 & 108.8 & 113,3 \\
\hline & $w$ & $\mathrm{~kg} / \mathrm{h}$ & 1.508 .426 & 1.508 .426 & 1.508 .426 \\
\hline & $\mathrm{h}_{\mathrm{i}}$ & $\mathrm{W} / \mathrm{m}^{2} *{ }^{\circ} \mathrm{C}$ & $1.01 E+(1) 4$ & $9.97 E+03$ & $1,02 \mathrm{E}+04$ \\
\hline & $\mathrm{h}_{\mathrm{io}}$ & $\mathrm{W} / \mathrm{m}^{2} *{ }^{\circ} \mathrm{C}$ & $4,09 \mathrm{E}+03$ & $8.93 \mathrm{k}+113$ & $9,15 \mathrm{E}+(1) 3$ \\
\hline \multirow{13}{*}{ Casco } & $\mathrm{ti}_{\text {agfia }}$ & ${ }^{5} \mathrm{C}$ & 32,1 & 34,0 & 31,0 \\
\hline & $\mathrm{to}_{\mathrm{agua}}$ & ${ }^{\circ} \mathrm{C}$ & 69,4 & 63.9 & 70,8 \\
\hline & $\mathrm{tc}_{\text {tiqun }}$ & ${ }^{\circ} \mathrm{C}$ & 50,8 & 48,9 & 50,9 \\
\hline & $\mathrm{I}_{\mathrm{w}}$ & ${ }^{\circ} \mathrm{C}$ & 104.8 & 100.3 & 106.2 \\
\hline & W & $\mathrm{kg} / \mathrm{h}$ & 38.728 & 52.326 & 35.8 .51 \\
\hline & $\mathrm{ll}_{\text {ideal }}$ & $\mathrm{W} / \mathrm{m}^{2} *^{\circ} \mathrm{C}$ & 3.351 & 3.963 & 3.207 \\
\hline & $\mathbf{J}_{\mathrm{C}}$ & & 1.02 & 1.02 & 1.02 \\
\hline & $\mathrm{J}_{\mathrm{L}}$ & & 0.58 & 0,58 & 0,58 \\
\hline & $J_{b}$ & & 0.62 & 0.62 & 0,62 \\
\hline & $J_{r}$ & & 1.00 & 1,00 & 1,00 \\
\hline & $\mathrm{J}_{\mathrm{s}}$ & & 1.01 & 1,01 & 1,01 \\
\hline & $h_{s}$ & $\mathrm{~W} / \mathrm{m}^{2} *{ }^{\circ} \mathrm{C}$ & $1,25 E+03$ & $1,48 \mathrm{E}+03$ & $1,20 \mathrm{E}+03$ \\
\hline & $\mathrm{T}_{\mathrm{w}}$ & ${ }^{\mathrm{C} C} \mathrm{C}$ & 104.7 & 100.3 & 106.1 \\
\hline
\end{tabular}

A resistência a troca de calor está principalmente do lado do casco: no início da batelada ela é 19 a 32 vezes maior que a resistência nos tubos, enquanto no final da batelada estes valores variaram entre 6 e 8 . Por esse motivo, as temperatura de parede Tw são mais próximas da temperatura do meio reacional do que da temperatura da água. De fato, a diferença entre a temperatura do produto no seio do fluido e na parede é em media $1,5^{\circ} \mathrm{C}$ no início da batelada e $7,7^{\circ} \mathrm{C}$ em seu final.

\subsubsection{SUBRESFRIAMENTO DO REAGENTE E DO PRODUTO NO INÍCIO DA REAÇ̃̃o E EM SEU FINAL}

Com a concentração de produto, sua temperatura e a curva de solubilidade, pode-se calcular o subresfriamento a que ele é submetido. Nesta avaliação, foi considerada a curva de solubilidade do produto puro.

Consideremos o reagente $A$ no início da batelada, quando a sua concentração é máxima. A Tabela 3-8 e a Figura 3-10 mostram que a solução no seio do líquido não está subresfriada. Já nas proximidades da parede do trocador de calor, a solução encontra-se ou próxima da saturação ( $\Delta T$ $\left.=-1,7{ }^{\circ} \mathrm{C}\right)$ ou fortemente subresfriada $\left(\Delta \mathrm{T}=-18^{\circ} \mathrm{C}\right)$. Ao longo da batelada, à medida que o reagente é consumido na reação, a solução passa a subsaturada. $O$ depósito de reagente eventualmente formado no início da batelada tende a se dissolver no seu final.

Em relação ao produto B (Tabela 3-9 e Figura 3-11), a solução no seio do líquido encontra-se próxima da saturação mesmo no inicio da batelada, devido ao fato de parte do produto da batelada anterior ser realimentado ao reator. No final da batelada, a solução no seio do fluido 
está subsaturada, pois a temperatura é elevada propositalmente, para compensar a maior concentração de produto no meio. No entanto, nas proximidades da parede a solução está subresfriada $\left(\Delta T=-2\right.$ a $-6{ }^{\circ} \mathrm{C}$ ). Conclui-se que há possibilidade de formação de glifosato nas paredes do trocador em toda a batelada. No final da reação a chance de deposição é maior que no início.

Tabela 3-8. Subresfriamento para o reagente $A$

\begin{tabular}{|c|c|c|c|c|c|}
\hline Etapa de & Reação & $T_{i}$ & $T_{w}$ & $\mathrm{~T}_{\text {saturatio }}$ & $T_{W}-T_{\text {satumacto }}$ \\
\hline \multirow{2}{*}{ Início Oxidação } & Janeiro / 2005 & 96.2 & 94.2 & 92.5 & 1.7 \\
\hline & Agosto $/ 2005$ & 93,3 & 92,1 & 110,1 & -18.0 \\
\hline \multirow{2}{*}{ Final Oxidaçāo } & Janeiro / 2005 & 112,6 & 104.7 & $<0$ & $>100$ \\
\hline & Agosto / 2005 & 109,3 & 100,3 & $<0$ & $>100$ \\
\hline
\end{tabular}

Tabela 3-9. Subresfriamento para o produto B

\begin{tabular}{|c|c|c|c|c|}
\hline Etapa de Reação & $\overline{T_{i}}$ & $\overline{T_{w}}$ & $\mathrm{~T}_{\text {saturacào }}$ & $\mathrm{T}_{\mathrm{w}}-\mathrm{T}_{\text {saturacao }}$ \\
\hline Janeiro / 2005 & 96,2 & 94,2 & 99,8 & $-5,6$ \\
\hline Início Oxidação & 93.3 & 92,1 & 85,2 & 6,9 \\
\hline \multirow{2}{*}{ Final Oxidação } & 112,6 & 104,7 & 107,1 & $-2,3$ \\
\hline & 109.3 & 100.3 & 106,3 & $-6,0$ \\
\hline
\end{tabular}

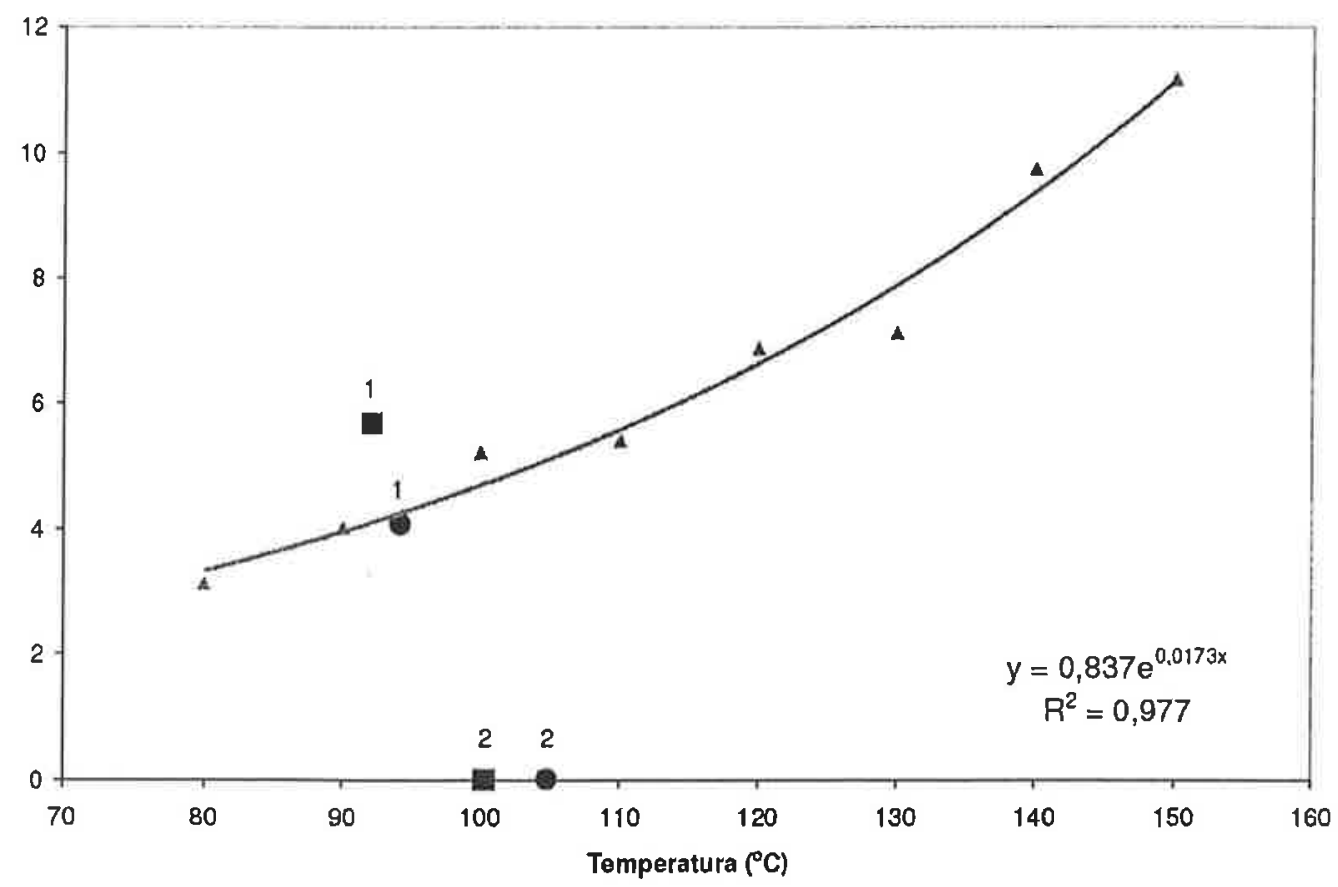

Figura 3-10. Supersaturação em relação ao reagente. Curva dá a solubilidade do reagente (em g / $100 \mathrm{~g}$ solução) em função da temperatura. Pontos redondos indicam amostragem em janeiro de 2005, quadrados em agosto de 2005. Índice 1 indica início da reação, índice 2 seu final. 


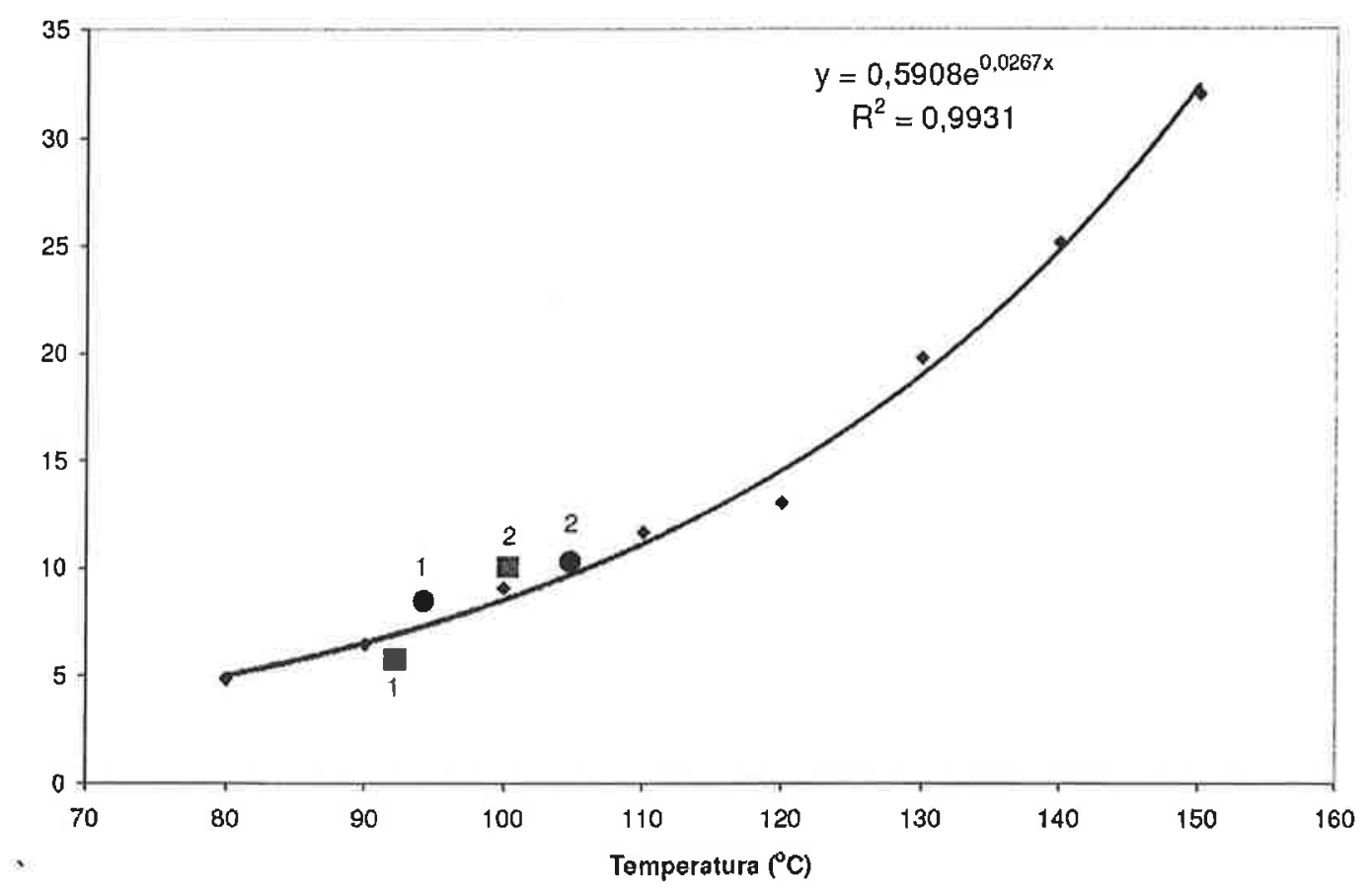

Figura 3-11. Supersaturação em relação ao produto. Curva dá a solubilidade do produto (em $\mathrm{g} / 100 \mathrm{~g}$ solução) em função da temperatura. Pontos redondos indicam amostragem em janeiro de 2005, quadrados em agosto de 2005. Índice 1 indica início da reação, índice 2 seu final.

\subsubsection{DISCUSSÃo E PROPOSTAS PARA MINIMIZAR A INCRUSTAÇÃo}

A solução no cristalizador encontra-se subresfriada com relação ao reagente no inicio do processo, e com relação ao produto em seu final, indicando que a cristalização é um potencial mecanismo de incrustação. Esta hipótese é confirmada pelo fato destes dois compostos serem os principais constituintes dos depósitos. Como o depósito contem ainda cerca de $25 \%$ de sílica, é provável que incrustação por particulado também contribua para a formação do depósito.

Propõe-se a seguinte seqüência de eventos numa batelada. No seu início, há deposição do reagente, provavelmente assistida pelo particulado de sílica. Ao longo da batelada, ocorre deposição de produto sobre os cristais do reagente, também possivelmente assistida pelas partículas de sílica. $O$ deposito de produto isola os cristais de reagente do líquido, evitando assim que ele se dissolva em bateladas sucessivas.

Nas sucessivas análises do processo em 2005 e 2006 houve uma redução significativa do número de tubos incrustados. Esta diminuição parece estar associada a maiores cuidados tomados para se evitar o subresfriamento do reagente e do produto. Assim, temperatura na parede e teor de glifosato seriam os dois fatores principais que determinam a ocorrência de incrustação no trocador de calor.

Inspeção do trocador de calor mostra que a deposição ocorre preferencialmente na periferia do trocador de calor e que a resistência mecânica do deposito é maior nas proximidades da entrada e da saída de água de resfriamento. A menor deposição pode ser explicada pela maior velocidade 
do fluido nos tubos do centro, pois há uma placa de orifício na entrada de calor que dirige o escoamento para a região central. Assim sendo, é provável que o aumento da velocidade do fluido de processo contribua para minimizar a incrustação.

Com base nos mecanismos de incrustação, diversas medidas podem ser propostas para minimizar o subresfriamento do reagente e produto no trocador de calor: aumento da temperatura do fluido frio, diminuir a alimentação de produto no inicio da batelada, remover sílica do reator, aumentar a velocidade do meio reacional nos tubos. A segunda hipótese foi testada industrialmente com sucesso (não mostrado neste trabalho).

\subsection{Conclusões}

Os mecanismos de incrustação em um trocador de calor associado a um reator químico foram esclarecidos a partir de uma analise da potencial cristalização do reagente e do produto no meio, do comportamento térmico do trocador, bem como a partir da caracterização físico-química do deposito.

Os principais mecanismos de incrustação são a cristalização de reagente, de produto e deposição particulada de sílica. Propõe-se a seguinte seqüência de eventos numa batelada. No seu início, há deposição do reagente por cristalização, assistida por deposição particulada. Ao longo da batelada, ocorre cristalização de produto sobre os cristais do reagente, também assistida pelas partículas de sílica. $O$ deposito de produto isola os cristais de reagente do líquido, evitando assim que ele se dissolva em bateladas sucessivas.

Com base nos mecanismos citados, diversas medidas foram propostas para minimizar a incrustação. Uma das medidas, a redução do teor de produto recirculado no início da batelada, foi testada industrialmente com sucesso.

\subsection{Referências}

Araújo ECC, Trocadores de Calor. São Carlos, EdUFSCar, 2002.

Bansal B, Chen XD, Muller-Steinhagen H. Int. Comm. Heat Mass Transfer, v.30, n. 5, p. 695-706, 2003.

Bansal B, Chen XD et al.. Analysis of deposits to study the effect of particles on crystallisation fouling. J. Chin. Inst. Chem. Eng. 34, p 299-303, 2003.

Bramson D, Hasson D, et al.. The roles of gas bubbling, wall crystallization and particulate deposition in CaSO4 scale formation. Desalination 100, p 105-113, 1996.

Herz AMR, Malayeri, et al.. Fouling of roughened stainless steel surfaces during convective heat transfer to aqueous solutions. Energy Convers. Manage. 49, p 3381-3386, 2008. 
Garrett-Price $A B$, Smith $S A$, Watts RL et al., Overview of fouling, in: Fouling of Heat Exchangers, Characteristics, Costs, Prevention, Control and Removal, Noyes Publications, Park Ridge, NJ, 1985, p. 9-19.

Jeronimo MAS et al. Monitoring the thermal efficiency of fouled heat exchangers: a simplified method. Experimental Thermal and Fluid Science, 14, p 455 - 463. 1997.

Mai TH, Chitou N, Padet J, Method for the heat exchanger effectiveness calculation under variable dynamic conditions, Int. Commun. Heat Mass Transfer, 26 (5), p 739-748, 1999.

Mwaba MG, Golriz MR, Gu J, A semi-empirical correlation for crystallization fouling on heat exchange surfaces, Applied Thermal Engineering 26, p 440-447, 2006.

Sahin AZ et al.. Energy Conversion \& Management, 41, p 1485-1496, 2000.Sheikholeslami R. Calcium sulfate fouling-precipitation or particulate: a proposed composite model. Heat Transfer Eng. 21, p 24-33, 2000.

Sheikholeslami R and Zhou S. Performance of RO membranes in silica bearing waters. Desalination 132, p 337-344, 2000.

Shilling RL, Bernhagen PM, Goldshmit VM et al., Perry's Chemical Engineers' Handbook, Section 11, Heat Transfer Equipment, $8^{\text {th }}$ Ed., 2008.

Steinhagen R, Muller-Steinhagen $\mathrm{H}$, Maani $\mathrm{K}$, Problems and costs due to heat exchanger fouling in New Zealand industries, Heat Transfer Engineering 14 (1993) 19-30.

Zubair SM et al., A risk based heat exchanger analysis subject to fouling. Part I: Performance evaluation. Energy, 25, p 427 443, 2000. 


\section{EFEITO DA TEMPERATURA E DA TAXA DE OXIDAÇÃO SOBRE OS POLIMORFOS E A MORFOLOGIA DAS PARTÍCULAS DE ÓXIDOS AMARELOS SINTÉTICOS DE FERRO $^{8}$}

\subsection{Introdução}

$\mathrm{Na}$ natureza os óxidos de ferro são facilmente encontrados no solo, sedimentos, rochas e sistemas aquáticos. A importância econômica dos pigmentos naturais tem decrescido atualmente em comparação com os materiais sintéticos pela exigência cada vez maior da qualidade dos produtos. Os óxidos de ferro sintéticos têm apresentado um importante aumento na produção devido a sua tonalidade pura, propriedades de resistência a meios ácidos e alcalinos, poder de tingimento, não toxicidade, além de excelente resistência à luz ultravioleta e baixo preço. Os óxidos sintéticos representam $84 \%$ dos 1,2 milhões de toneladas anuais de óxidos de ferro produzidos (Will, Raymond, 2006).

Os principais óxidos naturais são: a hematita, a goethita e a magnetita. A hematita $\left(\alpha-\mathrm{Fe}_{2} \mathrm{O}_{3}\right)$ tem importância econômica como pigmento vermelho, a goethita $(\alpha-\mathrm{FeOOH})$ como amarelo e a magnetita $\left(\mathrm{Fe}_{3} \mathrm{O}_{4}\right)$, preta. Estes compostos também podem ser obtidos sinteticamente. Misturas desses compostos resultam em produtos de outras cores, como marrons (Ullmann, 1998).

O processo Penniman-Zoph (Penniman, Zoph, 1917; Penniman, Zoph, 1920) é, provavelmente, o método mais usado industrialmente na produção de pigmento de óxido de ferro amarelo, tendo em vista o baixo custo, a utilização de matérias-primas recicladas como a sucata de ferro oriundas de diversos processos de laminação e estamparia, e a baixa geração de resíduos quando comparado a outros processos de produção de óxidos de ferro. O processo é conduzido em duas etapas. Na primeira são formados por nucleação primária os cristais-base de goethita conhecidos como sementes, que são muito pequenos e que, devido à pouca reflexão da luz, apresentam cores pouco agradáveis e pequeno poder de tingimento. Numa etapa posterior é realizado o crescimento cristalino (reação a quente) responsável pelo desenvolvimento final da cor. A etapa de nucleação primária determina as características cristalográficas das partículas que constituem o produto final. Dessa forma, o conhecimento de faixas de variáveis simples como a temperatura, vazão de ar, pH e concentração dos reagentes, dentro das quais seja possível garantir a formação do cristal desejado, é bastante desejado pelas indústrias de óxidos de ferro. Além disso, o tamanho das partículas obtidas nesta etapa tem impacto no custo da fabricação dos pigmentos, pois quanto menores forem as partículas das sementes, menores as quantidades necessárias para

\footnotetext{
${ }^{8}$ Nelson Pedro Baptista, Investigação das características cristalográficas de óxidos amarelos sintéticos de ferro produzidos por nucleações primárias heterogêneas, Dissertação de mestrado, IPT 2010. Orientador Marcelo Seckler. $O$ aluno é engenheiro da empresa produtora de pigmentos Lanxess.
} 
desenvolver uma determinada cor no produto final. Assim sendo, a qualidade do produto e o custo do produto estão diretamente ligados à etapa de formação das sementes.

As características das fases cristalinas dos óxidos de ferro têm sido estudadas por diversos autores, porém na maioria dos trabalhos, é dada ênfase à transformação de um dado composto ferroso para outro através do envelhecimento lento dos cristais ou através de transformações térmicas. Além desses, alguns tratam de mecanismos e cinéticas dessas transformações. No entanto, praticamente não há trabalhos em condições de interesse para a obtenção de pigmentos industriais. A formação de óxidos de ferro em soluções contendo o íon ferro, onde as variáveis como temperatura e fluxo de ar como oxidante são abordadas (Prokopenko et al., 2007) têm mostrado que diversas fases cristalinas são formadas, ora com predominância de uma ou outra fase, dependendo do cátion presente como $\mathrm{Fe}^{2+}$ ou $\mathrm{Fe}^{3+}$, do álcali usado e do $\mathrm{pH}$ de formação da fase. No entanto é comum a formação de diversas fases simultaneamente, como a goethita, hematita e magnetita numa ampla faixa de temperatura e fluxo de ar como oxidante.

Neste trabalho propõe-se produzir, no processo Penniman-Zoph em escala de bancada, o óxido de ferro conhecido como goethita e modificar suas caracteristicas físico-químicas através do uso de diferentes condições de temperatura e taxa de aeração na fase de precipitação.

\subsection{Revisão Bibliográfica}

\subsubsection{OS ÓXIDOS DE FERRO}

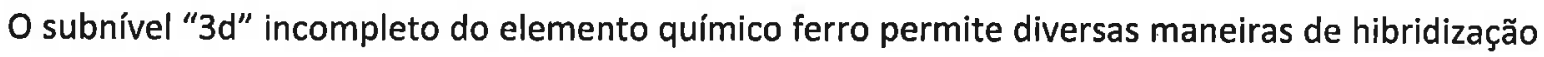
dos orbitais, as quais são responsáveis pelas diferentes maneiras de ordenação dos hidróxidos e óxidos de ferro. Essas ordenações por sua vez podem promover formações cristalinas bastante variadas, produzindo óxidos, óxidos hidratados e hidróxidos de ferro. Dezesseis tipos de compostos podem ser assim denominados. São eles: Goethita $(\alpha-\mathrm{FeOOH})$, Lepidocrocita $(\gamma-$ $\mathrm{FeOOH})$, Acaganeita $(\beta-\mathrm{FeOOH})$, Ferroxita $\left(\delta^{\prime}-\mathrm{FeOOH}\right),(\delta$-FeOOH), Goethita de Alta Pressão $(\mathrm{FeOOH})$, "Schwertmannite" $\left(\mathrm{Fe}_{16} \mathrm{O}_{16}(\mathrm{OH})_{y}\left(\mathrm{SO}_{4}\right)_{2} \cdot \mathrm{nH}_{2} \mathrm{O}\right)$, Ferridrita $\left(\mathrm{Fe}_{5} \mathrm{HO}_{8} \cdot 4 \mathrm{H}_{2} \mathrm{O}\right)$, Bernalita $\left(\mathrm{Fe}(\mathrm{OH})_{3}\right)$ e Hidróxido de Ferro (II) $\left(\mathrm{Fe}(\mathrm{OH})_{2}\right)$. Os óxidos são: Hematita $\left(\alpha-\mathrm{Fe}_{2} \mathrm{O}_{3}\right)$, Magnetita $\left(\mathrm{Fe}_{3} \mathrm{O}_{4}\right)$, Maghemita $\left(\gamma-\mathrm{Fe}_{2} \mathrm{O}_{3}\right)$, "Wüstite" (FeO), $\beta-\mathrm{Fe}_{2} \mathrm{O}_{3}$ e $\varepsilon-\mathrm{Fe}_{2} \mathrm{O}_{3}$ (Cornell, Schwertmann, 1996). Apresenta-se a seguir informações básicas sobre os principais compostos para deste trabalho.

\section{Goethita}

A goethita $(\alpha-\mathrm{FeOOH})$ tem célula unitária ortorrômbica com empacotamento hexagonal compacto dos anions $\left(\mathrm{O}^{2-}\right)$ e $\left(\mathrm{OH}^{-}\right)$ligados com ions de $\mathrm{Fe}^{3+}$. É a forma termodinamicamente mais estável dos óxidos de ferro a temperatura ambiente, sendo, portanto, normalmente o resultado final de muitas transformações das outras formas de óxidos. A coloração marrom escura ou preta é apresentada pela goethita em agregados massivos de cristais, no entanto, na forma de pó sua coloração é amarela. Os cristais de goethita sintética ou natural são aciculares e alongados na direção "a". (Cornell, Schwertmann, 1996), conforme é mostrado na Figura 4-1. 


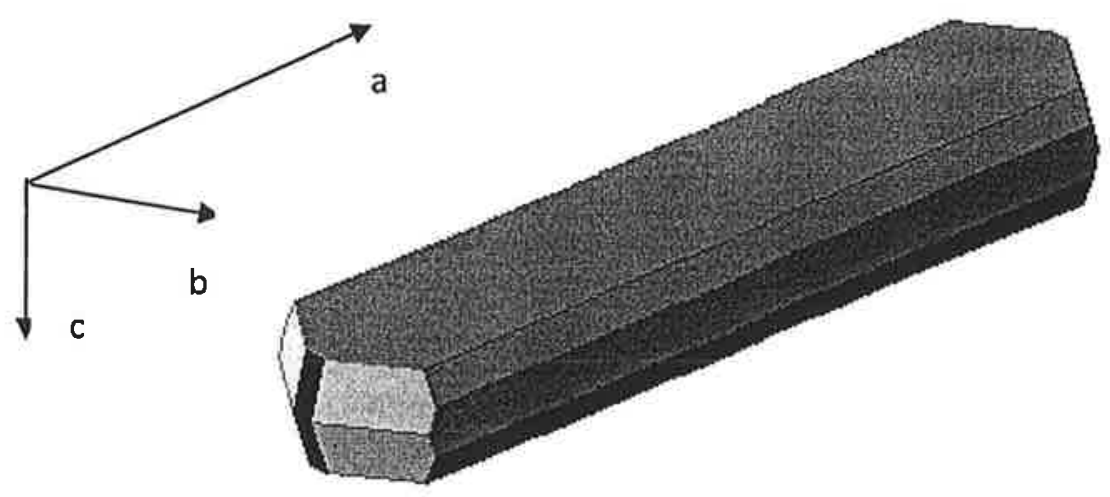

Figura 4-1. Morfologia típica do cristal de goethita sintético e natural. Fonte: Mineralogy Database (2010)

\section{Lepidocrocita}

A lepidocrocita $(\gamma$-FeOOH) tem empacotamento cúbico fechado. Sua formação é decorrente do produto de oxidação do ferro (II), sendo normalmente encontrado em solos, plantas e peças enferrujadas. Ela tem coloração alaranjada típica (Flynn Jr., 1984; Cornell, Schwertmann, 1996). A morfologia da lepidocrocita é mostrada na Figura 4-2.

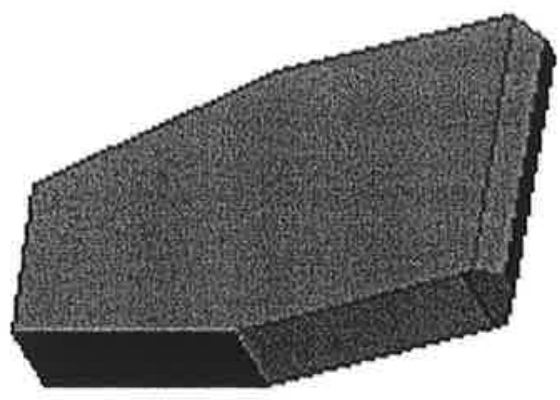

Figura 4-2. Morfologia do cristal de Lepidocrocita. Fonte: Mineralogy Database (2010)

\section{Ferridrita}

A ferridrita $\left(\mathrm{Fe}_{5} \mathrm{HO}_{8} \cdot 4 \mathrm{H}_{2} \mathrm{O}\right)$ é um mineral de baixa cristalinidade, marrom avermelhado, facilmente encontrado no ambiente e rotulado freqüentemente com designações enganosas como "óxido férreo amorfo" ou "hidróxido férrico" (Cornell, Schwertmann, 1996). Tanto a ferridrita natural como a sintética ocorrem na forma de nanopartículas com área superficial superior a $200 \mathrm{~m}^{2} / \mathrm{g}$. Ao contrário dos outros óxidos de ferro, sua ordenação é fraca e, a menos que seja estabilizada nessa forma, é facilmente transformada em formas mais estáveis de óxidos de ferro como a goethita e hematita (Jambor, Dutrizac, 1998; Loan et al., 2001).

\section{Hidróxido de ferro (II) e Ferrugem Verde}

O hidróxido de ferro (II) $\left(\mathrm{Fe}(\mathrm{OH})_{2}\right)$ não existe como mineral. Sua estrutura é baseada no empacotamento hexagonal compacto com o cátion no estado divalente. O hidróxido de ferro II 
quando puro apresenta a coloração branca, no entanto é rapidamente oxidado, desenvolvendo um composto de coloração azul-esverdeada conhecido como ferrugem verde. A magnetita preta é decorrente da oxidação desse composto (Cornell, Schwertmann, 1996). A fórmula sugerida para a ferrugem verde pode ser descrita como $\left.\left(\mathrm{Fe}^{2+}{ }_{(1-x)} \mathrm{Fe}^{3+}{ }_{x}(\mathrm{OH})_{2}\right)^{x+}\left(\mathrm{A}^{\mathrm{m}-}\right)_{\mathrm{x} / \mathrm{m}} \cdot \mathrm{nH}_{2} \mathrm{O}\right)$, onde " $A$ " é um ânion de valência negativa " $m$ " (Géhin, et. al., 2002).

\section{Hematita}

A hematita $\left(\alpha-\mathrm{Fe}_{2} \mathrm{O}_{3}\right)$ é o mais antigo óxido mineral de ferro conhecido, sendo facilmente encontrado em solos e rochas. A coloração vermelha é notada se o óxido estiver finamente dividido. A cor preta ou cinza brilhante é observada em partículas grosseiras. Sua estrutura é baseada em empacotamento hexagonal. Da mesma forma que a goethita, a hematita é extremamente estável, sendo freqüentemente a forma final das transformações de outros óxidos de ferro.

\section{Magnetita}

A magnetita $\left(\mathrm{Fe}_{3} \mathrm{O}_{4}\right)$ é um mineral ferromagnético preto contendo tanto os íons de ferro (II) como ferro (III), considerado, portanto um óxido misto de fórmula fundamental $\left(\mathrm{Fe}_{2} \mathrm{O}_{3}\right.$. $\left.\mathrm{FeO}\right)$. A estrutura tem forma cúbica de corpo centrado. A magnetita, juntamente com a titanomagnetita $\left(\mathrm{Fe}_{(1+x)} \mathrm{Ti}_{(2-}\right.$ х) $\mathrm{O}_{5}$ ), é responsável pelas propriedades magnéticas das rochas (Cornell, Schwertmann, 1996).

\section{Schwertmanita}

A schwertmanita $\left(\mathrm{Fe}_{16} \mathrm{O}_{16}(\mathrm{OH})_{y}\left(\mathrm{SO}_{4}\right)_{7} \cdot \mathrm{nH}_{2} \mathrm{O}\right)$, (Claassen et al., 2002), é um mineral oxihidroxissulfato de ferro com a fórmula química ideal de $\mathrm{Fe}_{8} \mathrm{O}_{8}(\mathrm{OH})_{6}\left(\mathrm{SO}_{4}\right) \cdot \mathrm{nH}_{2} \mathrm{O}$. A schwertmanita gradualmente se converte em goethita (Bigham et al. 1996, Claassen et al., 2002). Ela é formada por pequenas partículas com tamanhos abaixo de $10 \mathrm{~nm}$. Mesmo com os parâmetros físicos avaliados com difração de raios $X$ e espectroscopia de Mössbauer, a identidade deste mineral como espécie individual não é reconhecida (Bigham et al., 1996).

\subsubsection{MÉTODOS DE OBTENÇÃO DE ÓXIDOS DE FERRO}

A maioria dos óxidos hidratados e óxidos como a goethita, lepidocrocita, acaganeita, magnetita, maghemita, ferridrita, ferroxita e hematita podem ser produzidos com soluções de ferro (II) hidrolisadas por álcalis com posterior oxidação. Esses processos são de grande interesse para a indústria, onde muitos esforços são feitos para produzir óxidos de ferro puros e de alta qualidade. A formação dos óxidos de ferro é governada pelo $\mathrm{pH}$, taxa de oxidação, temperatura, concentração $\left[\mathrm{Fe}^{2+}\right] /\left[\mathrm{OH}^{-}\right]$no início do processo de precipitação e pela presença de componentes estranhos. A menos que as condições da reação sejam cuidadosamente controladas, são produzidas misturas desses compostos ao invés de um produto único (Cornell, Schwertmann, 1996).

Reações de oxidação do ferro (II) foram investigadas por diversos autores (Dousma, Ottelander, de Bruyn, 1979, von Gunten, Schneider, 1991; Claassen et al., 2002; Gotic, Music, 2007). A goethita $(\alpha-\mathrm{FeOOH})$ pode ser obtida com soluções de sulfato de ferro (II) $\left(\mathrm{FeSO}_{4}\right)$, cloreto de ferro 
(II) $\left(\mathrm{FeCl}_{2}\right)$ ou brometo de ferro (II) $\left(\mathrm{FeBr}_{2}\right)$, pela oxidação do $\left(\mathrm{Fe}^{2+}\right)$ por $\mathrm{O}_{2}$ em meio alcalino, segundo a seguinte reação:

$$
2 \mathrm{Fe}^{2+}+3 \mathrm{H}_{2} \mathrm{O}+1 / 2 \mathrm{O}_{2} \quad \rightarrow \quad 2 \alpha-\mathrm{FeOOH}+4 \mathrm{H}^{+}
$$

A presença de $\mathrm{SO}_{4}{ }^{2-}$ resulta numa maior taxa de precipitação, principalmente em valores mais baixos de $\mathrm{pH}$ ou menor razão molar $\left(\mathrm{OH}^{-}\right) /(\mathrm{Fe})$, quando comparados com soluções com ânions monovalentes (Dousma, Ottelander, De Bruyn, 1979).

As reações de hidrólise do $\left(\mathrm{Fe}^{3+}\right)$ em meios aquosos também podem ser utilizadas na síntese de uma forma específica de óxido de ferro como a hematita ou goethita (Flynn Jr., 1984; Cornell, Schwertmann, 1996). Na presença de $\mathrm{FeCl}_{3}$, resultam precipitados de Acaganeita ( $\beta-\mathrm{FeOOH}$ ) ou hematita $\alpha-\mathrm{Fe}_{2} \mathrm{O}_{3}$, enquanto soluções de $\mathrm{Fe}\left(\mathrm{NO}_{3}\right)_{3}$ e $\mathrm{Fe}\left(\mathrm{ClO}_{4}\right)_{3}$ resultam em precipitados de hematita $\left(\alpha-\mathrm{Fe}_{2} \mathrm{O}_{3}\right.$ ) (Matijevic, Scheiner, 1978). Na presença de percloratos, formam-se $\gamma-\mathrm{FeOOH}$, $\alpha-\mathrm{FeOOH}$ e $\alpha-\mathrm{Fe}_{2} \mathrm{O}_{3}$ (Ristic, Music, Godec, 2006). Misturas de soluções de $\mathrm{FeCl}_{3}$ e $\mathrm{Fe}\left(\mathrm{NO}_{3}\right)_{3}$ induzem a formação de diferentes estruturas cristalinas conforme a concentração do sal dominante (Music, Orehovec, Popovic, 1994). Em soluções de sulfato de ferro (III) $\left(\mathrm{Fe}_{2}\left(\mathrm{SO}_{4}\right)_{3}\right)$ foram observadas goethita e $\mathrm{H}_{3} \mathrm{OFe}_{3}(\mathrm{OH})_{6}\left(\mathrm{SO}_{4}\right)_{2}$, conhecido como hidrônio jarosita. A formação de goethita foi verificada em soluções com baixas concentrações de sulfato de ferro (III) e da jarosita em soluções com alta concentração.

As precipitações em soluções hidrolisadas de ferro (III) são notadas em dias ou semanas e continuam por período de meses. A lepidocrocita é notada em soluções com baixa concentração de ferro (III) e baixa razão molar $\left(\mathrm{OH}^{-}\right) /(\mathrm{Fe})$ (Murphy et al., 1975; Murphy et al., 1976; Dousma, de Bruyn, 1976). As quantidades formadas de goethita e lepidocrocita indicam que a goethita é decorrente do envelhecimento de polímeros das espécies aquosas do íon ferro e a lepidocrocita é formada diretamente de espécies de baixo peso molecular. A taxa de precipitação da goethita é acelerada com o aumento da atividade iônica, e a formação da lepidocrocita, nesse caso, é inibida (Murphy, Posner, Quirk, 1975; Murphy, Posner, Quirk, 1976; Dousma, de Bruyn, 1978; Dousma, de Bruyn, 1979).

\subsubsection{EFEITO DO PH E DA TEMPERATURA}

As regiões de estabilidade de fases férreas obtidas na presença de sulfato variando o $\mathrm{pH}$ e temperatura são mostradas na Figura 4-3.

A goethita foi observada em uma larga faixa de pH (3 -10) (Babcan, 1971), sendo sua formação preferencial em meios alcalinos e neutros (Prokopenko, Lavrinenko, Mamunya, 2007). A formação de hematita e maghemita em soluções de ferro II são favorecidas em soluções bastante alcalinas com pH entre 9,5 a 11,0 (Belous, et al., 2000). A formação de lepidocrocita é favorecida em soluções férreas com baixos valores de $\mathrm{pH}$. 


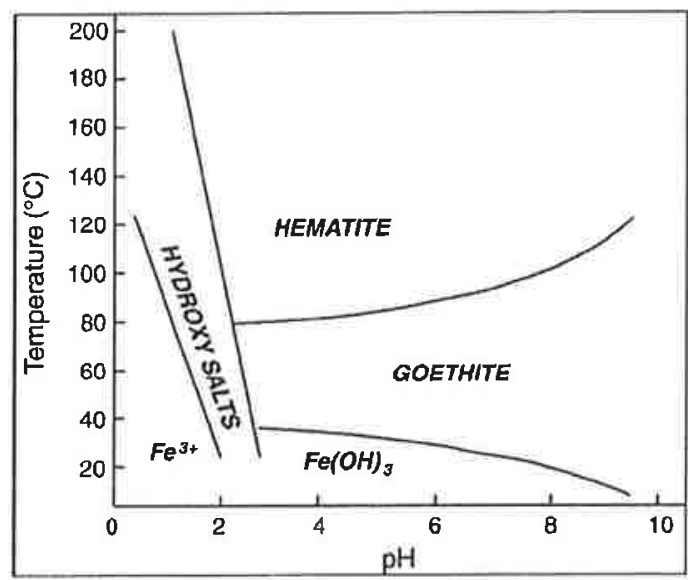

Figura 4-3. Fases férreas em soluções de sulfato com variação do pH e temperatura. Fonte: Babcan (1971)

Em meios levemente ácidos a meios levemente básicos ( $\mathrm{pH}$ entre $6 \mathrm{e} 7$ ) são encontrados produtos intermediários como a ferrugem verde com a fórmula sugerida $\left(\mathrm{Fe}_{4}{ }^{2+} \mathrm{Fe}_{2}{ }^{3+}(\mathrm{OH})_{12} \mathrm{SO}_{4} \cdot 3 \mathrm{H}_{2} \mathrm{O}\right)$ e próximo à faixa do $\mathrm{pH} 6$ são encontrados complexos solúveis com as fórmulas $\left(\mathrm{Fe}^{2+}{ }_{2} \mathrm{Fe}^{3+} \mathrm{O}_{x}(\mathrm{OH})_{y}{ }^{17-}\right.$ $\left.{ }^{2 x-y)+}\right)$ e $\left(\mathrm{Fe}^{2+} \mathrm{Fe}^{3+} \mathrm{O}_{x}(\mathrm{OH})_{y}^{(5-2 x-y)+}\right)$ (MISAWA et al., 1973). Esses compostos são precursores das formas mais estáveis de óxidos de ferro como a goethita, lepidocrocita e magnetita. Em trabalhos anteriores (Schwertmann, Fechter, 1994) com pequenos volumes de soluções $0,1 \mathrm{M}$ de cloreto ou sulfato de ferro (II) mantidas com pH em torno 7,0, sob baixo fluxo de ar, foi mostrado que a precipitação ocorre em dois diferentes passos. A primeira reação envolve a formação de ferrugem verde, após alguma oxidação do ferro (II) da solução original, já que a estrutura da ferrugem verde contém ferro (III). Apesar da coloração verde escura, devido à adição do álcalis, o precipitado verde-azulado só ocorre após o ar ser introduzido no sistema. Se oxidado em torno de $\mathrm{pH} 7$, uma vez formados os íons de ferro(III) a precipitação ocorre imediatamente como um hidrato pobremente ordenado, um óxido de ferro (III) denominado de "2-line-ferrihydrite" ou "6line-ferrihydrite", dependendo do número de linhas mostradas pela difração de raios-X, cuja composição exata não é conhecida. Esse óxido pobremente ordenado é instável, reagindo rapidamente com o ferro (II) dissolvido e para formar a ferrugem verde, através da reação sugerida a seguir:

$x^{\prime \prime} \mathrm{Fe}(\mathrm{OH})_{3}{ }^{11}+y \mathrm{FeSO}_{4}+2(y-z) \mathrm{NaOH} \rightarrow \mathrm{Fe}_{y}{ }^{2+} \mathrm{Fe}_{x}{ }^{3+}(\mathrm{OH})_{3 x+2 y-2 z}(\mathrm{SO} 4)_{z}+(y-z) \mathrm{Na}_{2} \mathrm{SO}_{4}$

No processo Penniman-Zoph, a variação do $\mathrm{pH}$ serve como indicativo dos processos de hidrólise e das zonas lábeis da supersaturação, pois não há adições de álcalis para corrigir o pH durante a oxidação da solução hidrolisada.

Diversos trabalhos mostraram que a goethita pode ser obtida na faixa de temperatura entre $10 \mathrm{e}$ $80^{\circ} \mathrm{C}$ (Prokopenko, Lavrinenko, Mamunya, 2007).

\subsubsection{EFEITO DA TAXA DE OXIDAÇÃo}

A taxa de oxidação depende do $\mathrm{pH}$ e da temperatura do sistema, da solubilidade do $\mathrm{O}_{2}$, da agitação e da geometria do reator. Ela pode ser controlada pela taxa de injeção de ar ou oxigênio. 
Devido ao consumo do ânion $\mathrm{OH}^{-}$há uma alteração do $\mathrm{pH}$ do meio reacional durante o processo de oxidação, se esse íon não for reposto.

Baixas taxas de oxidação favorecem a formação de magnetita e goethita. A formação de goethita por oxidação com ar é precedida por complexos hidroaquosos como a lepidocrocita $(\gamma-\mathrm{FeOOH})$ e $\delta$-FeOOH (Prokopenko, Lavrinenko, Mamunya, 2007; Music, Popovic, Gotic, 1990).

Altas taxas de oxidação favorecem a formação da lepidocrocita. Taxas ainda mais altas, por exemplo pela adição de peróxido de hidrogênio $\left(\mathrm{H}_{2} \mathrm{O}_{2}\right)$ ou exposição do $\mathrm{Fe}(\mathrm{OH})_{2}$ ao ar, levam à formação de ferroxita $\left(\delta^{\prime}-\mathrm{FeOOH}\right)$ e $\delta$-FeOOH em uma larga faixa de $\mathrm{pH}$ (Cornell, Schwertmann, 1996).

\subsubsection{EFEITO DOS ÍONS FE(II)}

Soluções aquosas concentradas de sulfato de ferro II favorecem a formação de goethita (Music, Popovic, Gotic, 1990; Prokopenko, Lavrinenko, Mamunya, 2007) e a lepidocrocita é favorecida em baixas concentrações do íon ferro (II) (Cornell, Schwertmann, 1996).

\subsubsection{EFEITO DE COMPONENTES ESTRANHOS}

A formação dos óxidos de ferro pela oxidação de complexos verdes de ferro ou hidróxido de ferro (II) é normalmente influenciada por compostos estranhos presentes no sistema, particularmente ânions. A lepidocrocita é favorecida pela presença de cloreto ou outros halogênios (Detournay et al., 1975).

A presença de carbonato em oxidações de complexos ferrosos verdes leva à formação de lepidocrocita e goethita. A proporção da goethita aumenta quando a relação $\mathrm{CO}_{2} / \mathrm{O}_{2}$ é elevada. 0 ânion carbonato pode suprimir a formação de lepidocrocita (Cornell, Schwertmann, 1996).

A formação de lepidocrocita é dificultada pela presença do íon silicato, provavelmente por bloqueio na nucleação, sendo a ferridrita favorecida.

O aluminio tem uma considerável influência na cinética e nos produtos. A presença de hidróxicátions de alumínio conduz à precipitação de fases sólidas sob pH mais baixo ou concentrações molares de ferro mais baixas quando comparadas a soluções com ausência de alumínio. A taxa de oxidação é mais lenta do que em soluções ferrosas puras e a produção de espécies de ferro (III) é reduzida, sendo sugerido que a formação de estruturas fracamente ordenadas são favorecidas. A formação de magnetita é suprimida e a goethita favorecida pela presença do alumínio em soluções alcalinas à temperatura ambiente (Cornell, Schwertmann, 1996).

\subsubsection{NuCleação e Crescimento de CRistais}

Uma solução supersaturada é aquela que contém um teor de soluto acima do equilíbrio termodinâmico. O nível de supersaturação máximo ou supersaturação crítica é descrito pela curva denominada de metaestabilidade ou limite de metaestabilidade. A zona de metaestabilidade está compreendida na região entre a curva de solubilidade e o limite de metaestabilidade. Quando a concentração da solução excede o limite metaestável, diz-se que o estado da solução encontra-se 
na zona lábil (instável), caracterizada pela deposição instantânea dos sólidos (Nývlt, Hostomký, Giulietti, 2001).

A cristalização a partir de soluções é normalmente resultante de nucleação, crescimento molecular do cristal e ações secundárias como, por exemplo, a aglomeração, envelhecimento e recristalização (Söhnel, Garside, 1992). A complexidade do mecanismo de cristalização em solução está relacionada entre outros fatores pela interação entre os íons ou moléculas do soluto e dos solventes, temperatura, pureza física, ação mecânica e impurezas solúveis na solução.

A nucleação pode ser primária homogênea, primária heterogênea ou secundária. Na nucleação primária homogênea, a fase sólida é formada a partir de um líquido límpido. Pequenas regiões são formadas dentro da solução, nas quais propriedades diferentes da fase original são apresentadas pelos átomos ou moléculas. Essas moléculas ou átomos ordenados são chamados de clusters. Os clusters são instáveis, podem sofrer desintegração ou crescimento. Se atingirem um tamanho crítico, se estabilizam, tornando-se núcleos, os quais, por posterior crescimento molecular, tornam-se cristais maduros. Quando a supersaturação excede o limite metaestável, aumenta a probabilidade dos clusters crescerem até o tamanho crítico, e a e a taxa de nucleação torna-se muito elevada.

Na nucleação primária heterogênea a energia requerida para a estabilização dos clusters é reduzida pela presença de partículas estranhas. O processo é similar ao da nucleação primaria homogênea, mas aqui o limite metaestável é menor. Virtualmente todas as soluções contêm partículas de sujeira, a menos que se tomem cuidados extremos para removê-las. Por isso, entre nucleação primária homogênea e a heterogênea, apenas a segunda é de interesse para situações industriais.

A nucleação secundária é o mecanismo pelo qual a formação da fase sólida é iniciada pela presença de fase sólida do próprio material cristalizado (Söhnel, Garside, 1992), ou seja, a nucleação secundária é resultante da presença de cristais na solução supersaturada. Ela é importante apenas para cristais maiores que $100 \mu \mathrm{m}$, não sendo importante no presente estudo.

Quando um sistema apresenta polimorfismo e pseudopolimorfismo, como é o caso dos óxidos e hidróxidos de ferro, normalmente formam-se fases metaestáveis primeiro, as quais se dissolvem e dão lugar à fase estável. Dependendo da supersaturação, pode haver variação da seqüência de fases que cristaliza. Alem disso, o grau de perfeição da estrutura cristalina e a estabilidade também são influenciadas pela supersaturação. Este especificamente é o caso quando ferro é precipitado a quente, em soluções diluídas, onde é requerida diluição para melhorar cristalinidade do produto final.

\subsection{Materiais e Métodos}

\subsubsection{CONDIÇÕES EXPERIMENTAIS}

Foram conduzidos ensaios para a produção das sementes em regime de bateladas, em escala de bancada e com matérias-primas industriais. A faixa operacional foi escolhida de maneira que a formação da goethita seja favorecida, porém com características bastante distintas de área 
superficial, tamanho e distribuição granulométrica, além de possiveis diferenças na aglomeração dos cristais.

$\mathrm{O}$ pH inicial de 7,8 foi escolhido para favorecer a formação da goethita e evitar a formação de magnetita principalmente sob temperaturas mais elevadas. $\mathrm{O} \mathrm{pH}$ final foi estabelecido próximo a 3,5, pois abaixo desse valor os compostos como a schwertmanita, 6-line ferrihydrite and 2-line ferrihydrite, podem ocorrer, principalmente em altas temperaturas. Infelizmente nessa faixa $(3,5$ $-7,8)$ também ocorre a formação de intermediários. As eventuais formações desses compostos intermediários serão investigadas experimentalmente.

A concentração inicial de íons Fe (II) escolhida foi de $0,5 \mathrm{~mol} / \mathrm{L}^{-1}$ de $\mathrm{Fe}^{2+}$ (antes da adição de hidróxido de sódio) e a quantidade de hidróxido de sódio para permitir um pH inicial menor que 8,0 , determinadas de forma a favorecer a formação da goethita em detrimento da lepidocrocita.

Hidróxido de sódio foi adicionado de forma que, ao final da adição, a mistura possua uma relação molar de $\left(\mathrm{OH}^{-}\right) /\left(\mathrm{Fe}^{2+}\right)$ igual a 0,71. Ao final da reação de oxidação, o excesso do sulfato de ferro (II) permaneceu livre na solução. A formulação empregada é mostrada na Tabela 4-1.

Tabela 4-1. Formulação para Produção da Semente

\begin{tabular}{|l|l|l|l|}
\hline Reagente & $\mathrm{C}(\mathrm{mol} . \mathrm{L}-1)$ & $\mathrm{m}(\mathrm{g})$ & $\mathrm{V}(\mathrm{mL})$ \\
\hline Água & - & - & $1.270,4$ \\
\hline Sulfato de Ferro (II) & 1,44 & 278 & 694,4 \\
\hline Hidróxido de Sódio & 19,16 & 27,0 & 35,2 \\
\hline Total & - & - & 2.000 \\
\hline
\end{tabular}

As temperaturas e a vazões de ar foram variadas nas faixas mostradas na Tabela 4-2. A codificação dos ensaios (TXXAFYY) indica a temperatura e a taxa de aeração (Air Flow).

Escolheu-se trabalhar com temperaturas em torno daquela normalmente utilizada em processos industriais $\left(35^{\circ} \mathrm{C}\right)$. Como temperatura inferior foi escolhida $15^{\circ} \mathrm{C}$ devido à dificuldade e alto custo de obtenção de temperaturas ainda menores nos processos industriais. A temperatura superior adotada foi de $60^{\circ} \mathrm{C}$, para reduzir a probabilidade de formação de outras fases cristalinas como a hematita e magnetita. Além disso, temperaturas mais elevadas podem tornar a evaporação excessiva antes do final da reação. Assim ficou estabelecido que, apesar da variação de volume nas reações aquecidas, não foram efetuadas adições de água para manter o volume estável.

O fluxo de ar injetado na reação é normalmente adotado como parâmetro para a taxa de oxidação. A vazão de ar atmosférico de $3 \mathrm{NL} \cdot \mathrm{min}^{-1} \cdot \mathrm{L}^{-1}$ no ensaio a $35^{\circ} \mathrm{C}$ foi ajustada, por meio de ensaios preliminares, para produzir o tempo de oxidação entre 10 e $12 \mathrm{~h}$, da mesma ordem de grandeza que a obtida industrialmente. A taxa de aeração atmosférica foi então variada em torno deste valor, de 2 a $7,5 \mathrm{NL} \cdot \mathrm{min}^{-1} \cdot \mathrm{L}^{-1}$. 
Tabela 4-2. Condições dos Ensaios

\begin{tabular}{|l|l|l|}
\hline \multirow{2}{*}{ Ensaio } & $\mathrm{T}_{i}$ & $\Phi_{A R}$ \\
\cline { 2 - 3 } & ${ }^{\circ} \mathrm{C}$ & $\mathrm{NL} \cdot \mathrm{min}^{-1} \cdot \mathrm{L}^{-1}$ \\
\hline T35AF3,0 & 35 & 3,0 \\
\hline T15AF2,0 & 15 & 2,0 \\
\hline T15AF4,0 & 15 & 4,0 \\
\hline T15AF7,5 & 15 & 7,5 \\
\hline T25AF2,0 & 25 & 2,0 \\
\hline T25AF4,0 & 25 & 4,0 \\
\hline T25AF7,5 & 25 & 7,5 \\
\hline T60AF2,0 & 60 & 2,0 \\
\hline T60AF4,0 & 60 & 4,0 \\
\hline T60AF7,5 & 60 & 7,5 \\
\hline
\end{tabular}

\subsubsection{Procedimento EXPERIMENTAL}

A solução diluída de sulfato ferroso foi alimentada em primeiro lugar. Em seguida, foi ajustada a temperatura com o auxílio de um banho de água gelada ou aquecida. Depois foi adicionada a quantidade estabelecida de hidróxido de sódio com o auxílio de uma bureta num intervalo de tempo de 2 e 3 minutos. A suspensão foi mantida sob agitação a $150 \mathrm{rpm}$ por dois minutos antes da medição do $\mathrm{pH}$ inicial. Os valores de $\mathrm{pH}$ inicial obtidos na suspensão ficaram muito próximos do valor estimado $(<8,0)$. Em seguida a rotação do agitador foi aumentada para $300 \mathrm{rpm}$ e a oxidação foi iniciada mediante um fluxo de ar atmosférico $\left(\Phi_{A R}\right)$ ajustado através de válvula reguladora. As soluções foram oxidadas até $\mathrm{pH}$ menor que $3,5.0 \mathrm{pH}$, a vazão de ar e a temperatura foram monitoradas a cada 30 minutos.

Ao final de cada ensaio, a suspensão de óxidos foi amostrada para análises. A separação das sementes obtidas ao final da reação foi feita por filtração a vácuo em funil de Büchner e papel filtro marca Whatman tipo 45. As sementes foram lavadas com um litro de água para cada meio litro da suspensão. Após a filtração as amostras foram secas em estufa a $60{ }^{\circ} \mathrm{C}$ para evitar uma possível decomposição térmica da goethita. Essas amostras foram caracterizadas quanto à fase cristalina e área superficial pelo método BET. A outra parte da suspensão de óxidos foi diluída na proporção de 1 gota $(50 \mu \mathrm{L}$ ) para $10 \mathrm{~mL}$ de água acidificada com ácido sulfúrico a pH menor que 2,0 para evitar a aglomeração e formação de novos cristais. Essa suspensão diluída foi usada para as análises de distribuição granulométrica e microfotográfia, sendo que para a microfotografia a suspensão foi depositada sobre um filtro Millipore $(0,45 \mu \mathrm{m})$ e lavada com água acidificada para eliminação dos sais presentes na suspensão. 


\subsubsection{DESCRIÇÃo dOS EQUIPAMENTOS}

Foi usado um reator aberto e cilíndrico com diâmetro $20,3 \mathrm{~cm}$ e altura $25,0 \mathrm{~cm}$, construído em aço inox 316 (Figura 4-4). O reator é provido de agitador mecânico marca IKA modelo RW20n com impelidor tipo hélice naval em aço inox $316 \mathrm{~L}$ com diâmetro de $100 \mathrm{~mm}$ acoplado a um eixo central sob rotação constante de $300 \mathrm{rpm}$. O reator possui um distribuidor de ar tubular com diâmetro interno de $6 \mathrm{~mm}$ feito em aço inox 316L. O distribuidor possui oito furações de $3 \mathrm{~mm}$ para entrada do ar atmosférico. Os detalhes do impelidor e do distribuidor tubular são mostrados na Figura 4-5. A hélice do impelidor foi montada a cerca de um centímetro acima do distribuidor de ar dentro do reator. A vazão de ar injetado no reator foi medida com um sistema de rotâmetros em paralelo, acoplados ao distribuidor dentro do reator por meio de mangueiras.
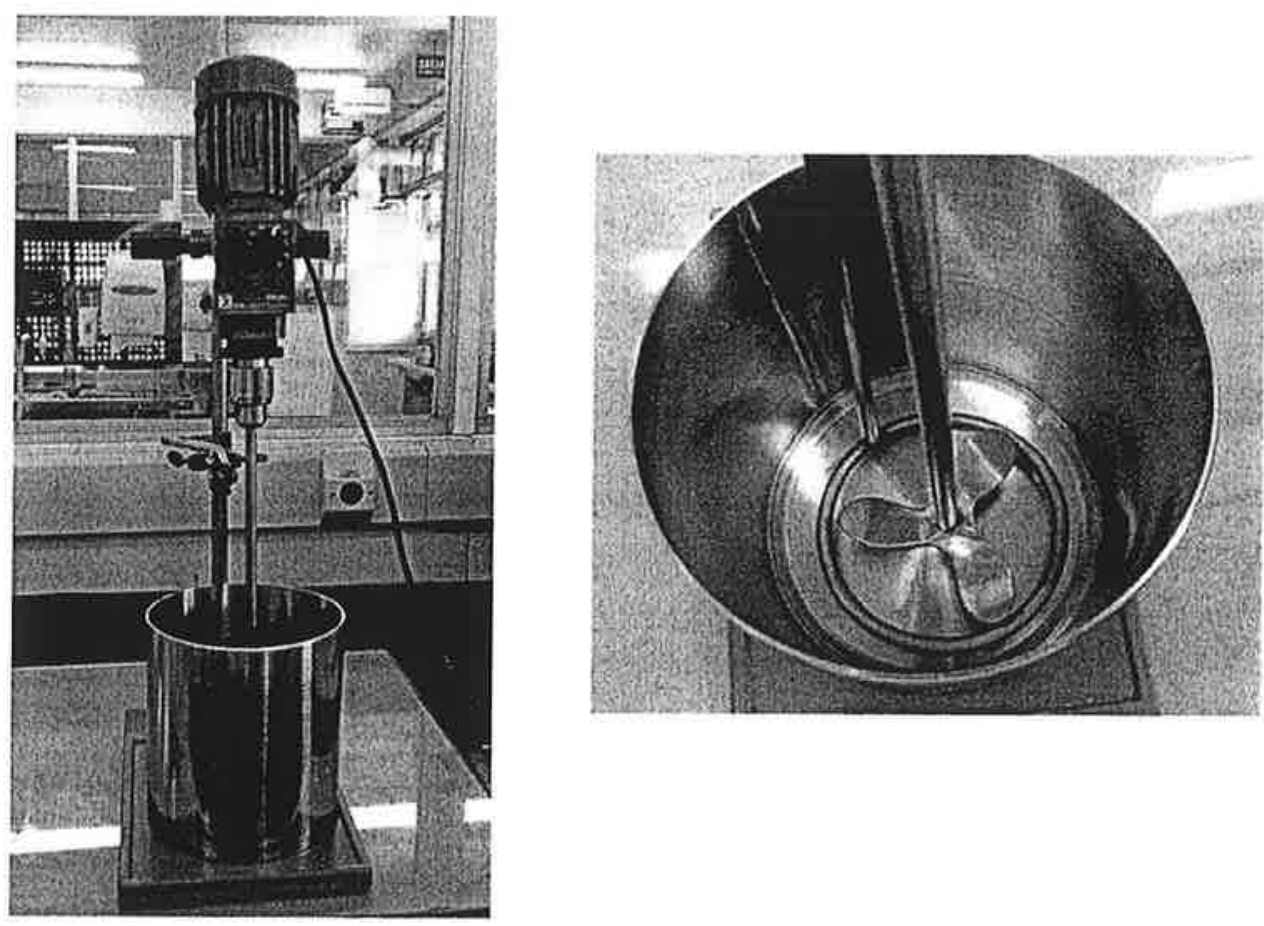

Figura 4-4. Montagem do reator cilíndrico em aço inox 316 (esquerda), sistema impelidor e tubulação para distribuição de ar (direita)
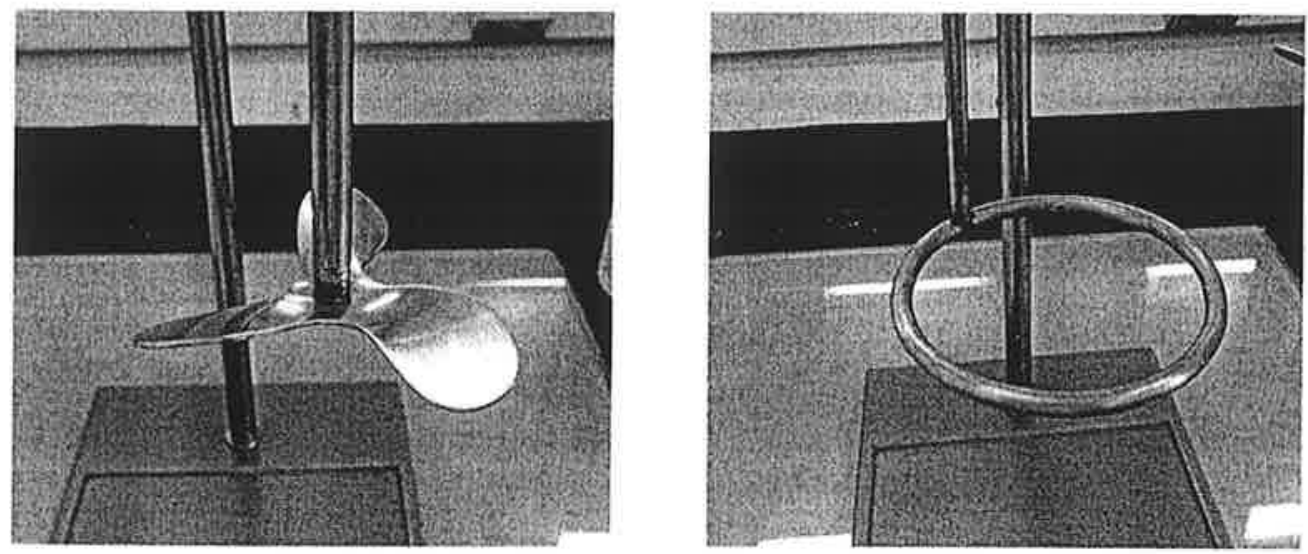

Figura 4-5. Detalhes do impelidor (esquerda) e do distribuidor de ar (direita). 


\subsubsection{REAGENTES}

Foram utilizadas as seguintes soluções: (i) sulfato de ferro (II) $\left(\mathrm{FeSO}_{4}\right)$ com concentração de 1,44 mol. $L^{-1}$, produzido industrialmente através da reação de sucata de ferro (aço SAE 1005) com ácido sulfúrico comercial adquirido da empresa Elekeiroz S.A. Esse sulfato foi filtrado em papel filtro qualitativo para eliminação de materiais particulados; (ii) Hidróxido de Sódio comercial 19,16 mol. $L^{-1}$ adquirido da Dow Química S.A.; (iii) água purificada por osmose reversa. (iv) 0 reator foi aerado com ar atmosférico fornecido por meio de compressores com pressão de saída regulada para $4 \mathrm{kgf} / \mathrm{cm}^{2}$ com filtro de linha para eliminação de água.

\subsubsection{CARACTERIZAÇõES FÍSICO-QUÍMICAS}

$\mathrm{O} \mathrm{pH}$ ao longo do tempo durante a fase de nucleação foi avaliado utilizando um pHmetro Digimed DM20 com o eletrodo imerso na suspensão.

As caracterizações das fases cristalinas foram fornecidas por um espectro Mössbauer, ou seja, pelos parâmetros de interações hiperfinas, que no caso de um material magneticamente ordenado são os seguintes: campo magnético hiperfino $\left(B_{h f}\right)$, desvio isomérico $(\delta)$ e interação quadrupolar $(\varepsilon)$. O primeiro é dado em quilogauss $(\mathrm{kG})$ ou em tesla $(T)$, enquanto os outros dois são dados em milímetros por segundo $(\mathrm{mm} / \mathrm{s})$.

A identificação de materiais foi feita por comparação dos parâmetros hiperfinos medidos com os da literatura. No caso presente, utilizamos como referência o opúsculo Mössbauer spectra and parameters of standard samples -1 (Childs, Baker-Sherman, 1984).

Os equipamentos utilizados para as medidas da espectroscopia Mössbauer foram um transdutor de velocidade Mössbauer, drive e gerador de funções da Halder Elektronik (Alemanha) com fonte de ${ }^{57} \mathrm{Co}$ de raios gama de atividade de $50 \mathrm{mCi}$, da Ritverc $\mathrm{GmbH}$, St. Petersburg (Rússia) com detector de raios gama tipo contador proporcional, com mistura de gases $\mathrm{Kr}^{+} \mathrm{CO}_{2}$ a $1 \mathrm{~atm}$, da Reuter-Stokes Inc. (Estados Unidos da América). A eletrônica para detecção, controle de sinais e espectroscopia (pré-amplificador, amplificador, fonte de alta tensão para detector, e analisador multicanal), da ORTEC (Estados Unidos da América).

O tratamento dos dados obtidos foi feito pelo programa "FeSitios" de ajuste dos espectros Mössbauer. O programa foi desenvolvido e escrito em linguagem "FORTRAN" pelo Laboratório de Espectroscopia Mössbauer do IFUSP.

As análises de área superficial específica por BET foram feitas em equipamento da marca QuantaChrome modelo NOVA 1200. Os ensaios foram realizados em banho de nitrogênio líquido a $77 \mathrm{~K}$ com sob as pressões parciais $P / P_{0}$ de $0,05,0,10$ e 0,15 onde $P_{0}$ é igual a $700,00 \mathrm{mmHg}$. As amostras foram previamente submetidas a uma secagem e degaseificação a vácuo prévia por três horas. Esse processo é auxiliado por meio de aquecimento da cubeta imersa em areia fina mantida sob aquecimento a $140^{\circ} \mathrm{C}$.

A distribuição granulométrica por espalhamento dinâmico de luz (DLS) foi feita no equipamento Beckman Coulter Versão $2.21 / 2.03$ com faixa de medição 50 a $50.000 \mathrm{~nm}$. As amostras foram 
preparadas mediante a diluição da suspensão na proporção de uma gota (aprox. $50 \mu \mathrm{L}$ ) para 10 $\mathrm{mL}$ de água purificada por osmose reversa.

Microscopia eletrônica de varredura foi realizada com o instrumento 6460LV da Jeol. As amostras foram preparadas por meio de deposição da suspensão sobre papel filtro $45 \mu \mathrm{m}$. A suspensão foi lavada com água de osmose reversa acidificada para retirada dos sais presentes na suspensão para evitar a formação de cristais salinos de sulfato de sódio e sulfato de ferro (II). As amostras foram secas a temperatura ambiente num dessecador antes da preparação para a microscopia.

\subsection{Resultados}

\subsubsection{COMPORTAMENTO DO PH DURANTE A OXIDAÇÃo}

O comportamento do $\mathrm{pH}$ nos experimentos é mostrado da Figura 4-6 até a Figura 4-11. As legendas nessas figuras indicam a temperatura $\left({ }^{\circ} \mathrm{C}\right)$ e a taxa de aeração (NL.min $\left.{ }^{-1} \cdot L^{-1}\right)$. $O$ curso da precipitação pode ser divido em quatro regiões distintas. A primeira região compreende uma queda de $\mathrm{pH}$ entre o valor inicial de 7,8 e aproximadamente 5,5. Na segunda região o pH forma um patamar bem definido com valor em torno de 5,5. Na terceira região ocorre uma queda brusca do $\mathrm{pH}$ até valores próximos a 3,5. Finalmente na quarta região o pH cai lentamente, com valores abaixo de 3,5 .

O comportamento do $\mathrm{pH}$ é similar ao encontrado na literatura (Detournay, et al., 1975). A queda do $\mathrm{pH}$ na primeira região sugere a formação dos compostos como a ferrugem verde e a schwertmanita, além dos complexos solúveis (Prokopenko, Lavrinenko, Mamunya, 2007). Esses compostos são precursores das formas mais estáveis dos óxidos de ferro como a lepidocrocita e goethita (Bigham et al. 1996, Claassen et al., 2002). Na segunda região são encontrados os patamares de transição do hidróxido de ferro (II) para as chamadas ferrugens verdes (Cornell, Schwertmann, 1996). Para os experimentos com taxas maiores de aeração, estes patamares são pouco definidos. Na terceira região ocorre a transição da ferrugem verde / ferridrita para a goethita.

Na primeira região, o precursor tem estequiometria de hidróxido ferroso, bem como de diversos complexos hidroaquosos de ferro. Devido ao contato com o ar, parte dos íons $\mathrm{Fe}^{2+}$ se oxida para $\mathrm{Fe}^{3+}$, o que promove a formação adicional de fases férreas metaestáveis. Este processo ocorre com consumo de íons $\mathrm{OH}^{-}$. Por isso, nas primeiras cinco horas da reação, há uma queda progressiva do $\mathrm{pH}$. A partir deste instante, inicia-se a precipitação de goethita, que também consome íons $\mathrm{OH}^{-}$. Como o $\mathrm{pH}$ do meio tornou-se mais ácido, inicia-se a dissolução das fases precursoras. Tal dissolução libera ions $\mathrm{OH}^{-}$, que são consumidos pela formação progressiva da goethita. Por isso, resulta um pH relativamente constante entre as 6 e 10 horas de reação. Findo este período, toda a fase precursora se dissolve. Como a precipitação de goethita continua, o pH cai rapidamente. Esta queda brusca de pH é acompanhada de alteração no aspecto visual da suspensão, que passa de gelatinosa para fluida. $O$ aspecto gelatinoso está relacionado com a grande afinidade das fases férreas metaestáveis com a água. 
A dissolução das fases precursoras parece ser mais lenta nas temperaturas mais baixas (Figura 4-6). A exceção fica por conta dos ensaios conduzidos a $60^{\circ} \mathrm{C}$ que mostraram maior velocidade na dissolução das fases precursoras em relação ao ensaio T35AF3,0 sob todas as taxas de aeração testadas. A exceção dos ensaios a $60^{\circ} \mathrm{C}$ pode estar relacionada com a mudança do equilíbrio dos íns na suspensão e/ou associado também a perda de volume ocasionada pela evaporação durante o processo de oxidação.

Se a vazão de ar for aumentada (Figura 4-7 e Figura 4-8), além das fases já mencionadas, forma-se também a lepidocrocita. Taxas maiores de aeração, numa mesma temperatura, também aceleram a dissolução das fases precursoras (Figura 4-9, Figura 4-10 e Figura 4-11).

Estudos anteriores (Cornell, Schwertmann, 1996) mostram que o alongamento do tempo na primeira região, onde ocorre a primeira queda do $\mathrm{pH}$, como mostrado nos experimentos com menor taxa de ar atmosférico (T15AF2,0, T25AF2,0 e T60AF2,0), é de grande importância para induzir a formação da goethita. Quando esta queda de $\mathrm{pH}$ é rápida, é favorecida a formação dos compostos ferrosos como a ferridrita, desfavorecendo a completa desidroxilação do hidróxido de ferro (II) antes da oxidação para a formação da goethita. Nestes casos, observou-se a formação de misturas de goethita com lepidocrocita. Os patamares pouco definidos na segunda região, nos ensaios com maior vazão de ar, indicam também que a rápida transformação desses compostos em fases mais estáveis favorece a formação de lepidocrocita.

A coloração fortemente esverdeada é característica da primeira região. A coloração final (quarta região) variou entre amarela para os ensaios com maiores temperaturas ( 35 e $60{ }^{\circ} \mathrm{C}$ ) e menor taxa de aeração $\left(2,0 \mathrm{NL} \cdot \mathrm{min}^{-1} . \mathrm{L}^{-1}\right)$ e alaranjado/castanho para os ensaios com menores temperaturas $\left(15\right.$ e $\left.25^{\circ} \mathrm{C}\right)$ e maiores taxas de aeração $\left(4,0\right.$ e $\left.7,5 \mathrm{NL} \cdot \mathrm{min}^{-1} \cdot \mathrm{L}^{-1}\right)$. 


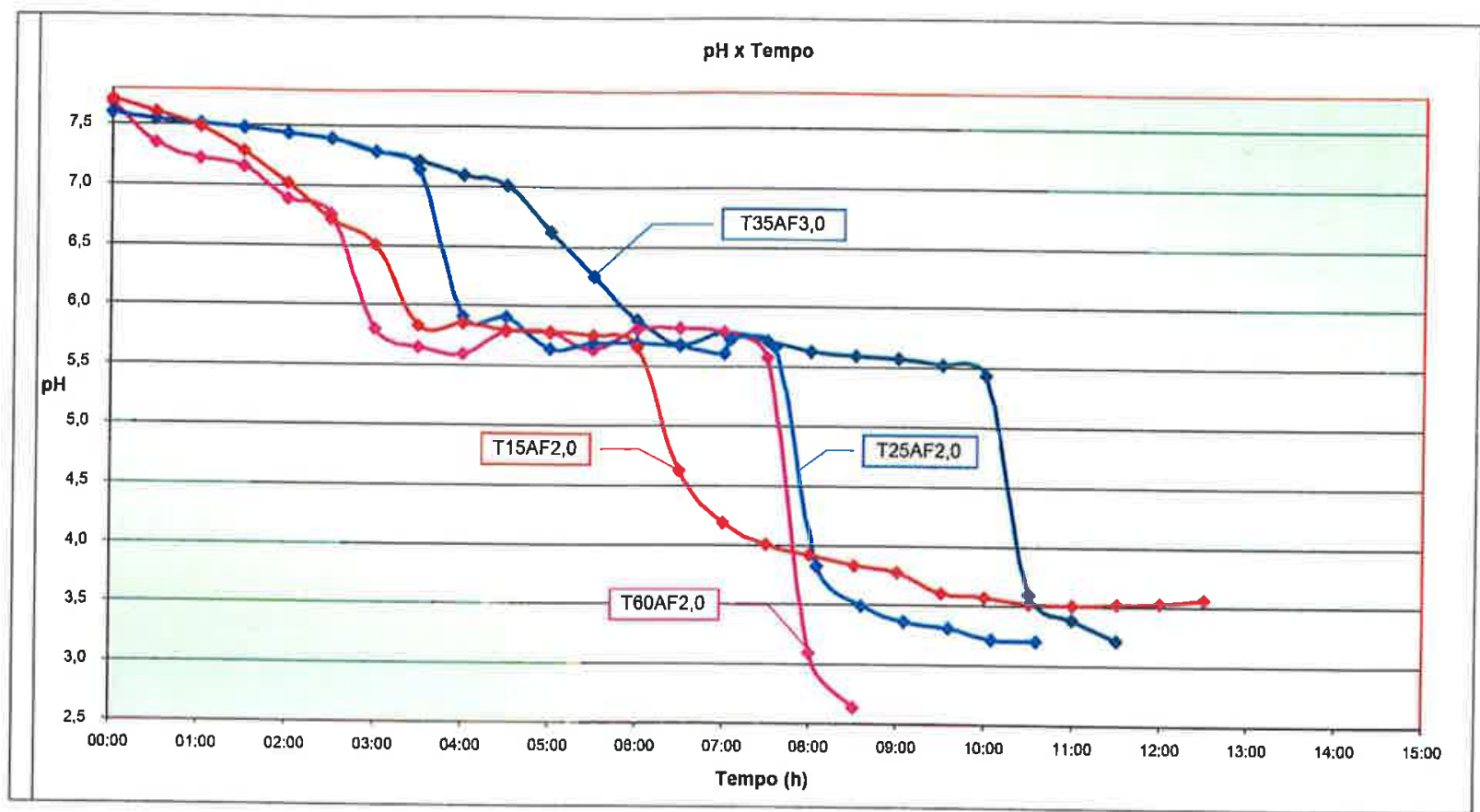

Figura 4-6. Comparação do ensaio T35AF3,0 com o comportamento do $\mathrm{pH}$ em diferentes temperaturas com taxa de aeração de $2 \mathrm{NL} \cdot \mathrm{min}^{-1} \cdot \mathrm{L}^{-1}$.

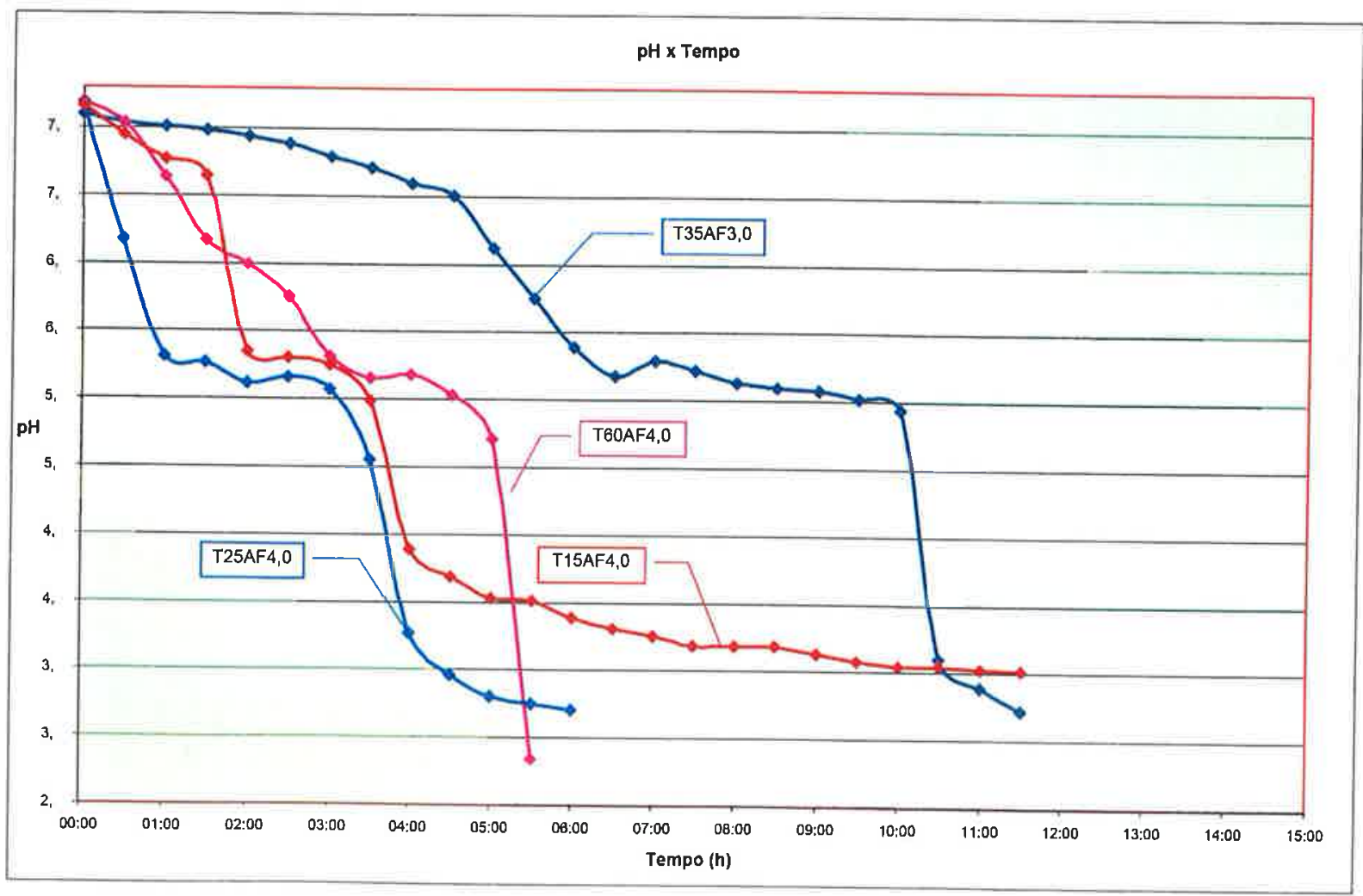

Figura 4-7. Comparação do ensaio T35AF3,0 com o comportamento do $\mathrm{pH}$ em diferentes temperaturas com taxa de aeração de 4 NL. $\min ^{-1} \cdot L^{-1}$. 


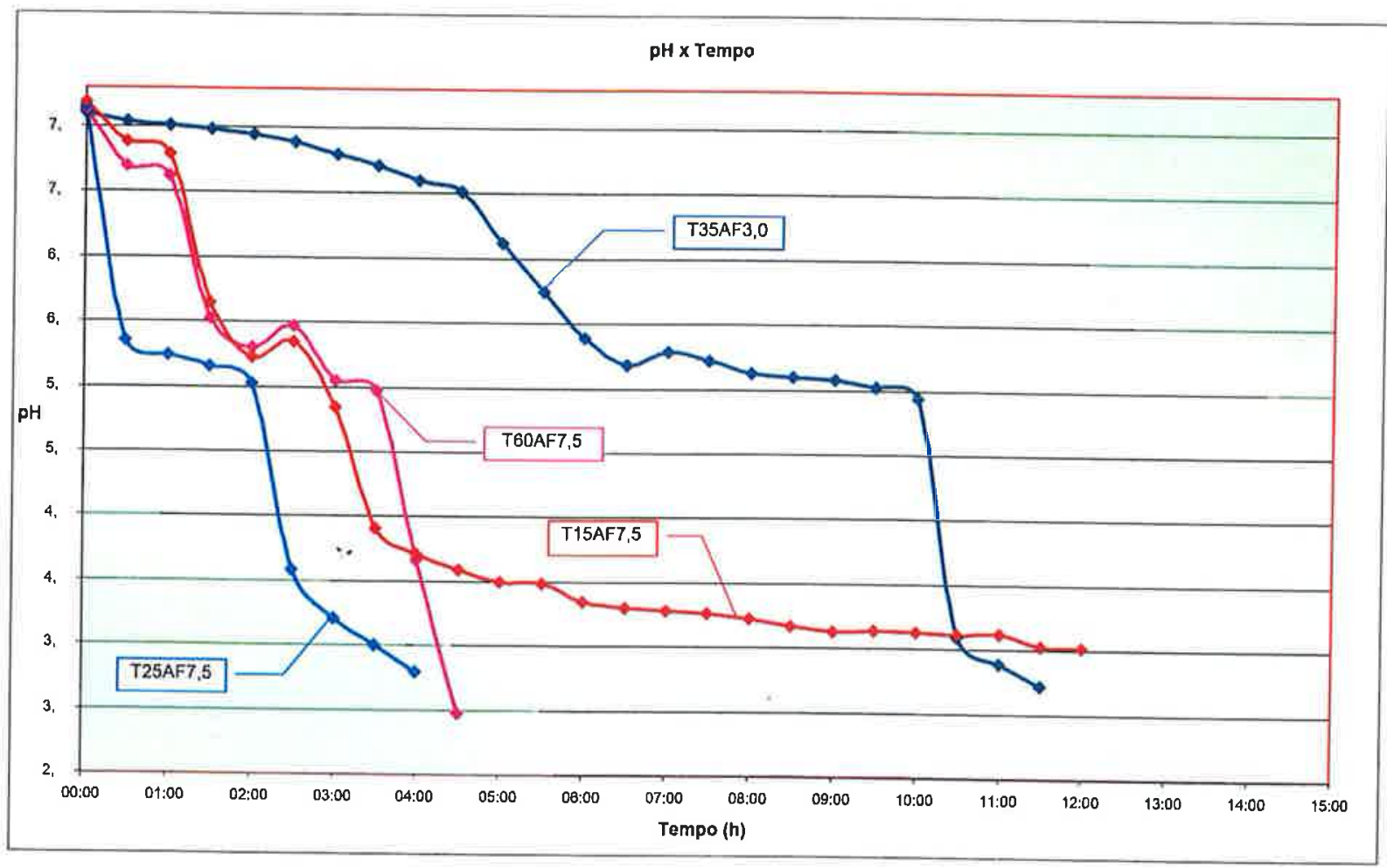

Figura 4-8. Comparação do ensaio T35AF3,0 com o comportamento do $\mathrm{pH}$ em diferentes temperaturas com taxa de aeração de $7,5 \mathrm{NL} \cdot \mathrm{min}^{-1} \cdot \mathrm{L}^{-1}$.

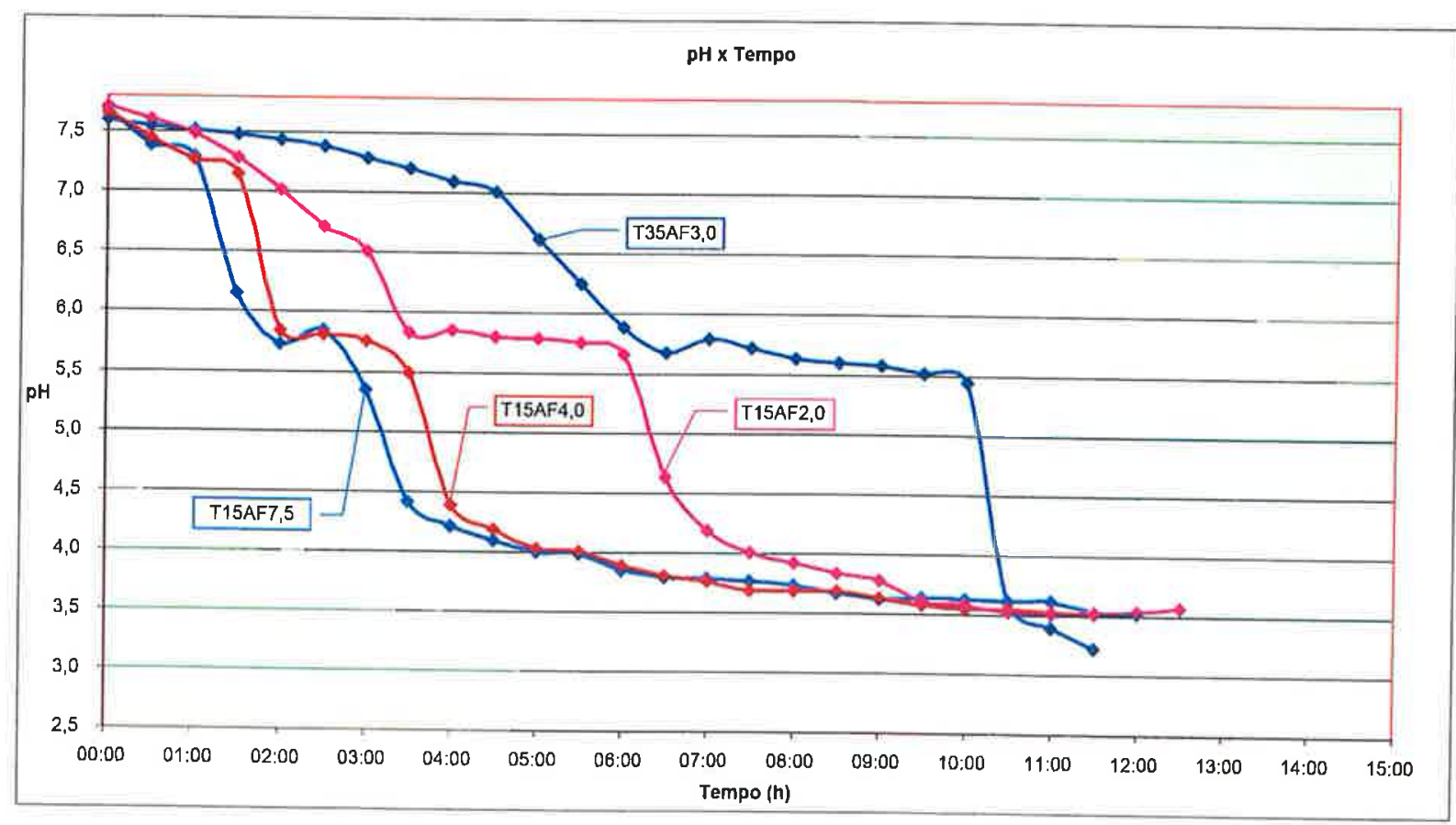

Figura 4-9. Comparação do ensaio T35AF3,0 com o comportamento do pH na oxidação conduzida em diferentes taxas de aeração na temperatura de $15^{\circ} \mathrm{C}$. 


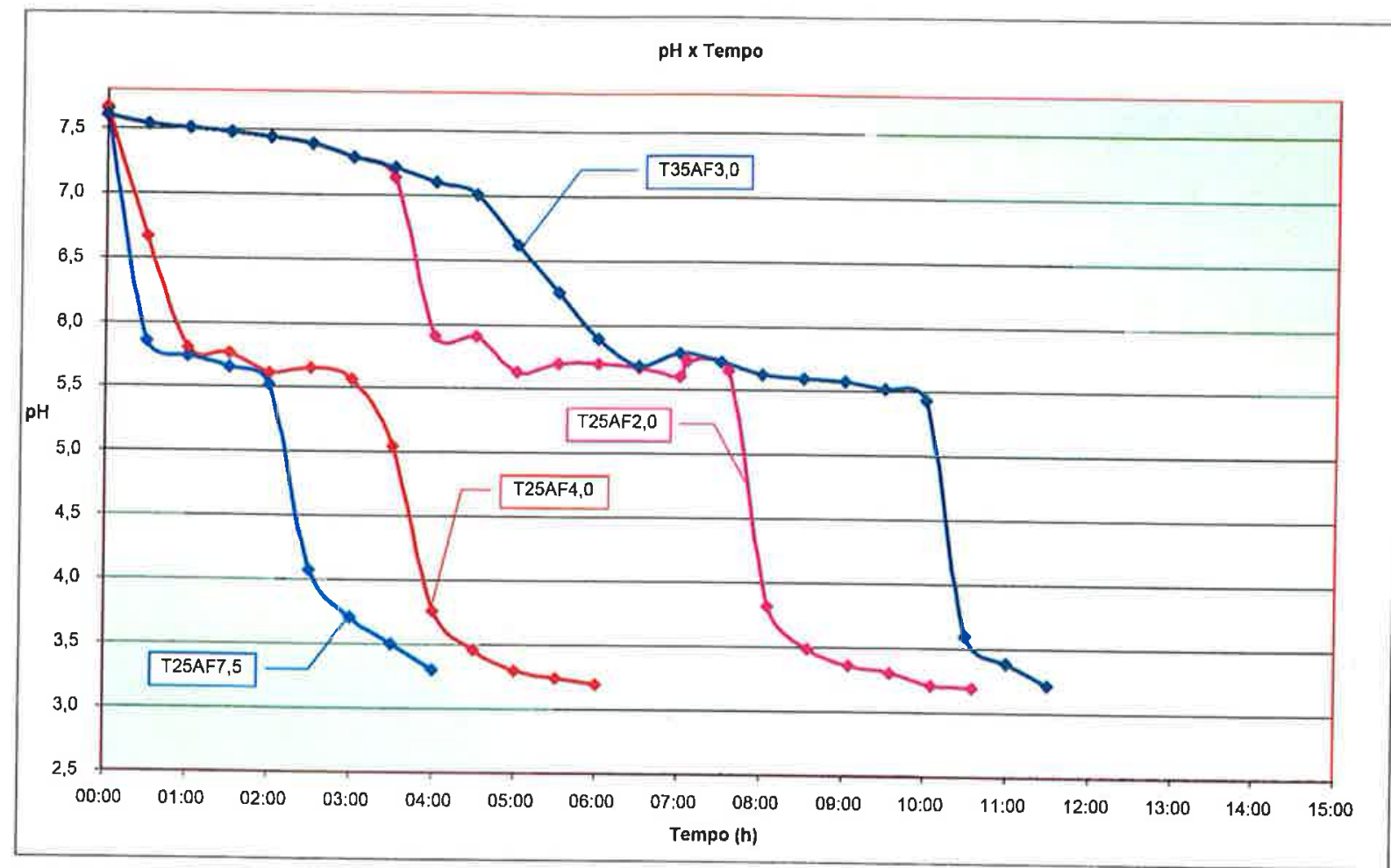

Figura 4-10. Comparação do ensaio T35AF3,0 com o comportamento do pH na oxidação conduzida em diferentes taxas de aeração na temperatura de $25^{\circ} \mathrm{C}$.

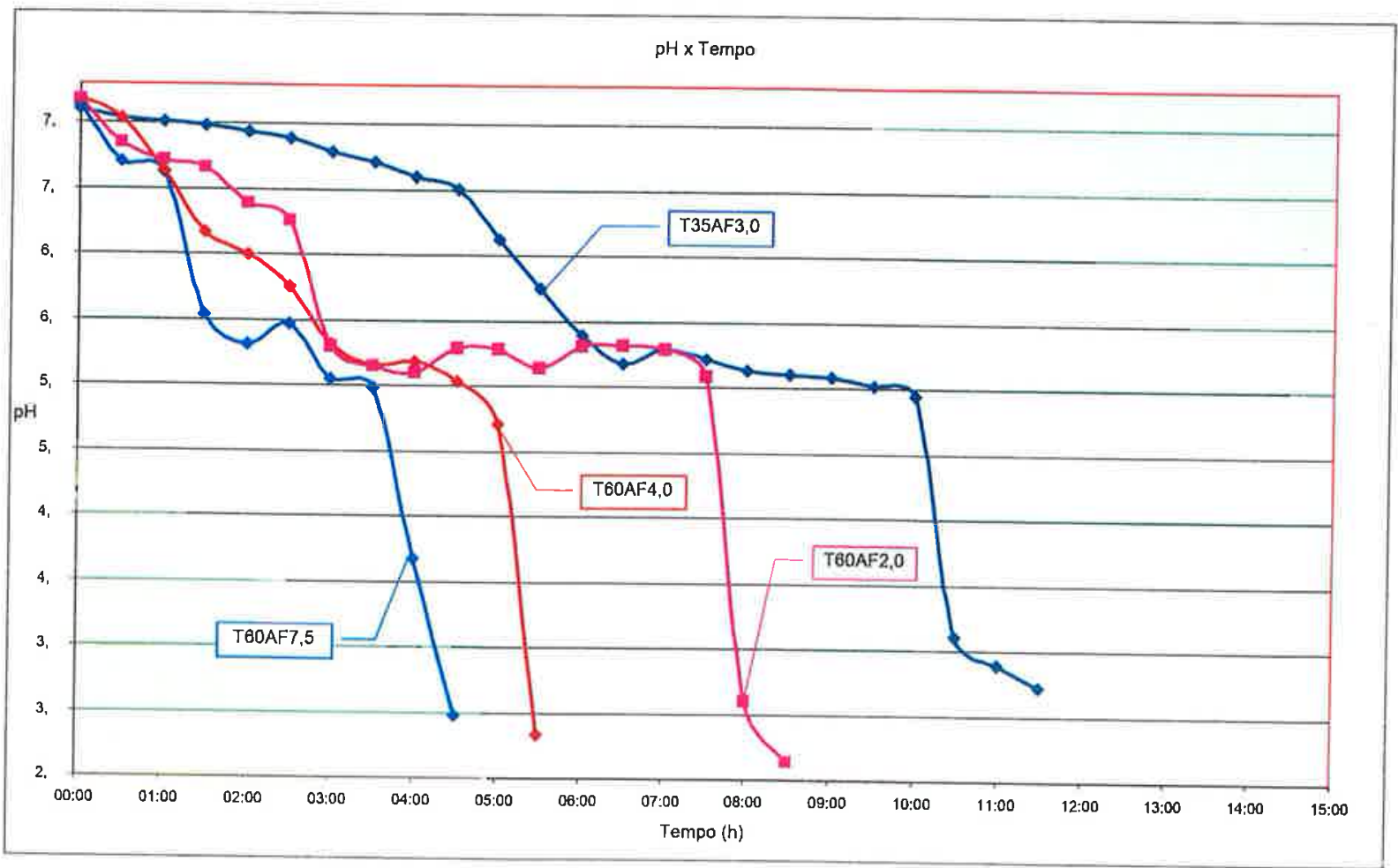

Figura 4-11. Comparação do ensaio T35AF3,0 com o comportamento do pH na oxidação conduzida em diferentes taxas de aeração na temperatura de $60^{\circ} \mathrm{C}$. 


\subsubsection{CARACTERIZAÇÃo dAS FASES CRISTALINAS}

Os espectros de Mössbauer obtidos apresentam uma boa concordância com os dados da literatura para a temperatura de $80 \mathrm{~K}$ para $\alpha-\mathrm{FeOOH}$ e $\gamma-\mathrm{FeOOH}$. Além destas, não se observa a presença de outra fase contendo ferro em nenhum dos espectros obtidos. Os detalhes da interpretação da análise encontram-se em Baptista (2010). Pelos espectros obtidos podemos afirmar que uma baixa taxa de oxidação e uma queda lenta do $\mathrm{pH}$ na primeira região conduzem a um produto de fase única, a goethita. Sob taxas maiores de oxidação, exceto a $60{ }^{\circ} \mathrm{C}$, o produto resultante foi uma mistura de goethita e lepidocrocita. As temperaturas mais baixas tiveram maior influência do que a taxa de aeração para a formação da lepidocrocita. Para as amostras que apresentaram duas fases (goethita e lepidocrocita) foi estimada a porcentagem relativa de ferro presente em cada fase. Os cálculos foram feitos através das áreas relativas entre o sexteto (correspondente à fase contendo $\alpha$-FeOOH) e o dubleto (correspondente à fase contendo $\gamma$ $\mathrm{FeOOH}$ ). Os resultados relativos à composição dessa mistura são mostrados na Tabela 4-3.

Tabela 4-3. Composição da Mistura Goethita e Lepidocrocita

\begin{tabular}{||l|l|l||}
\hline \multirow{2}{*}{ Ensaio } & Goethita & Lepidocrocita \\
\cline { 2 - 3 } & $(\%)$ & $(\%)$ \\
\hline T15AF4,0 & 71 & 29 \\
\hline T15AF7,5 & 61 & 39 \\
\hline T25AF4,0 & 90 & 10 \\
\hline T25AF7,5 & 86 & 14 \\
\hline
\end{tabular}

\subsection{3 ÁREA SUPERFICIAL (BET)}

Houve variações bastante significativas na área superficial especifica das sementes, sendo obtidos valores entre 44 e $160 \mathrm{~m}^{2} / \mathrm{g}$. A Figura 4-12 mostra que a área superficial específica $\left(\mathrm{S}_{\mathrm{BET}}\right)$ diminui com o aumento da temperatura. Nota-se também que, para os ensaios conduzidos numa mesma temperatura, as maiores taxas de aeração favorecem áreas superficiais maiores, mas a influencia da taxa de aeração é menor que a da temperatura. Apenas nos ensaios à temperatura de $60^{\circ} \mathrm{C}$ não houve variação significativa da área superficial com a taxa de aeração. 


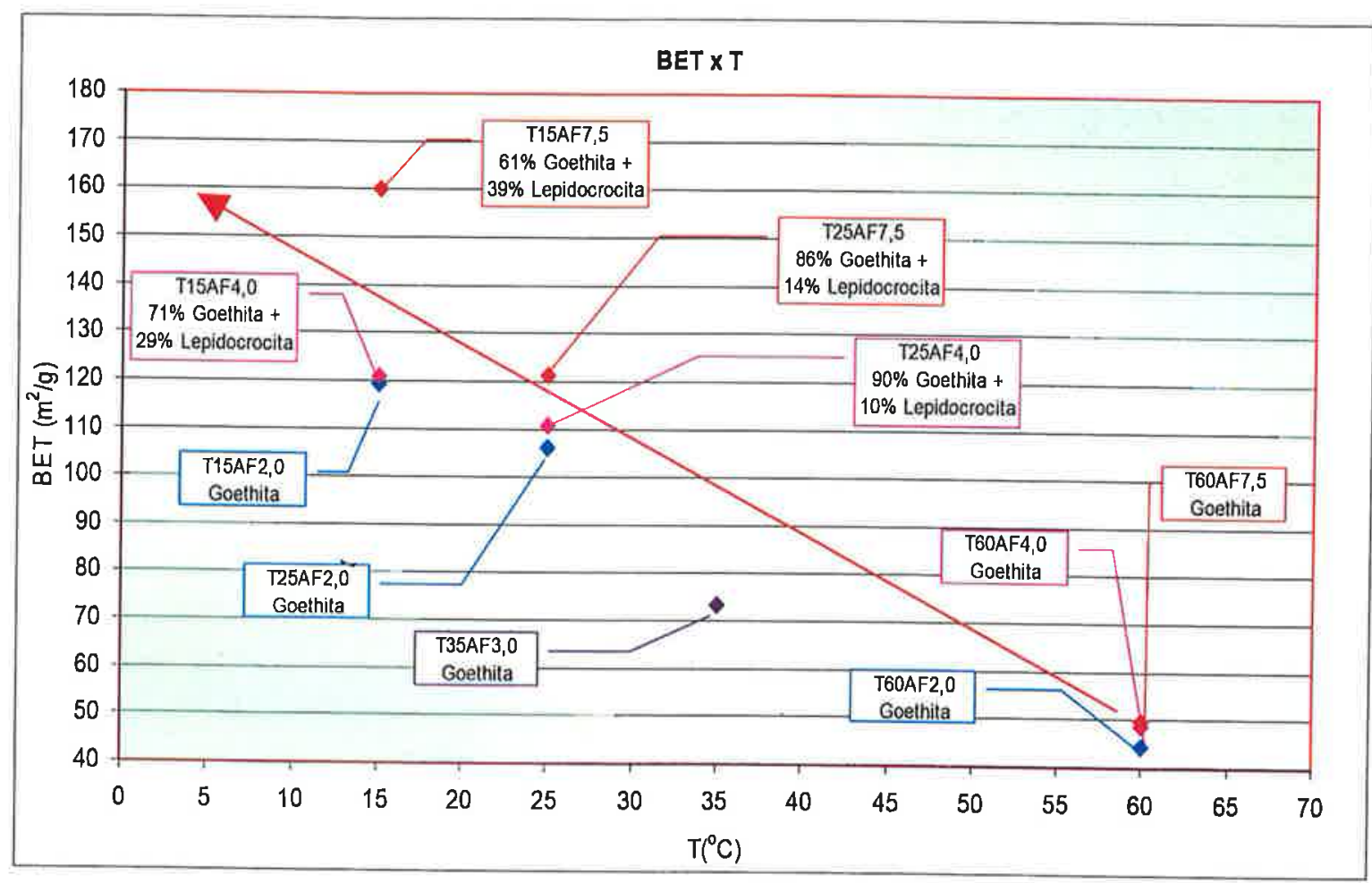

Figura 4-12. Valores de $S_{B E T}$ em função da temperatura.

Nos ensaios com lepidocrocita foram obtidas as maiores áreas superficiais. A maior área superficial obtida em todos os ensaios, de $160 \mathrm{~m}^{2} / \mathrm{g}$ obtida no ensaio T15AF7,5 deve estar relacionada com a maior porosidade decorrente do maior grau de irregularidade das partículas provocado pela grande presença de lepidocrocita.

As áreas superficiais nos ensaios T15AF2,0 $\left(119 \mathrm{~m}^{2} / \mathrm{g}\right)$ e T15AF4,0 $\left(121 \mathrm{~m}^{2} / \mathrm{g}\right)$ foram bastante similares, porém a análise das fases cristalinas mostrou a presença de lepidocrocita no ensaio T15AF4,0 (29\%). A similaridade dos valores da área superficial entre os ensaios T15AF2,0 e T15AF4,0 pode estar relacionada aos agregados formados (ver adiante), que afetaram a área superficial específica e a porosidade das sementes.

As áreas superficiais quando a goethita é a única fase são bem distintas daquela obtida nas condições similares à do processo industrial $(T 35 A F 3,0)$. Alguns ensaios sob baixa temperatura (T15AF2,0 e T25AF2,0) mostraram áreas específicas maiores. Por outro lado os ensaios conduzidos a $60^{\circ} \mathrm{C}$ mostraram áreas específicas menores.

\subsubsection{DiSTRIBUIÇÃO GRANULOMÉTRICA}

As distribuições granulométricas por espalhamento dinâmico de luz (DLS) foram expressas em porcentagem numérica e volumétrica. Algumas distribuições representativas são mostradas na Figura 4-13 (frações numéricas). Os tamanhos médios ponderados em número e em volume, bem como seus desvios padrões, encontram-se na Tabela 4-4. Eles situam-se na mesma ordem de grandeza: as médias numéricas situaram-se entre 0,7 e 1,5 $\mu \mathrm{m}$ e as médias volumétricas entre 1,1 
e 2,8 $\mu \mathrm{m}$. A ausência de valores menores que $0,4 \mu \mathrm{m}$ está relacionada com a presença de aglomerados mostrados pelas imagens obtidas por MEV (ver adiante).

Tabela 4-4. Valores médios DLS numérica e volumétrica.

\begin{tabular}{|c|c|c|}
\hline \multirow{2}{*}{ Ensaio } & DLS $_{\text {NUM }}$ & $D^{\prime} S_{\text {VOL }}$ \\
\hline & $(\mu \mathrm{m})$ & $(\mu \mathrm{m})$ \\
\hline T35AF3,0 & $1,1 \pm 0,3$ & $1,5 \pm 0,6$ \\
\hline T15AF2,0 & $0,8 \pm 0,3$ & $1,1 \pm 0,4$ \\
\hline T15AF4,0 & $0,7 \pm 0,2$ & $1,1 \pm 0,5$ \\
\hline T15AF7,5 & $1,3 \pm 0,4$ & $2,8 \pm 1,3$ \\
\hline T25AF2,0 & $0,7 \pm 0,2$ & $1,1 \pm 0,5$ \\
\hline T25AF4,0 & $1,5 \pm 0,5$ & $1,9 \pm 0,7$ \\
\hline T25AF7,5 & $0,7 \pm 0,2$ & $1,1 \pm 0,5$ \\
\hline T60AF2,0 & $1,0 \pm 0,3$ & $1,7 \pm 0,8$ \\
\hline T60AF4,0 & $1,2 \pm 0,4$ & $1,7 \pm 0,7$ \\
\hline T60AF7,5 & $0,7 \pm 0,2$ & $1,2 \pm 0,5$ \\
\hline
\end{tabular}

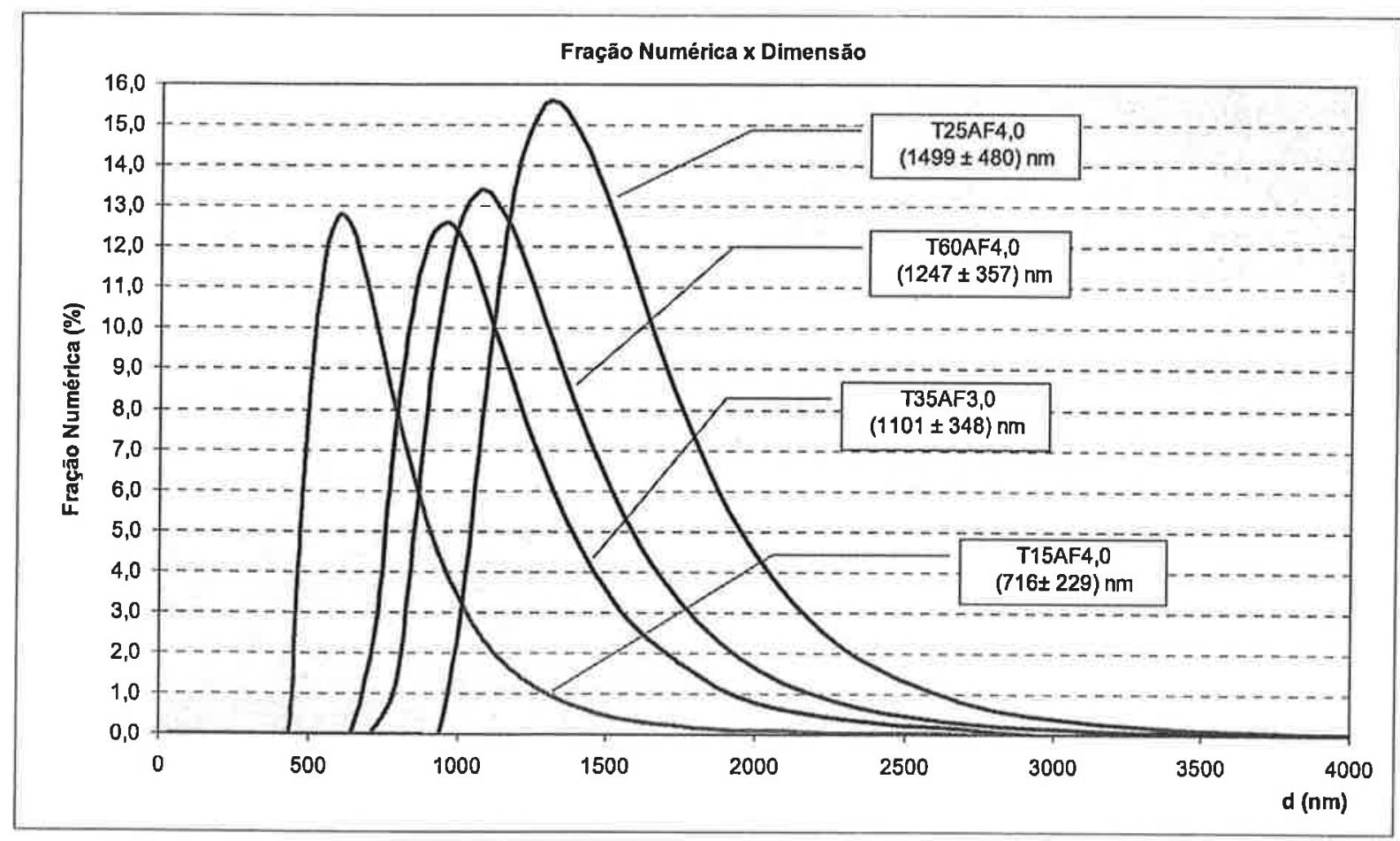

Figura 4-13. DLS Fração Numérica nos ensaios: T35AF3,0, T15AF4,0, T25AF4,0 e T60AF4,0

\subsubsection{Microscopia Eletrônica de VaRREdura (MEV)}

Desde a Figura 4-14 até a Figura 4-23 são mostradas imagens de MEV dos produtos obtidos experimentalmente com aumento de 30.000 vezes. Cristais aciculares típicos da goethita são observados nos ensaios T15AF2,0, T25AF2,0, T35AF3,0 e nas amostras produzidas a $60^{\circ} \mathrm{C}$ (Figura 
4-14 a Figura 4-19). Estes resultados são consistentes com a espectrometria de Mössbauer, pela qual a goethita foi identificada como a única fase presente nos mesmos ensaios.

A morfologia tipo placas, típica para a lepidocrocita, foi observada da Figura 4-20 até a Figura 4-23. Este mineral apresenta-se como placas recobertas por agulhas de goethita, sendo que uma imagem nítida desse cristal é mostrada em detalhe na Figura 4-22. Estes resultados são consistentes com as espectroscopias de Mossbauer, que também mostraram a presença de lepidocrocita nos mesmos ensaios.

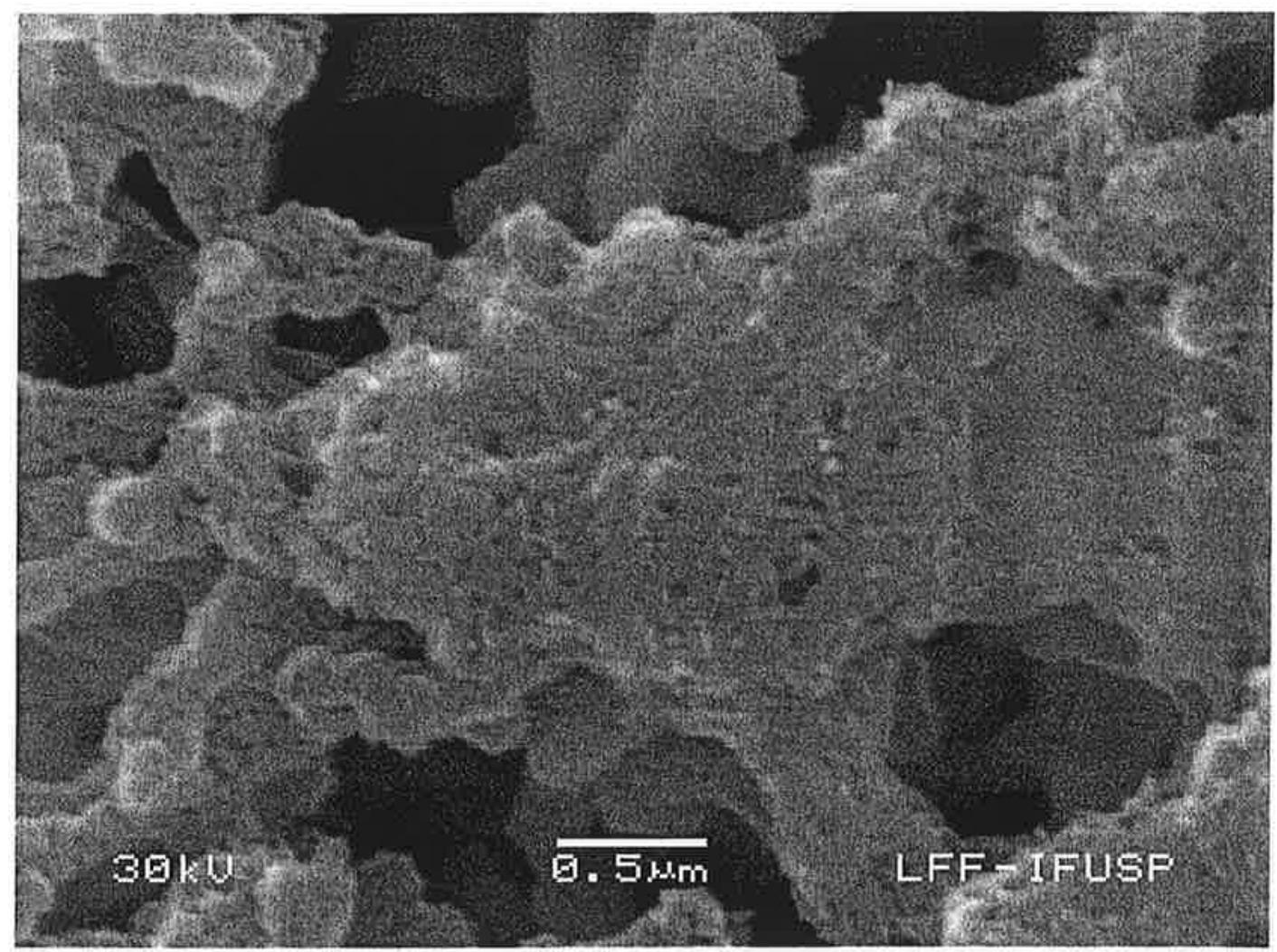

Figura 4-14. MEV do ensaio T15AF2,0: Aglomerado de cristais de Goethita 


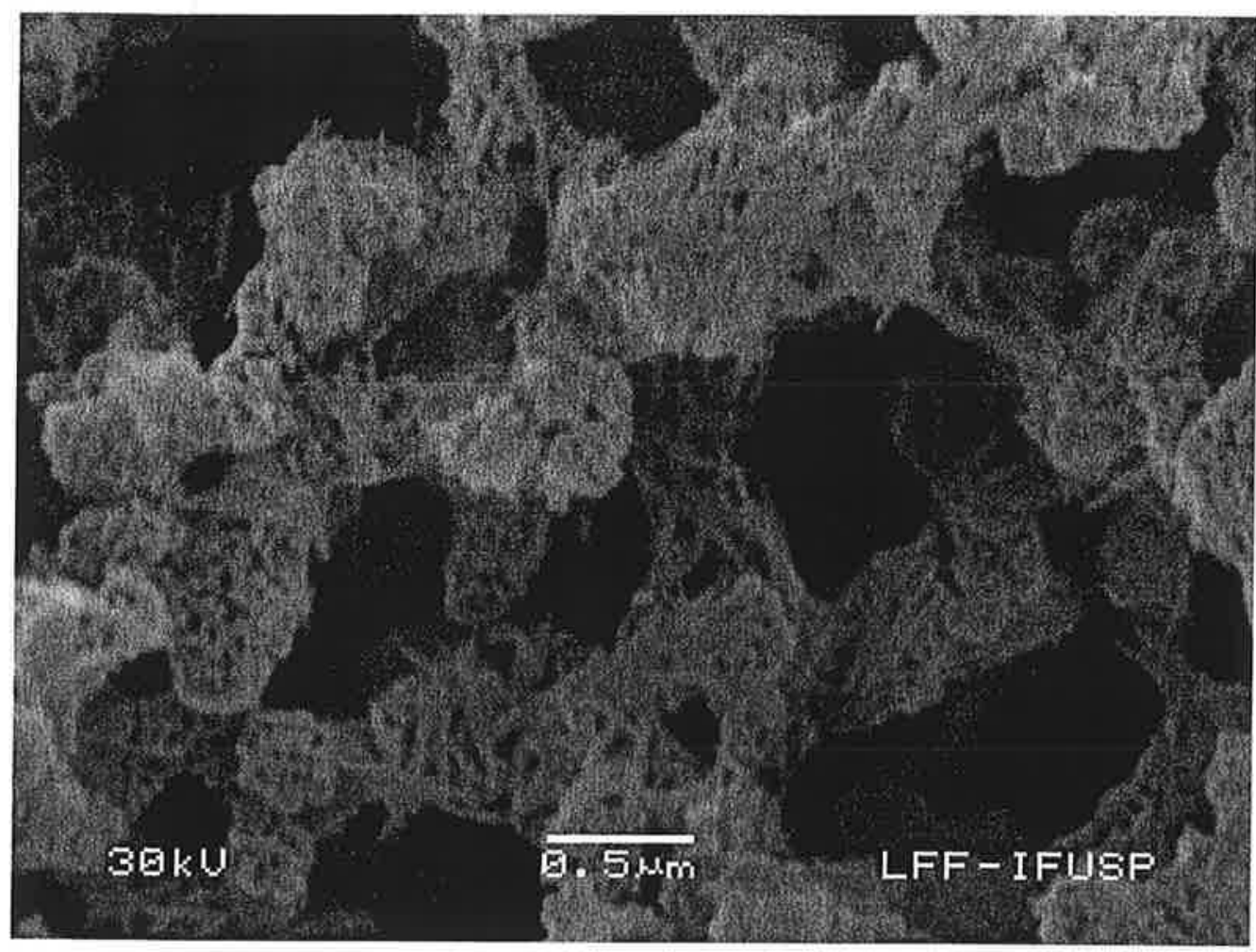

Figura 4-15. MEV do ensaio T25AF2,0: Aglomerado de cristais de Goethita

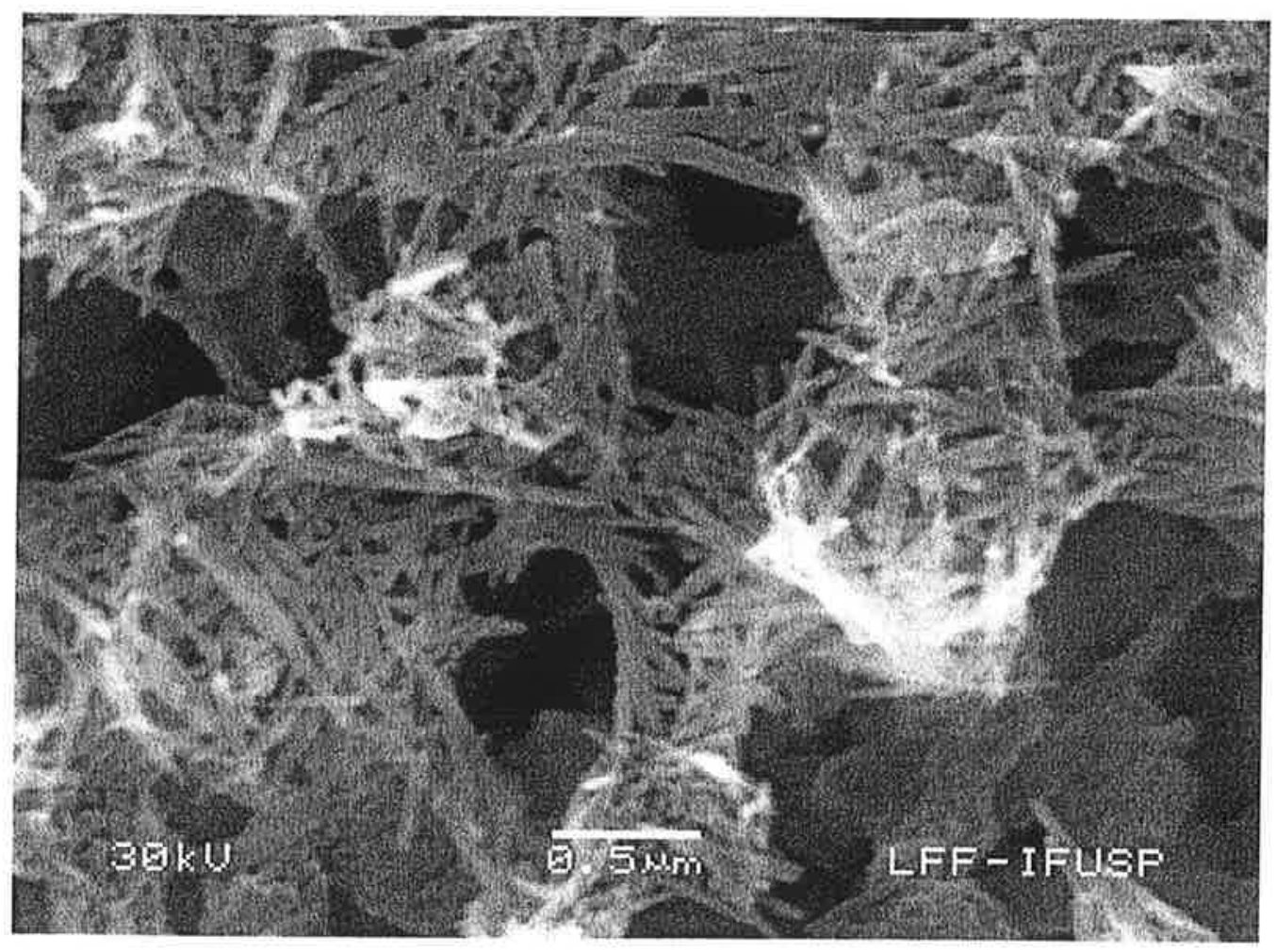

Figura 4-16. MEV do ensaio T35AF3,0: Aglomerado de cristais de Goethita 


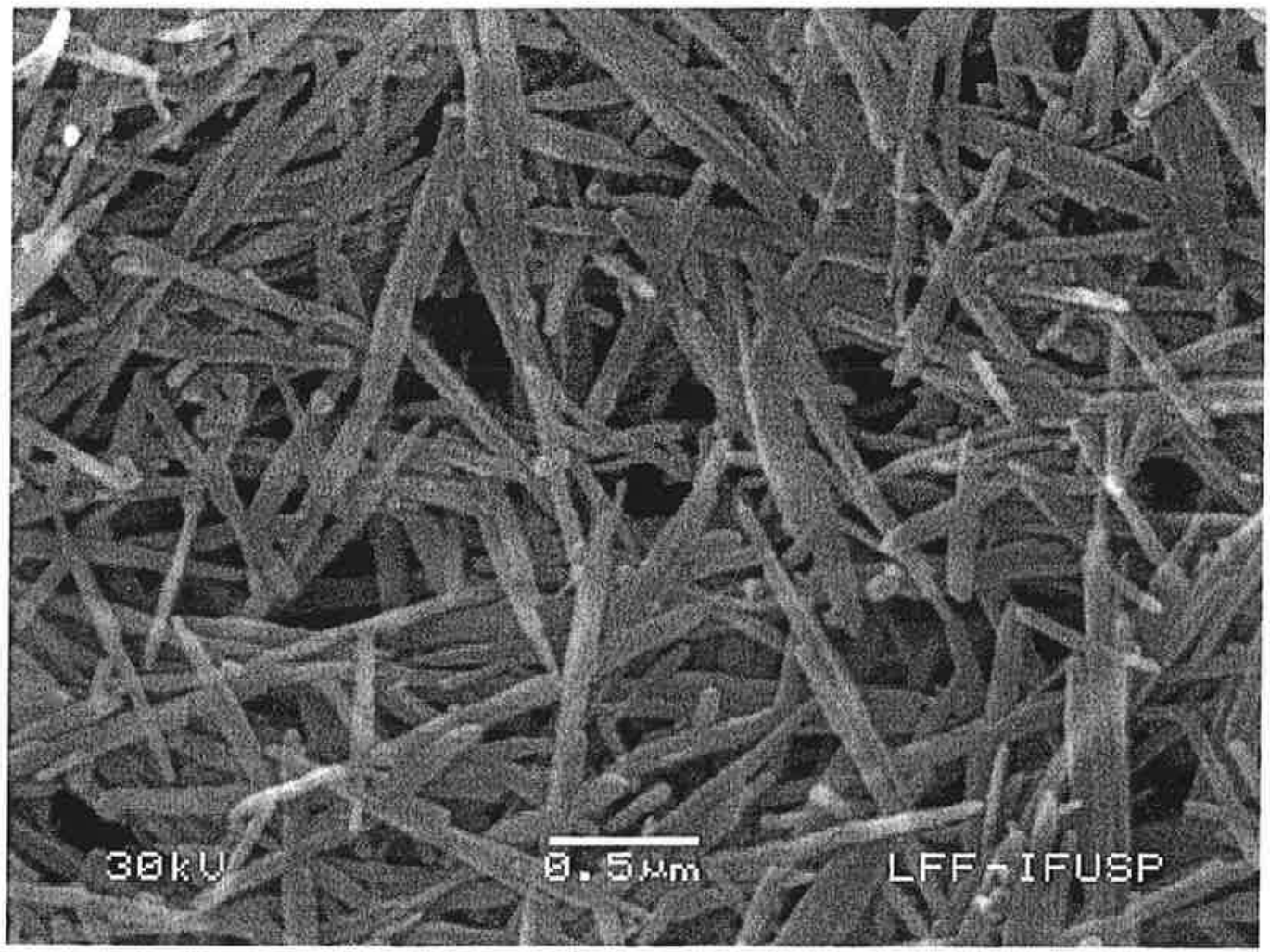

Figura 4-17. MEV do ensaio T60AF2,0: Aglomerado de cristais de Goethita

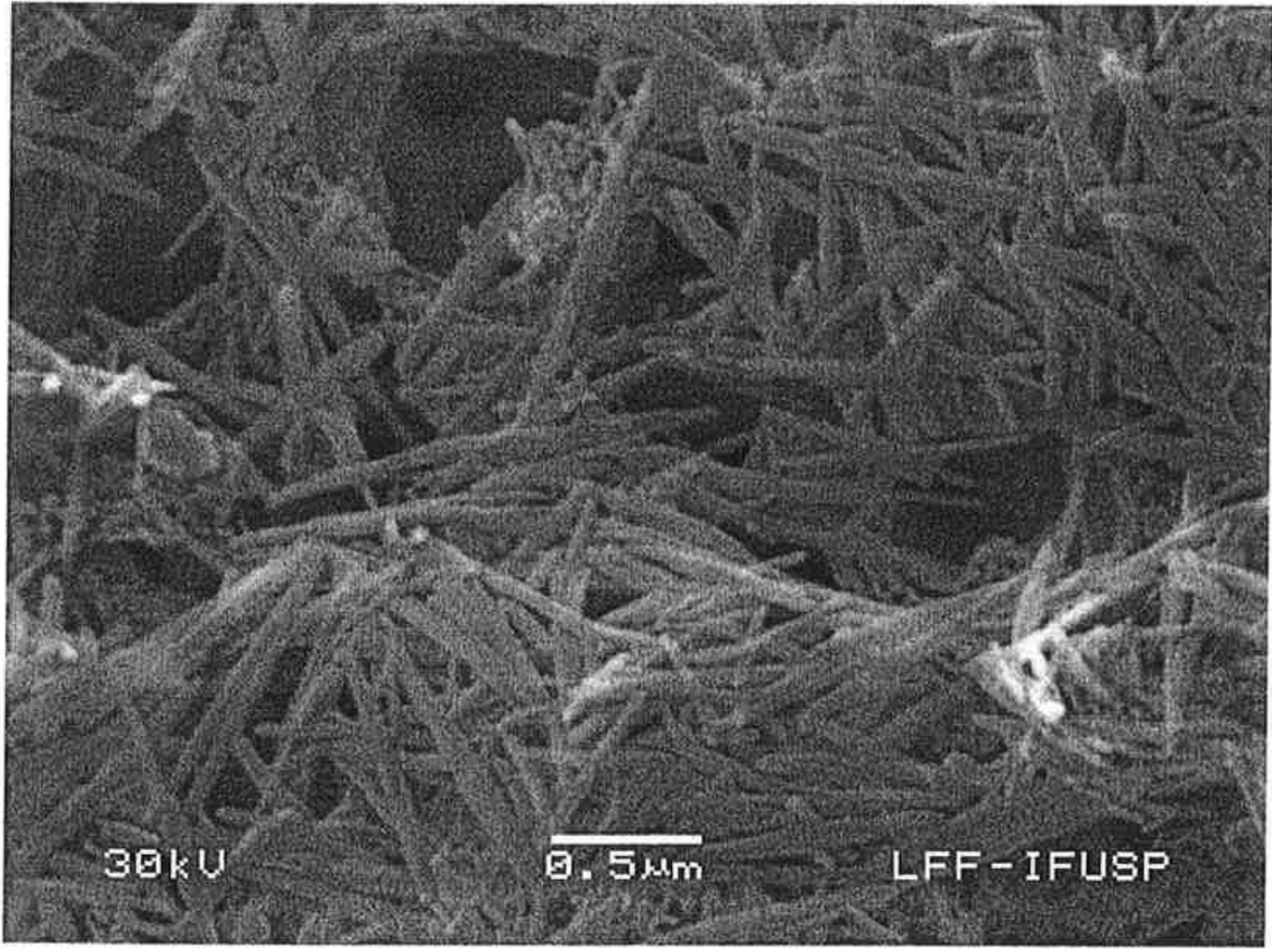

Figura 4-18. MEV do ensaio T60AF4,0: Aglomerado de cristais de Goethita 


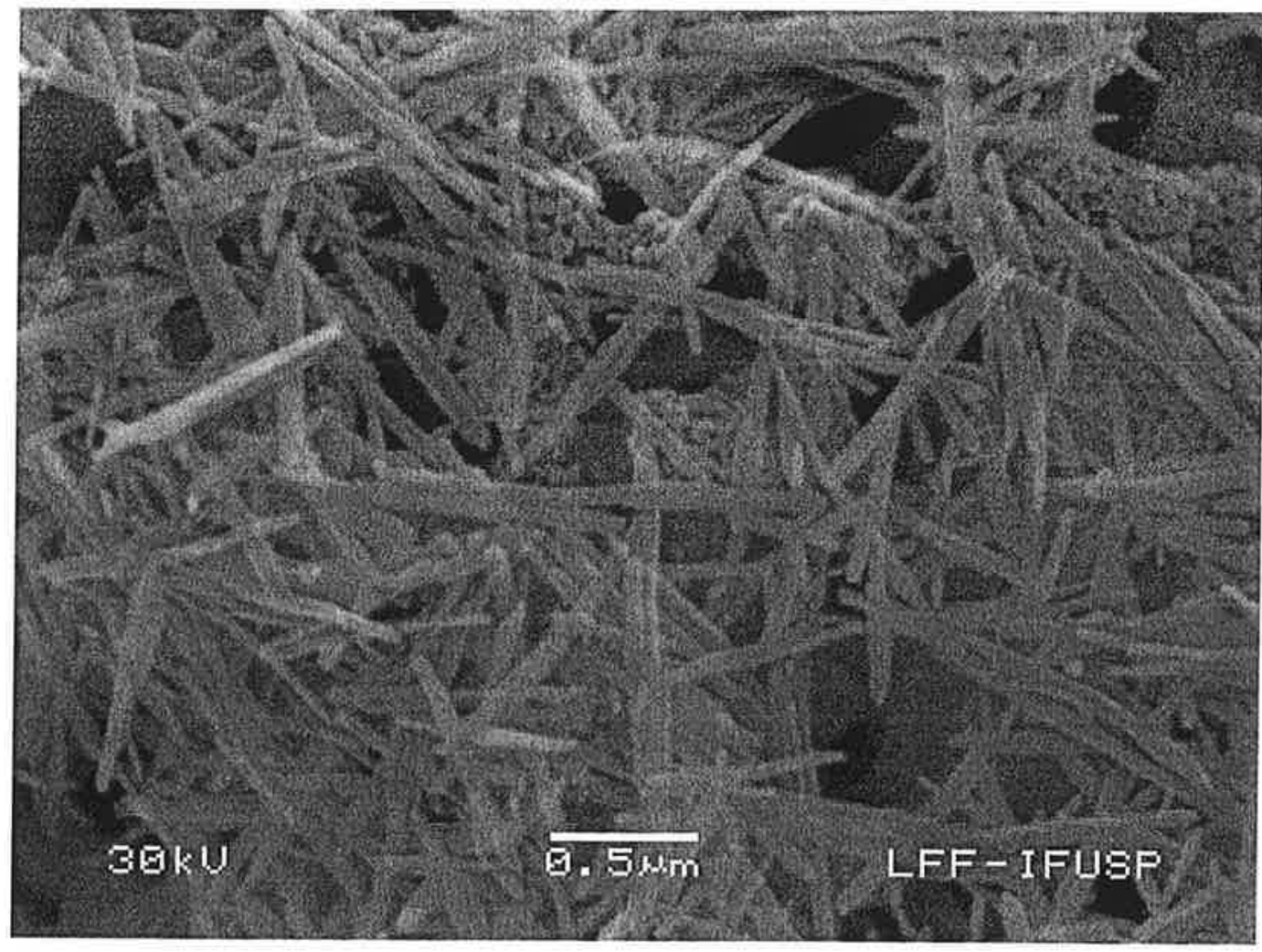

Figura 4-19. MEV do ensaio T60AF7,5: Aglomerado de cristais de Goethita

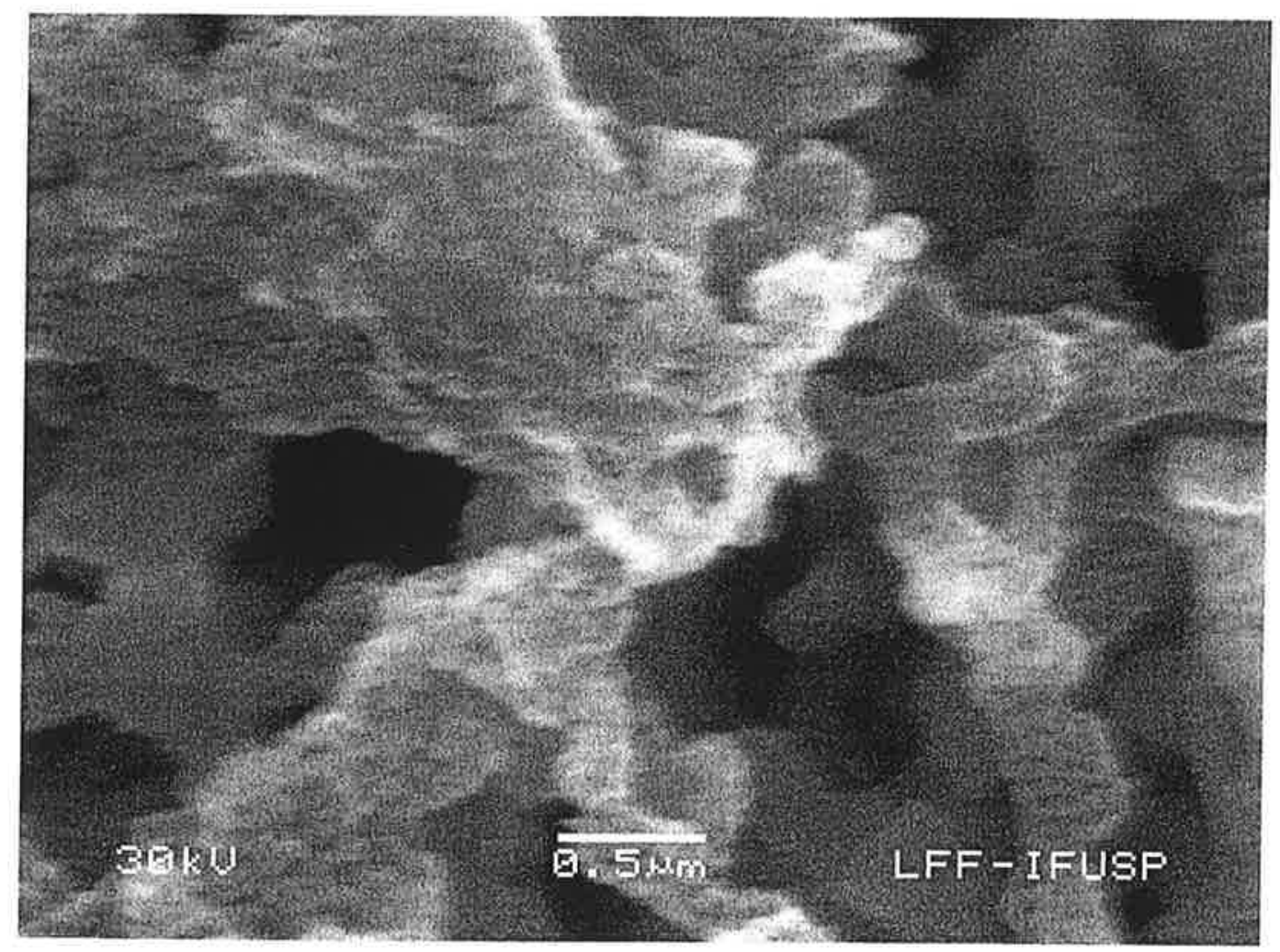

Figura 4-20. MEV do ensaio T15AF4,0: Aglomerado de cristais de Goethita e Lepidocrocita 


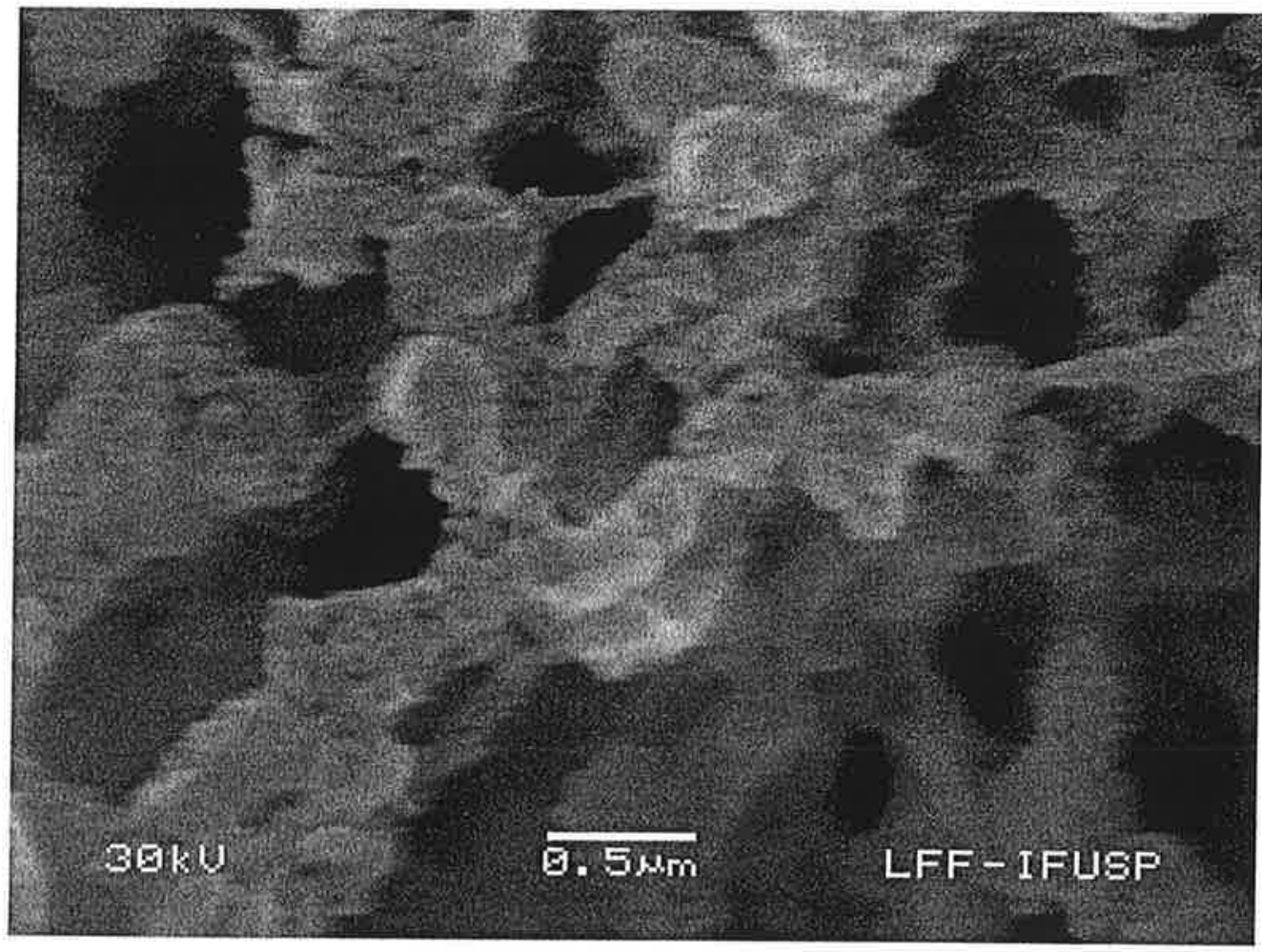

Figura 4-21. MEV do ensaio T15AF7,5: Aglomerado de cristais de Goethita e Lepidocrocita

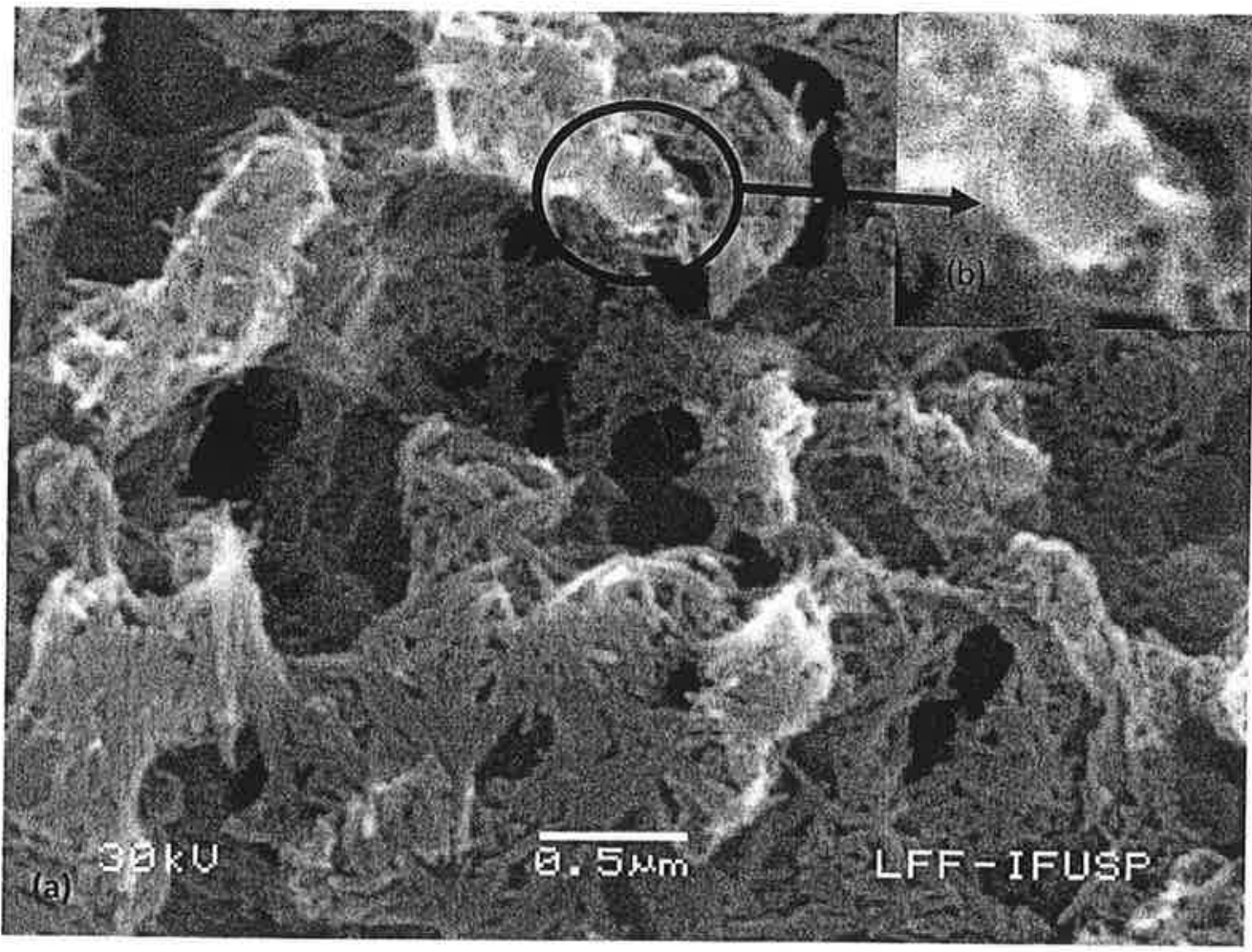

Figura 4-22. MEV do ensaio T25AF4,0: Aglomerado de cristais de (a) Goethita e (b) detalhe do cristal de lepidocrocita 


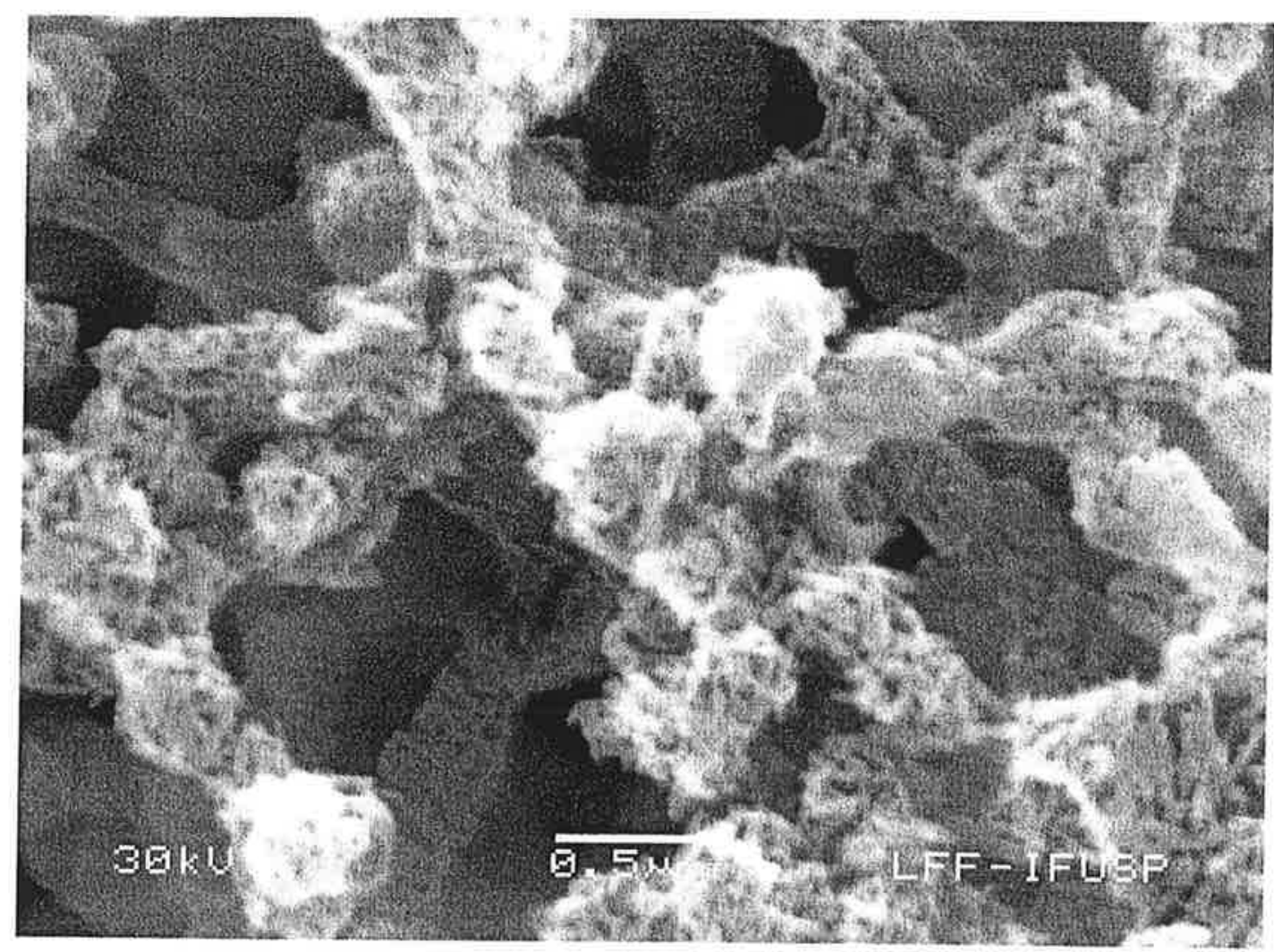

Figura 4-23. MEV do ensaio T25AF7,5: Aglomerado de cristais de Goethita e Lepidocrocita

A presença de aglomerados também é notada, principalmente nos ensaios feitos com temperaturas menores e maiores taxas de oxidação. 0 grau de aglomeração das partículas foi variável, sendo que nos casos onde as partículas primárias (os cristais individuais) são menores, os aglomerados são mais compactos. Nos ensaios com menor temperatura e maior taxa de oxidação (T15AF2,0, T15AF4,0, T15AF7,5 e T25AF7,5), as partículas primárias não são detectadas nas micrografias, sendo portanto ainda menores (têm comprimento $L_{\text {PRIM }}$ inferior ao limite de detecção do instrumento, $\left.L_{P R I M}<0,2 \mu \mathrm{m}\right)$.

Os ensaios conduzidos a $60{ }^{\circ} \mathrm{C}$ produziram partículas primárias relativamente grandes $\left(L_{\text {PRIM }}>1,0\right.$ $\mu \mathrm{m})$ e com baixo grau de aglomeração. Nos demais, as partículas primárias têm dimensões na faixa de 0,2 a 0,6 $\mu \mathrm{m}$. A razão de aspecto ( $L_{\text {PRIM }} /$ largura) é de aproximadamente 20 . Os tamanhos médios das partículas, a área superficial deles derivadas $\left(S_{M E v}\right)$ o tipo de aglomeração são resumidos na Tabela 4-5. O cálculo de $S_{M E V}$ foi feito admitindo-se que as partículas são paralelepípedos com largura igual à profundidade, isto é, $L_{\text {PRIM }} /$ largura $=L_{\text {PRIM }} /$ profundidade $=$ 20. O comprimento da partícula primária foi obtido pela média da medição de cinco partículas. A Figura 4-24 mostra que as áreas superficiais específicas estimadas por MEV apresentam uma boa correlação com os dados obtidos pelo método do BET. 
Tabela 4-5. Dimensões e área superficial obtidos via MEV

\begin{tabular}{||l|l|l|l||}
\hline \multirow{2}{*}{ Ensaio } & LPRIM & $\mathrm{S}_{\text {MEV }}$ & Aglomeração \\
\cline { 2 - 4 } & $(\mu \mathrm{m})$ & $\left(\mathrm{m}^{2} / \mathrm{g}\right)$ & Tipo \\
\hline T35AF3,0 & 0,6 & 34 & Média \\
\hline T15AF2,0 & 0,2 & 103 & Alta \\
\hline T15AF4,0 & 0,3 & 68 & Alta \\
\hline T15AF7,5 & 0,2 & 103 & Alta \\
\hline T25AF2,0 & 0,4 & 51 & Alta \\
\hline T25AF4,0 & 0,5 & 41 & Alta \\
\hline T25AF7,5 & 0,3 & 68 & Alta \\
\hline T60AF2,0 & 1,5 & 14 & Baixa \\
\hline T60AF4,0 & 1,2 & 17 & Baixa \\
\hline T60AF7,5 & 1,0 & 21 & Baixa \\
\hline \hline
\end{tabular}

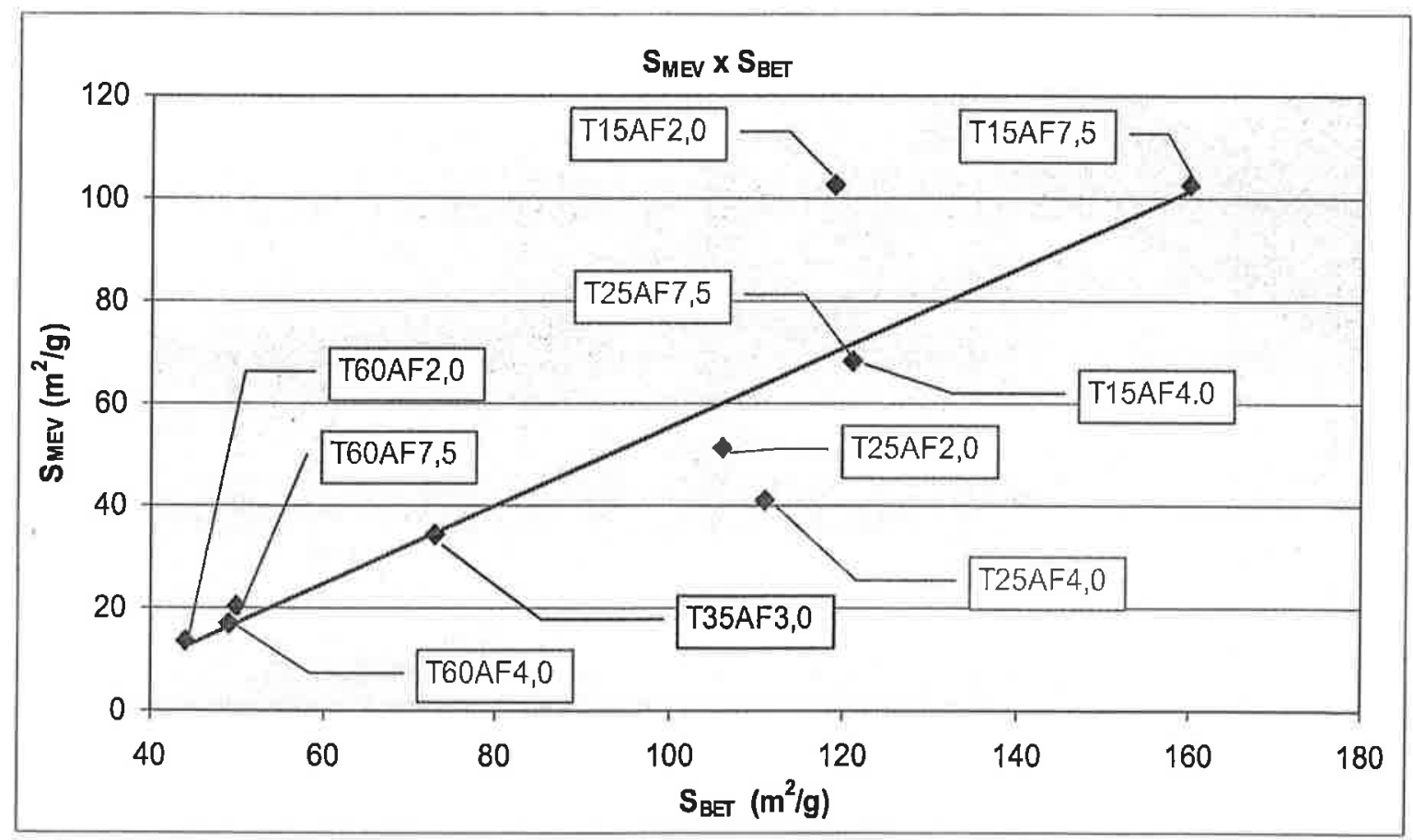

Figura 4-24. Comparação da área superficial calculada a partir da partícula primária obtida via MEV com a medida por BET. 
A Figura 4-25 mostra que a $\mathrm{S}_{\mathrm{BET}}$ apresenta uma relação consistente com os comprimentos médios das partículas primárias, independentemente da presença dos aglomerados presentes apenas nos ensaios com temperatura 15 e $25^{\circ} \mathrm{C}$. Esses resultados mostram que os aglomerados são porosos.

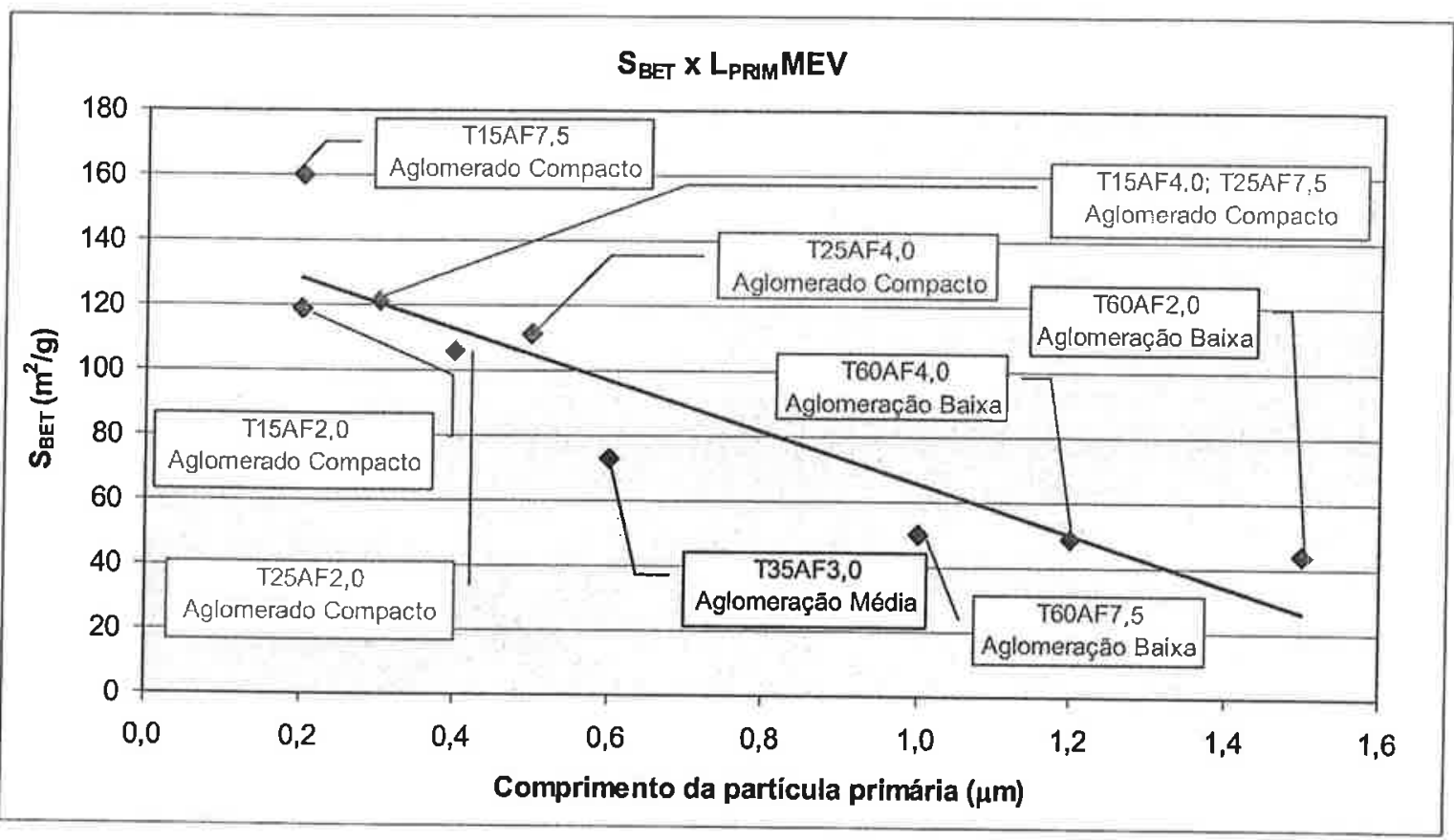

Figura 4-25. Área superficial por BET $\left(\mathrm{S}_{\mathrm{BET}}\right)$ em função do comprimento médio da partícula primária obtido por MEV.

A Figura 4-26 mostra que os tamanhos das partículas primárias obtidos por MEV e por DLS estão dentro da mesma ordem de grandeza. Nos ensaios com baixo grau de aglomeração (T60AF2,0, T60AF4,0 e T60AF7,5) os tamanhos médios das partículas, obtidos via MEV, (1,5, 1,2 e 1,0 $\mu \mathrm{m})$ foram próximos aos obtidos via $D L S(1,0,1,2$ e $0,7 \mu \mathrm{m})$.

A Figura 4-27 mostra que o tamanho das partículas primárias, obtidos via MEV, aumenta com a temperatura. Não há correlação entre a taxa de aeração e o tamanho das partículas primárias obtidos via MEV.

A Tabela 4-6 resume as principais características dos produtos obtidos nos ensaios. 


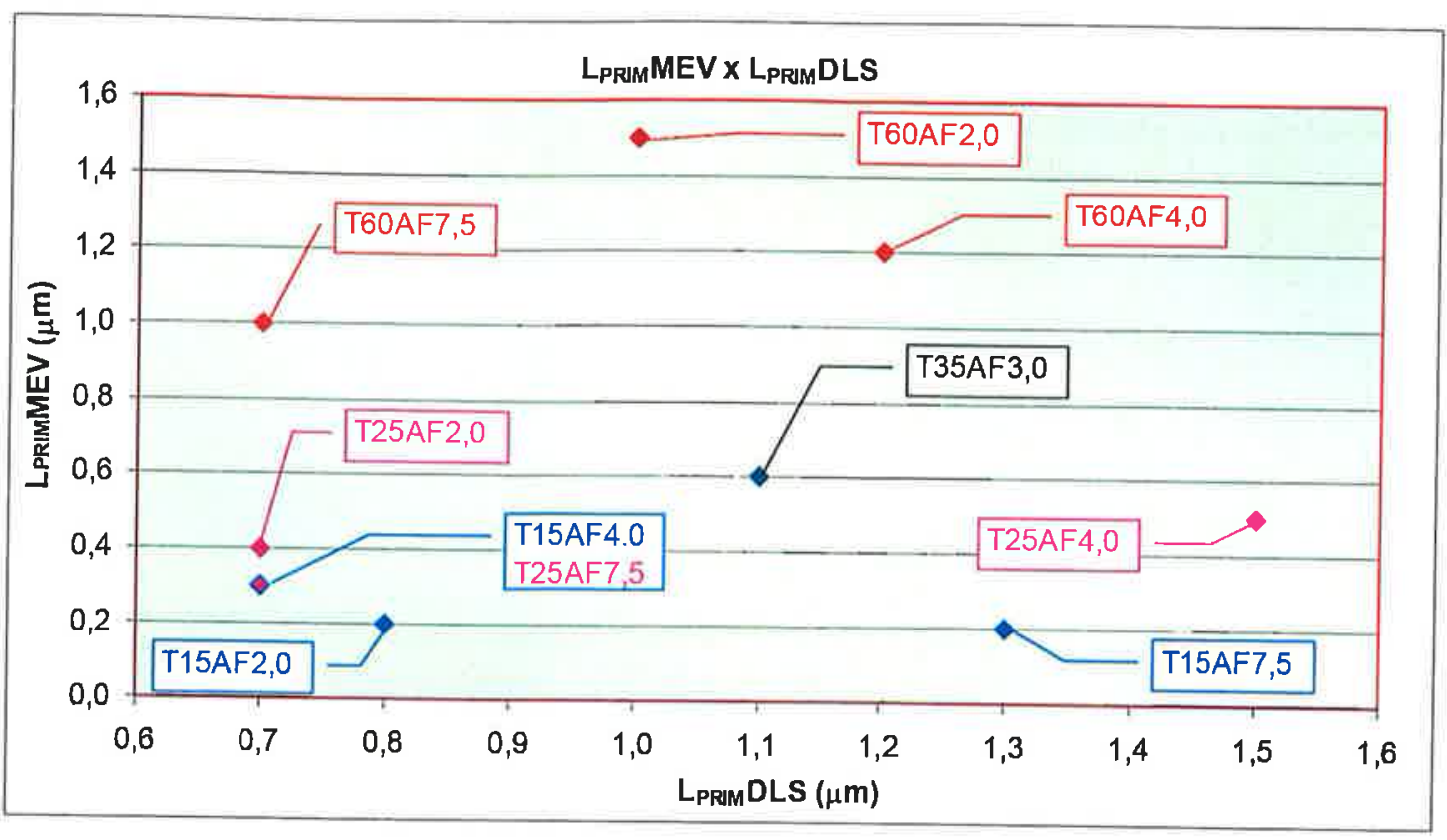

Figura 4-26. Comprimentos das partículas primárias obtidos por DLS e MEV.

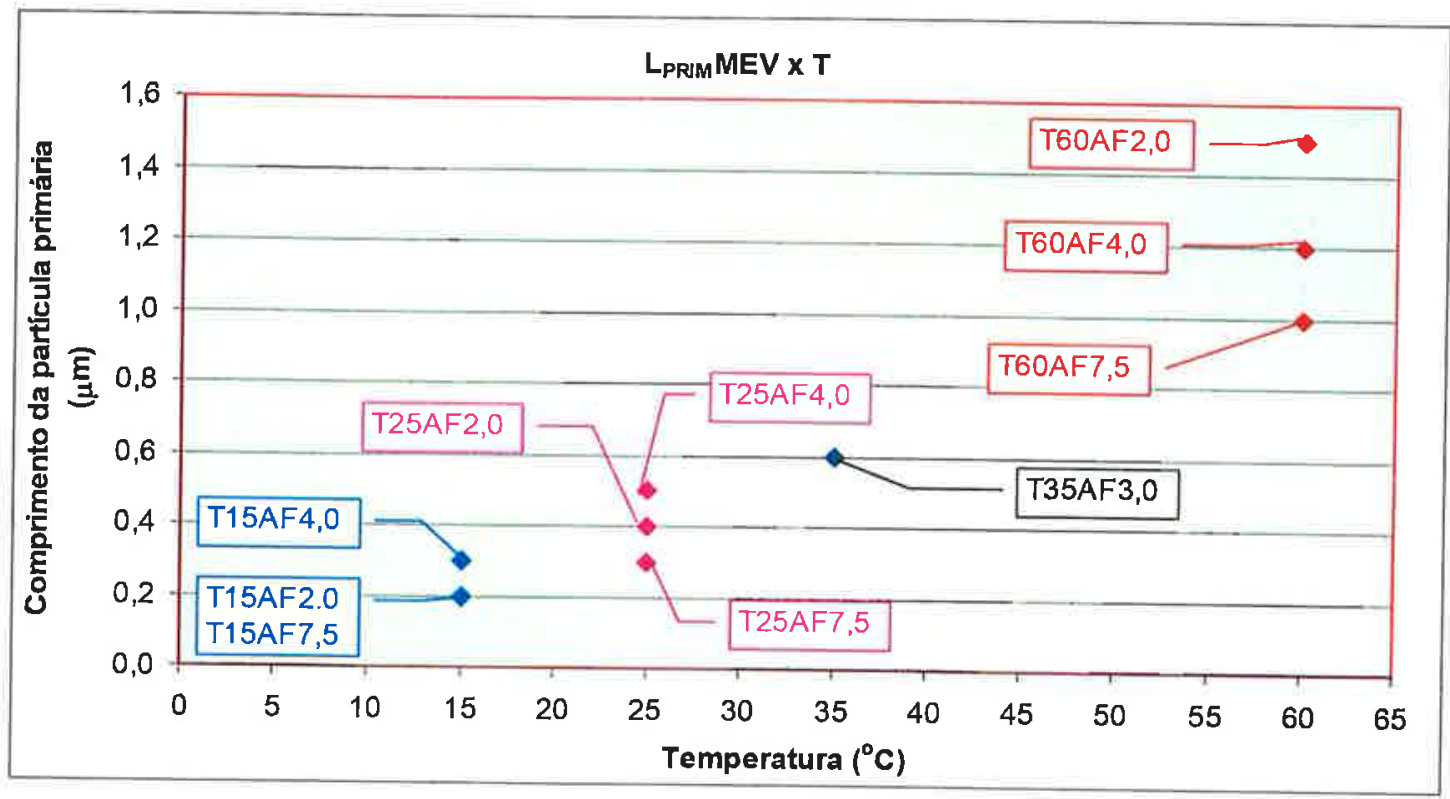

Figura 4-27. Comprimentos das partículas primárias obtidos via MEV em função das temperaturas dos ensaios. 
Tabela 4-6. Principais características dos produtos obtidos experimentalmente

\begin{tabular}{|c|c|c|c|c|c|c|c|c|}
\hline \multirow{2}{*}{ Ensaio } & \multirow{2}{*}{\begin{tabular}{|l} 
Fase \\
Cristalina
\end{tabular}} & \multirow{2}{*}{\begin{tabular}{|l} 
Aspecto \\
Particula
\end{tabular}} & \multirow{2}{*}{\begin{tabular}{|l}
$\mathrm{S}_{\mathrm{BET}}$ \\
$\left(\mathrm{m}^{2} / \mathrm{g}\right)$
\end{tabular}} & \multirow{2}{*}{$\frac{S_{\text {MEV }}}{\left(\mathrm{m}^{2} / \mathrm{g}\right)}$} & \multicolumn{2}{|c|}{ Aglomeração } & \multirow{2}{*}{$\begin{array}{l}\text { LPRIMM } \\
\text { EV } \\
(\mu \mathrm{m})\end{array}$} & \multirow{2}{*}{$\begin{array}{l}D^{\prime} S_{\text {NUM }} \\
(\mu \mathrm{m})\end{array}$} \\
\hline & & & & & Tipo & Aglomerado & & \\
\hline T35AF3,0 & $\alpha-\mathrm{FeOOH}$ & Acicular & 73 & 34 & Média & - & 0,6 & $1,1 \pm 0,3$ \\
\hline T15AF2,0 & $\alpha-\mathrm{FeOOH}$ & $\begin{array}{l}\text { Acicular / } \\
\text { Irregular }\end{array}$ & 119 & 103 & Alta & Compacto & 0,2 & $0,8 \pm 0,3$ \\
\hline T15AF4,0 & $\begin{array}{l}\alpha-\mathrm{FeOOH}+\gamma- \\
\mathrm{FeOOH}\end{array}$ & Irregular & 121 & 68 & Alta & Compacto & 0,3 & $0,7 \pm 0,2$ \\
\hline T15AF7,5 & $\begin{array}{l}\alpha-\mathrm{FeOOH}+\gamma- \\
\mathrm{FeOOH}\end{array}$ & Irregular & 160 & 103 & Alta & Compacto & 0,2 & $1,3 \pm 0,4$ \\
\hline T25AF2,0 & $\alpha-\mathrm{FeOOH}$ & Acicular & 106 & 51 & Alta & Compacto & 0,4 & $0,7 \pm 0,2$ \\
\hline T25AF4,0 & $\begin{array}{l}\alpha-\mathrm{FeOOH}+\gamma- \\
\mathrm{FeOOH}\end{array}$ & Acicular & 111 & 41 & Alta & Compacto & 0,5 & $1,5 \pm 0,5$ \\
\hline T25AF7,5 & $\begin{array}{l}\alpha-\mathrm{FeOOH}+\gamma- \\
\mathrm{FeOOH}\end{array}$ & Irregular & 121 & 68 & Alta & Compacto & 0,3 & $0,7 \pm 0,2$ \\
\hline T60AF 2,0 & $\alpha-\mathrm{FeOOH}$ & Acicular & 44 & 14 & Baixa & - & 1,5 & $1,0 \pm 0,3$ \\
\hline T60AF4,0 & $\alpha-\mathrm{FeOOH}$ & Acicular & 49 & 17 & Baixa & - & 1,2 & $1,2 \pm 0,4$ \\
\hline T60AF7,5 & $\alpha-\mathrm{FeOOH}$ & Acicular & 50 & 21 & Baixa & - & 1,0 & $0,7 \pm 0,2$ \\
\hline
\end{tabular}

\subsection{Conclusões}

O processo de formação das sementes pelo processo Penniman-Zoph foi estudado experimentalmente em escala de bancada. Foi mostrado que o comportamento do $\mathrm{pH}$ durante a oxidação é similar ao da literatura (Forsyth, et al., 1975). Esse comportamento é típico da transformação de fases férreas, passando de complexos hidroaquosos de ferro (II) e ferro (III) (Ferrugens Verdes) para compostos metaestáveis como Schwertmanita e ferridritas (Prokopenko, Lavrinenko, Mamunya, 2007), que por sua vez são precursores de fases mais estáveis (Bigham et al. 1996, Claassen et al., 2002).

O processo de cristalização e recristalização das fases férreas é notado pela diminuição do pH ao longo do tempo. A diminuição do $\mathrm{pH}$ está relacionada com o consumo dos íons $\mathrm{OH}^{-}$tanto na formação das fases precursoras quanto das fases mais estáveis. O comportamento do $\mathrm{pH}$ apresenta quatro regiões distintas. Na primeira região há uma queda gradativa do pH decorrente da formação das fases metaestáveis. A segunda região é caracterizada pela estabilidade no pH devido à liberação e consumo dos grupos $\mathrm{OH}^{-}$provenientes respectivamente da dissolução das fases precursoras e da formação de lepidocrocita e/ou goethita. Na terceira região já não há mais fases precursoras, $\mathrm{O} \mathrm{pH}$ decresce rapidamente pelo consumo dos grupos $\mathrm{OH}^{-}$necessários para a cristalização das fases mais estáveis. Na quarta região $\mathrm{opH}$ diminui mais lentamente, pois a formação residual das fases férreas estáveis praticamente cessa.

As fases finais são a goethita pura e, em alguns casos, misturas de goethita e lepidocrocita. Os espectros de Mössbauer mostram que a formação de goethita como fase única é favorecida em temperaturas mais altas $\left(35\right.$ e $\left.60^{\circ} \mathrm{C}\right)$ e com taxa de aeração menor $\left(2 \mathrm{NL} \cdot \mathrm{min}^{-1} \cdot \mathrm{L}^{-1}\right)$. A formação de 
lepidocrocita é favorecida por condições de temperatura mais baixa $\left(15{ }^{\circ} \mathrm{C}\right.$ e $\left.25^{\circ} \mathrm{C}\right)$ e maiores taxas de aeração $\left(4\right.$ e $\left.7,5 \mathrm{NL} \cdot \mathrm{min}^{-1} . \mathrm{L}^{-1}\right)$. A lepidocrocita chega a representar entre $10 \%(\mathrm{~T} 25 \mathrm{AF} 4,0) \mathrm{e}$ $39 \%(T 15 A F 7,5)$ da amostra.

As imagens MEV mostraram morfologias características da goethita e lepidocrocita. A goethita formada nesse processo tem forma acicular, partículas primárias com comprimento entre $0,2 \mathrm{a}$ $1,5 \mu \mathrm{m}$ e aglomerados de $0,2 \mu \mathrm{m}$ a alguns micrometros. Os cristais de lepidocrocita apresentam um formato achatado com tamanhos menores que 0,5 $\mu \mathrm{m}$. As imagens por MEV mostram também que o tamanho das partículas primárias decresce com a redução da temperatura. A distribuição granulométrica via DLS é monomodal e mostra partículas com tamanhos médios entre 0,7 e 1,5 $\mu \mathrm{m}$ com desvio padrão entre 0,2 e 0,5 $\mu \mathrm{m}$.

A área superficial obtida pelo método BET varia de 44 a $160 \mathrm{~m}^{2} / \mathrm{g}$. Ela é mais fortemente afetada pela temperatura do que pela taxa de oxidação. A área superficial aumenta com a redução da temperatura.

\subsection{Referências}

Babcan, J. Synthesis of Jarosite $-\mathrm{KFe}_{3}\left(\mathrm{SO}_{4}\right)_{2}(\mathrm{OH})_{6}$. Geol. Zb. v.22, p.299-304,1971.

Baptista NP, Investigação das características cristalográficas de óxidos amarelos sintéticos de ferro produzidos por nucleações primárias heterogêneas, Dissertação de Mestrado, IPT, 2010.

Belous, A. G.; Pashkova, E. V.; Elshanskii,V. A.; Ivanitskil,V. P. Effect of Precipitation Conditions on the Phase Composition, Particle Morphology and Properties of Iron(III,II) Hydroxide Precipitates. Inorganic Materials, v.36, p.343-351, 2000

Bigham, J. M.; Schwertmann, U.; Traina, S. J.; Winland, R. L.; Wolff, M. Schwertmannite and the Chemical Modeling of iron in Acid Sulfate Waters. Geochimica et Cosmochimica Acta, v.60, n.12, p. 2111-2121, 1996.

Childs, C. W.; Baker-Sherman, J. G.. New Zealand Bureau Scientific Report Lower Hutt, N.Z.,v.66, 1984.

Claassen, J.O.; Meyer, E.H.O.; Rennie, J.; Sandenbergh, R.F. Iron removal from zinc-rich process solutions: defining the Zincor Process. Hydrometallurgy v.67, p.87-108, 2002.

Cornell, R.M.; Schwertmann, U. The Iron Oxides: Structure, Properties, Reactions, Occurrence and Uses. VCH Publ., D-69451 Weinheim, Germany, 1996.

Detournay, J.; Miranda, L.; Derie, R.; Ghodsi, M. The region of stability of Green Rust in the electrochemical Potencial - pH Equilibrium Diagram of Iron in Sulphate Medium. Corrosion Science, v.15, p.295-306, 1975.

Dirksen, J.A.; Ring, T. A. Fundamentals of Crystallization: kinetic effects on particle size distribution and morphology. Chemical Engeneering. Science, v.46, p.2389-2427, 1991. 
Dousma, J.; Ottelander, D.; De Bruyn, P. L. The influence of sulphate ions on the formation of iron (III) oxides. Journal of Inorganic Nucleation Chemical , v.41, p.1565-1568, 1979

Dousma. J.; De Bruvn. P. L. Hydrolysis-Precipitation Studies of Iron Solutions: Model for Hydrolysis and Precipitation from Fe(III) Nitrate Solutions, J. Colloid and Interface Science, Vol. 56, p.527-539, 1976.

Dousma. J.; De Bruyn. P. L. Hydrolysis-Precipitation Studies of Iron Solutions: Aging Studies and the Model for Precipitation from Fe(III) Nitrate Solutions. J. Colloid and Interface Science, v.64, p.154-170, 1978.

Dousma. J.; De Bruyn. P. L. Hydrolysis-Precipitation Studies of Iron Solutions: AApplication of Growth Models to the Formation of Colloidal a-FeOOH from Acid Solutions. J. Colloid and Interface Science, v.72, p.314-320, 1979.

Flynn, Jr. C. M. Hydrolysis of Inorganic Iron( III) Salts. Chemical Review 84, p.31-41, 1984.

Forsyth, J. B.; Hedleys, I. G.; Johnson, C. E. The Magnetic Structure and Hyperfine Field of Goethite ( $\alpha-\mathrm{FeOOH}$ ), Journal Physics Society, v.1, p.179-188, 1968.

Géhin, A.; Ruby, C.; Abdelmoula, M.; Benali, O.; Ghanbaia, J.; Refait, P.; Géhin, J. M. Synthesis of $\mathrm{Fe}(I I-I I I)$ hydroxysulphate green rust by coprecipitation. Solid State Sciences, v.4, p.61-66, 2002.

Gotic, M.; Music, S. Mössbauer, FT-IR and FE SEM investigation of iron, oxides precipitated from $\mathrm{FeSO}_{4}$ solutions. Journal of Molecular Structure v.834-836, p.445-453, 2007.

Haire, N. J.; Beattie, J. K. Structure of Hexaaquairon(III) Nitrate Trihydrate: Comparison of Iron(II) and Iron(III) Bond Lengths in High-Spin Octahedral Environments. Inorganic Chemicals, v16, p.245250, 1977.

Jambor, J.L.; Dutrizac, J.E. Occurrence and Constitution of Natural and Synthetic Ferrihydrite. American Chemical Society, Chemical Review, v.98, p.2549-2585, 1998.

Kind, M. Colloidal Aspects of Precipitation Processes. Chemical Engeneering Science, v.57, p.42874293, 2002.

Loan, M.; Parkinson, G.; Newman, M.; Farrow, J. Iron Oxyhydroxide Crystallization in a Hydrometallurgical Residue. J. Cryst. Growth, v.235, p.482-488, 2001.

Matijevic, E.; Scheiner, P. Preparation of Uniform Particles by Hydrolysis of Fe(III) Chloride-Nitrate and Perchlorate Solutions, J. Colloid and Interface Science, v.63, p. 509-524, 1978.

Mineralogy Database. webmineral.com acessado em novembro de 2010. Disponível em: http://web.wt.net/daba/Mineral/

Music, S.; Orehovec, Z.; Popovic, S. Structural Properties of Precipitates Formed by Hydrolysis of $\mathrm{Fe}^{3+}$ lons in $\mathrm{Fe}_{2}\left(\mathrm{SO}_{4}\right)_{3}$ Solutions. J. Materials Science, v. 29, p.1991-1998,1994. 
Music, S.; Popovic, S.; Gotic, M. Mössbauer Spectroscopy and X-Ray Diffraction of Oxide Precipitates formed from $\mathrm{FeSO}_{4}$ Solution. J. Materials Science, v.25, p.3186-3190,1990.

Murphy, P. J.; Posner, A. M.; Quirk, J. P. Gel Filtration Chromatography of Partially Neutralized Ferric Solutions. J. Colloid and Interface Science, v.52, p.229-238, 1975.

Murphy, P. J.; Posner, A. M.; Quirk, J. P. Characterization of Hydrolysed Ferric lon Solutions a Comparison of the Effects of Various Anions on the Solutions. J. Colloid and Interface Science, v.56, p.312-319, 1976.

Murphy, P. J.; Posner, A. M.; Quirk, J. P. Characterization of Partially Neutralized Ferric Nitrate Solutions. J. Colloid and Interface Science, v.56, pag. 270-283, 1976.

Murphy, P. J.; Posner, A. M.; Quirk, J. P. Characterization of Partially Neutralized Ferric Chloride Solutions, J. Colloid and Interface Science, v.56, p.284-297, 1976.

Murphy, P. J.; Posner, A. M.; Quirk, J. P. Characterization of Partially Neutralized Ferric Perchlorate Solutions. J. Colloid and Interface Science, v.56, p.298-311, 1976.

Nývlt, J.; Hostomský, J.; Giulietti, M. Cristalização, Ed. Universidade Ferderal de São Carlos, 2001

Ou, C. C.; Wolllmann, R. G.; Hendrickson, D. N.; Potenza, J. A.; Schugar, H. J. Molecular Structure and Magnetic Properties of m-dihydroxo-bis[4-dimethylamino-2,6Pyridinedicarboxylatoaquoiron(III)]dihydrate, $\left[\left(\mathrm{CH}_{3}\right)_{2} \mathrm{NC}_{7} \mathrm{H}_{2} \mathrm{NO}_{4}\left(\mathrm{H}_{2} \mathrm{O}\right) \mathrm{FeOH}\right]_{2} \cdot 2 \mathrm{H}_{2} \mathrm{O}$. J. American Chemical Society, p.2053-2057,1978.

Penniman, R. S.; Zoph, N. M. Process of Manufacturing Iron Compounds. West Coast Kalsomine Company, US $1327061,1917$.

Penniman, R. S.; Zoph, N. M. Process of Manufacturing Iron Compounds. National Ferrite Company, US 1368 748, 1920.

Prokopenko, V. A.; Lavrinenko, E. N.; Mamunya, S. V. Phase Formation in $\mathrm{Fe}^{0}-\mathrm{H}_{2} \mathrm{O}-\mathrm{O}_{2}$. System in the Presence of Iron Cations: $\mathrm{Fe}^{0}-\mathrm{H}_{2} \mathrm{O}-\mathrm{O}_{2}-\mathrm{Fe}_{2}\left(\mathrm{SO}_{4}\right)_{3}$ System. Colloid Journal, v.69, p.82-88, 2007.

Ristic, M.; Music, S.; Godec, M. Properties of $\alpha-\mathrm{FeOOH}, \gamma-\mathrm{FeOOH}$ and $\mathrm{Fe}_{2} \mathrm{O}_{3}$ Particles Precipitated by Hydrolysis of $\mathrm{Fe}^{3+}$ ions in Perchlorate Containing Aqueous Solutions. Journal Alloys and Compound, p.292-299, 2006.

Schwertmann, U.; Fechter, H. The Formation of Green Rusts and its Transformation to Lepedocrocite. Clay Minerals, v. 29, p.87-92, 1994

Söhnel, O.; Garside, J. Precipitation: Basic Principles and Industrial Applications. ButterworthHeinemann Ltd.,1992.

Thich, J. A.; Ou, C. C.; Powers, D.; Vasiliou, B.; Mastropaolo, D.; Potenza, J. A.; Schugar, H. J. Magnetic Properties of $\mathrm{K}_{5}\left[\left(\mathrm{H}_{2} \mathrm{O}\right)_{3}\left(\mathrm{SO}_{4}\right)_{6} \mathrm{Fe}_{3} \mathrm{O}\right] .6 \mathrm{H}_{2} \mathrm{O}$, a Sulfate Analog of the Trimeric Basic Iron(III) Carboxylates. J. American Chemical Society, v.20, p.3314-3317, 1976. 
Ullmann's Encyclopedia. Industrial Inorganic Chemicals and Products. Willey- CH: Weinheim, 1998.

Von Gunten, U.; Schneider, W. Primary Products of the Oxygenation of Iron(I I) at an Oxic-Anoxic Boundary: Nucleation, Aggregation, and Aging. Journal of Colloid and Interface Science, v.145, p.127-139, 1991.

Will, Raymond. Global Markets for Iron Oxide Pigments-Construction market update, in Proceedings of Iron Oxides for Colorant and Chemical Applications, 2006. 


\section{QUALIDADE DA SUSPENSÃO EM TANQUES AGITADOS ${ }^{9}$}

\subsection{Introdução}

Durante a cristalização a partir de soluções, uma solução supersaturada transfere um ou mais componentes dissolvidos para a fase sólida. O processo pressupõe, portanto, o contato entre as fases líquida e sólida. Por isso, a cristalização é freqüentemente conduzida industrialmente em tanques agitados, os quais homogeinizam o líquido e o material particulado e promovem um contato íntimo entre as partículas sendo formadas e a solução. No entanto, uma homogeneização completa é raramente atingida, tanto no que diz respeito à fase líquida quanto à fase sólida. No segundo caso, persistem regiões com distintos teores de sólidos, o que traz diversas conseqüências para o processo de cristalização: (i) regiões pobres em sólidos tendem a ficar mais supersaturadas, o que propicia nucleação primária indesejável; (ii) regiões ricas em sólidos propiciam nucleação secundária excessiva; (iii) regiões estagnadas estimulam a deposição das partículas, que, ao crescer, passam a constituir um depósito contínuo ou incrustação no reator.

Pelo acima, o projeto de cristalizadores constituídos por tanques agitados deve garantir que os sólidos estejam uniformemente distribuídos no interior do tanque. No entanto, o projeto de tanques agitados é comumente baseado apenas no critério de suspensão mínima, condição suficiente para evitar que os sólidos se depositem no fundo do tanque, mas que não garante homogeneidade. Os estudos existentes ainda não são suficientes para garantir a homogeneidade em tanques agitados em escala real.

Duas situações limite podem ser empregadas para caracterizar a distribuição de partículas sólidas dispersas num líquido: suspensão mínima e suspensão homogênea. A primeira ocorre quando as partículas sólidas estão em movimento e nenhuma partícula permanece mais que um ou dois segundos no fundo do tanque. A segunda é caracterizada por uma distribuição espacial uniforme das partículas sólidas no tanque. Na prática, sistemas de agitação trabalham entre estes dois limites, numa condição que chamaremos aqui de suspensão completa.

A condição limite de suspensão minima é bem documentada. $\mathrm{Na}$ abordagem mais comum determina-se a rotação mínima do impelidor necessária para promover a suspensão mínima $\left(N_{j s}\right)$. Zwietering (1958) propôs a seguinte correlação empírica para $\mathrm{N}_{\jmath s}$ :

$\mathrm{NJS}=\frac{S v^{0,1} \mathrm{~d}_{\mathrm{p}}^{0,2}\left(\mathrm{~g} \frac{\Delta \rho}{\rho_{\mathrm{L}}}\right)^{0,45} X^{0,13}}{\mathrm{D}^{0,85}}$

\footnotetext{
${ }^{9}$ Publicado como Cekinski E, Giulietti M, Seckler MM. A new approach to characterize suspensions in stirred vessels based on computational fluid dynamics. Brazilian Journal of Chemical Engineering, Vol. 27, No. 02, pp. 265 - 273, April - June, 2010.
} 
Mais recentemente, correlações melhores foram propostas, as quais combinam evidencia experimental com várias teorias para a condição de suspensão mínima (Musil and Vlk, 1978; Wichterle, 1988; Rieger and Ditl, 1994; Rieger, 2000; Murugesan, 2001; Rieger, 2002).

Para suspensão completa, ainda não se dispõe de uma correlação similar à equação (5-1) e que seja válida para diversas propriedades de suspensão e para diversas geometrias de tanque e impelidores. Apesar disso, muitos progressos têm sido feitos no entendimento da distribuição de sólidos em tanques agitados. Está bem estabelecido que estudos de fluidodinâmica computacional (CFD) provêem uma descrição razoavelmente boa da suspensão completa, uma vez que um coeficiente de arraste adequado seja empregado. Por exemplo, foi demonstrado que modelos de arraste baseados na fração volumétrica de sólidos são melhores que aqueles baseados no número de Reynolds (Ochieng and Onyango, 2008). Tais modelos são quase sempre baseados no referencial Euler/Euler com 0 modelo k- $\varepsilon$ de turbulência (Spidla et al., 2005; Tamburini et al., 2009), mas a abordagem Euler/Lagrange respectivamente para o líquido e o sólido também foi reportada (Srinivasa and Jayanti, 2007). Modelos são geralmente em três dimensões, mas quando a geometria do tanque permite, modelos com duas dimensões podem ser usados (Khopkar et al., 2006). Em alguns casos, distribuições de sólidos calculadas por CFD são usadas como base para modelar outros processos como mistura (Ranade, 2009) e cristalização (Kougoulos et al., 2005; Woo et al., 2006) ou para derivar um projeto ótimo do impelidor (Spogis and Nunhez, 2009). Técnicas avançadas de CFD tais como simulações de grandes turbilhões (do inglês "large eddy simulation", LES) e simulações numéricas diretas também tem sido exploradas para descrever a mistura turbulenta em tanques agitados, de forma a entender os detalhes dos processos locais e as condições de escoamento transientes (Van den Akker, 2006). Recentemente, num estudo experimental detalhado usando partículas traçadoras radioativas, foram mostradas tanto as possibilidades quanto as limitações das abordagens Euler/Euler e LES para um tanque provido de turbina tipo Rushton com 6 pás (Guha et al., 2008).

Uma vez que a técnica de CFD permite uma descrição razoavelmente boa da distribuição de sólidos em tanques agitados, é razoável supor que ela possa ser aplicada para o projeto ou ampliação de escala com respeito ao grau de homogeneidade desejado para a suspensão. Nestes casos, novas simulações devem ser aplicadas para cada aplicação, de forma a determinar a rotação do impelidor que fornece a distribuição espacial de sólidos especificada para uma dada geometria de tanque e agitador. A desvantagem deste método é que o procedimento é exaustivo. Além disso, ele é pouco prático quando se procura pela geometria ótima para uma dada tarefa. Por isso, CFD tem sido usado em combinação com argumentos teóricos ou com evidencias empíricas, de forma a encontrar tendências de significado genérico. Por exemplo, o critério de ampliação de escala "ND ${ }^{0,93}=$ constante", derivado de uma teoria de intermitência da turbulência, foi proposto para preservar a distribuição vertical de sólidos (Montante et al., 2008) em tanques com alta razão de aspecto providos com impelidores múltiplos. Em outra contribuição, uma correlação empírica para a "altura da nuvem sólida" em tanques providos com chicanas e um agitador do tipo "hydrofoil propeller" foi sugerida com base em simulações por CFD e por experimentos (Ochieng and Lewis, 2006). Já num tanque provido de turbinas com pás inclinadas, foi sugerido que uma altura da suspensão média de $90 \%$ do nível do líquido garante uma distribuição vertical uniforme dos sólidos no interior da nuvem (Angst and Kraume, 2006). 
No presente trabalho, CFD foi empregada para descrever a suspensão de partículas em água. A distribuição espacial de sólidos foi caracterizada por um parâmetro único, chamado aqui de qualidade da suspensão. Com base em simulações para partículas de diferentes densidades e tamanhos em tanques de diversas geometrias e escalas, uma correlação semi-empírica foi desenvolvida para prever a qualidade da suspensão. Uma vez que a literatura é rica em estudos com agitadores com pás inclinadas de $45^{\circ}$ e com turbinas do tipo Rushton, impelidores de pás planas foram estudados. Estes impelidores são comumente encontrados quando se pretende promover a suspensão dos sólidos e também uma alta taxa de cisalhamento, como em sistemas de cristalização com reação química, dispersão de partículas e desagregação. A correlação proposta foi validada com dados experimentais da literatura (Bohnet and Niesmak, 1980).

\subsection{Procedimento}

O sistema de interesse é constituído por tanques sólido-líquido agitados em regime permanente e escoamento turbulento. A fase líquida é água e a fase sólida são partículas de tamanho e densidade uniformes. A fração volumétrica dos sólidos é de 5 vol\%. Os tamanhos de partículas são $10,50,100$ ou $500 \mu \mathrm{m}$. As densidades das partículas são $1375 \mathrm{~kg} / \mathrm{m}^{3}$ ou $2650 \mathrm{~kg} / \mathrm{m}^{3}$, representando respectivamente uma resina polimérica e areia.

$O$ tanque é cilíndrico é vertical com as dimensões mostradas na Figura 5-1. Ele contém 4 chicanas espaçadas de $90^{\circ}$. Ele contém também um agitador posicionado no seu eixo de simetria, que consiste de um impelidor plano de 2 pás. A largura das pás e também das chicanas correspondem a $10 \%$ do volume do tanque. A altura do líquido é igual ao diâmetro do tanque. Dois diâmetros de tanque são considerados, $1 \mathrm{~m}$ e $5 \mathrm{~m}$. As rotações do impelidor são 20,34 , 45 e $100 \mathrm{rpm}$. As relações $D / T$ e $C / T$ investigadas têm valores de $1 / 4,1 / 3$ e 1/2.

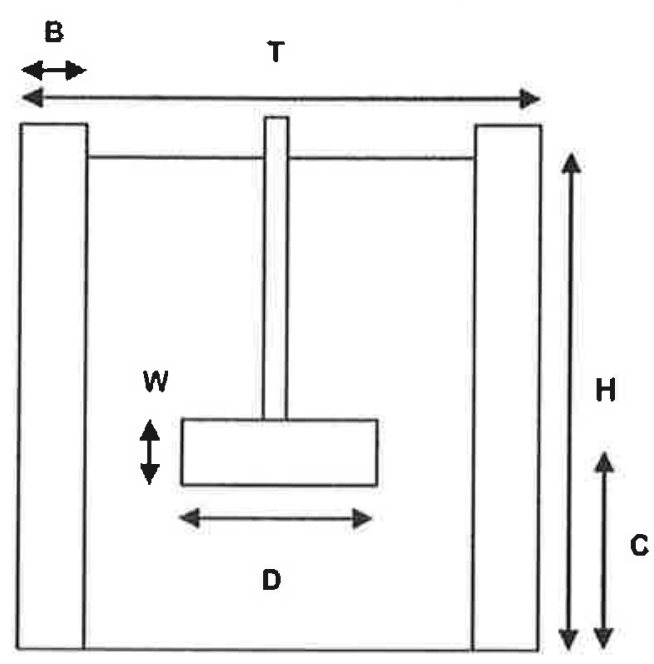

Figura 5-1. Dimensões principais do tanque agitado.

Os cálculos foram realizados com o software Fluent versão 4.5 em combinação com Mixim versão 1.7. Partículas foram tratadas como uma fase única, tendo sido considerada tanto forças de cisalhamento das partículas entre si quanto entre partículas e o fluido. A superfície do líquido foi 
considerada plana. Foi empregado o modelo $k-\varepsilon$ de turbulência. Os perfis de velocidade do fluido adjacentes ao impelidor foram obtidos a partir de simulações em três dimensões para sistema monofásico (não mostradas). Simulações em duas dimensões foram realizadas devido a limitações no tempo necessário para os cálculos. Para as simulações em 3D no tanque com $1 \mathrm{~m}$ de diâmetro foram usadas 80.000 células computacionais. Independência de malha foi verificada repetindo-se as simulações com 220.000 células. Para as simulações em 3D com o tanque de $5 \mathrm{~m}$ de diâmetro, o numero de células foi de 400.000 . As simulações 2D nos tanques de $1 \mathrm{~m}$ e $5 \mathrm{~m}$ foram realizadas, respectivamente, com 2.000 e 5.000 células computacionais. Os resultados de simulação incluíram a distribuição espacial média no tempo da concentração de sólidos, da dissipação energética e das velocidades da fase líquida e sólida (não mostradas).

\subsection{Caracterização da qualidade da suspensão}

Propõe-se avaliar o grau de homogeneidade da suspensão a partir da relação entre o desvio padrão e a média da fração volumétrica de partículas, definida pela equação:

$$
\sigma=\sqrt{\frac{1}{n} \sum_{1}^{n}\left(\frac{c}{c_{M}}-1\right)^{2}}
$$

A variável $\sigma$ é chamada aqui de qualidade da suspensão. Para uma distribuição de partículas perfeitamente homogênea no tanque, as concentrações local e média, $c$ e $c_{M}$, são idênticas em qualquer posição, de modo que a equação acima fornece o valor zero para $\sigma$. No entanto, uma suspensão verdadeiramente homogênea nunca acontece, então um valor 0,25 para sigma é convenientemente escolhido para descrever partículas uniformemente distribuídas em situações de interesse prático (se uma aplicação especifica o demandar, outros valores de $\sigma$ podem ser escolhidos). À medida que a mistura se torna mais pobre, $\sigma$ aumenta até que se inicie a sedimentação de sólidos no fundo do tanque. Nas simulações, sedimentação é facilmente identificada como uma região bem definida no fundo do tanque na qual o teor de sólidos é de cerca de 40 vol\% (com unidade de volume de sólidos por volume de suspensão), o qual é um valor característico de leitos de partículas em repouso. Considerou-se que a sedimentação não é desprezível se mais que 2 vol\% do sólido sedimentam. Na maior parte das simulações, esta condição ocorria quando $\sigma$ valia 0,8 ou mais. Portanto, o valor de 0,8 foi considerado como característico da situação de suspensão mínima. Suspensão completa ocorre, portanto para $0,25<$ $\sigma<0,8$. A Tabela 5-1 resume estas escolhas. Outra definição de qualidade da suspensão, muito similar à definição apresentada, foi proposta recentemente (Kasat et al., 2008).

Tabela 5-1. Caracterização da qualidade da suspensão em termos do parâmetro $\sigma$.

\begin{tabular}{|l|l|}
\hline$\sigma$ & Qualidade da suspensão \\
\hline$>0,8$ & Parte do sólido deposita-se no fundo do tanque \\
\hline$=0,8$ & Suspensão mínima \\
\hline $0,25-0,8$ & Suspensão completa \\
\hline$<0,25$ & Suspensão homogênea \\
\hline
\end{tabular}


Para ilustrar como os valores de $\sigma$ escolhidos se traduzem em distribuição espacial de partículas, duas simulações com um teor de sólidos médio de 5 vol\% são mostradas na Figura 5-2. A seção direita da figura mostra os teores de sólido locais para $\sigma$ próximo ao valor limite de 0,25 . Em cerca de $95 \%$ do volume do tanque os teores de sólido locais são próximos ao valor médio de 5 vol\%, enquanto nos restantes 5 vol\% o teor de sólidos é muito pequeno. A seção da esquerda da figura mostra a distribuição de teores de sólido quando o valor de $\sigma$ é cerca de 0,8 . Neste caso apenas uma pequena fração do volume do tanque apresenta teores de sólidos em torno do valor desejado de 5 vol\%. Numa simulação na qual a mistura foi extremamente pobre (não mostrada), na qual a maior parte das partículas se depositou no fundo, resultou um valor de $\sigma$ de 2,8 .

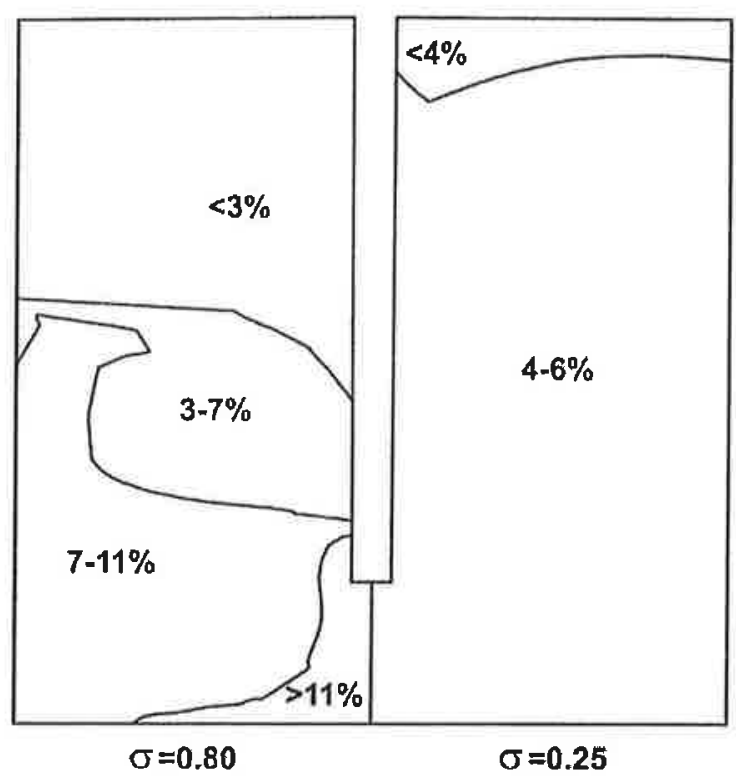

Figura 5-2. Distribuição espacial de teor de sólidos, em unidades de fração volumétrica, em tanques agitados para dois casos, um com qualidade de suspensão 0,8 (esquerda) e outro 0,25 (direita). Nos dois casos, o teor de sólidos médio no tanque é de $5 \%$.

Neste trabalho, o grau de homogeneidade em cada simulação fol avaliado com base na qualidade da suspensão $\sigma$ como definida acima. No total, 94 simulações foram efetuadas.

\subsection{Resultados e discussão}

\subsubsection{Tamanho da Partícula}

A Figura 5-3 mostra a qualidade da suspensão $\sigma$ como função do tamanho de partícula para diversas geometrias do tanque. Como esperado, a homogeneidade da suspensão decresce (isto é, $\sigma$ aumenta) com o tamanho da partícula, devido ao aumento da ação da gravidade com o tamanho. Nota-se também que a geometria do tanque (D/T e $C / T$ ) tem um papel importante sobre a qualidade da suspensão. A geometria torna-se irrelevante apenas para partículas extremamente pequenas, quando o misturador está superdimensionado. 

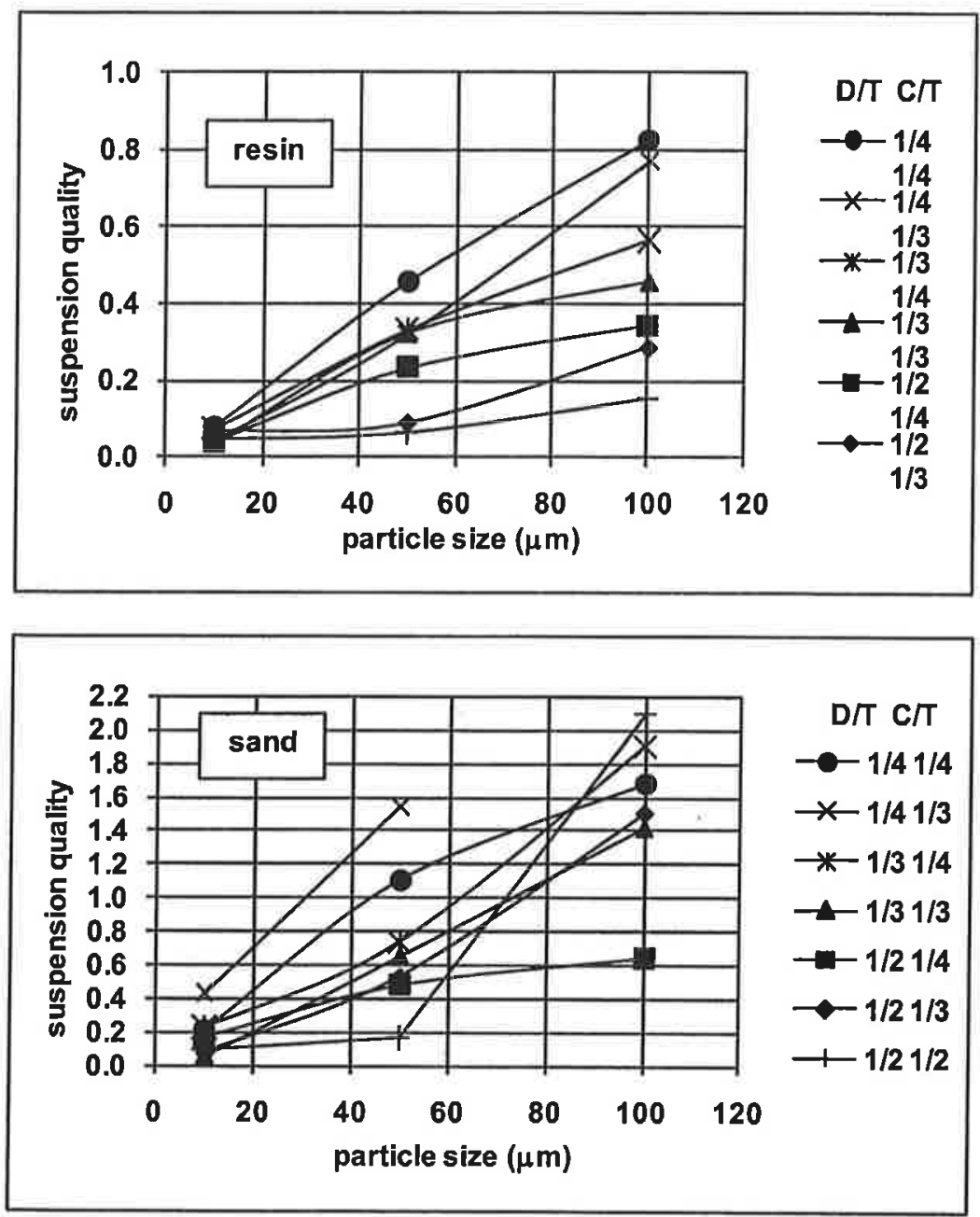

Figura 5-3. Qualidade da suspensão em função do tamanho da partícula para simulações com resina (figura superior) e com areia (inferior). Diâmetro do tanque $T=1 \mathrm{~m}$ e rotação do agitador $\mathbf{N}=100 \mathrm{rpm}$.

\subsubsection{DIÂMETRO DO IMPELIDOR}

As melhores qualidades de suspensão (menores valores de $\sigma$ ) foram obtidas, tanto para areia quanto para resina, com os impelidores de maiores diâmetros, como mostrado na Figura 5-4. Este resultado pode ser atribuído à forte dependência de $\mathrm{D} / \mathrm{T}$ sobre a potência dissipada pelo agitador. 

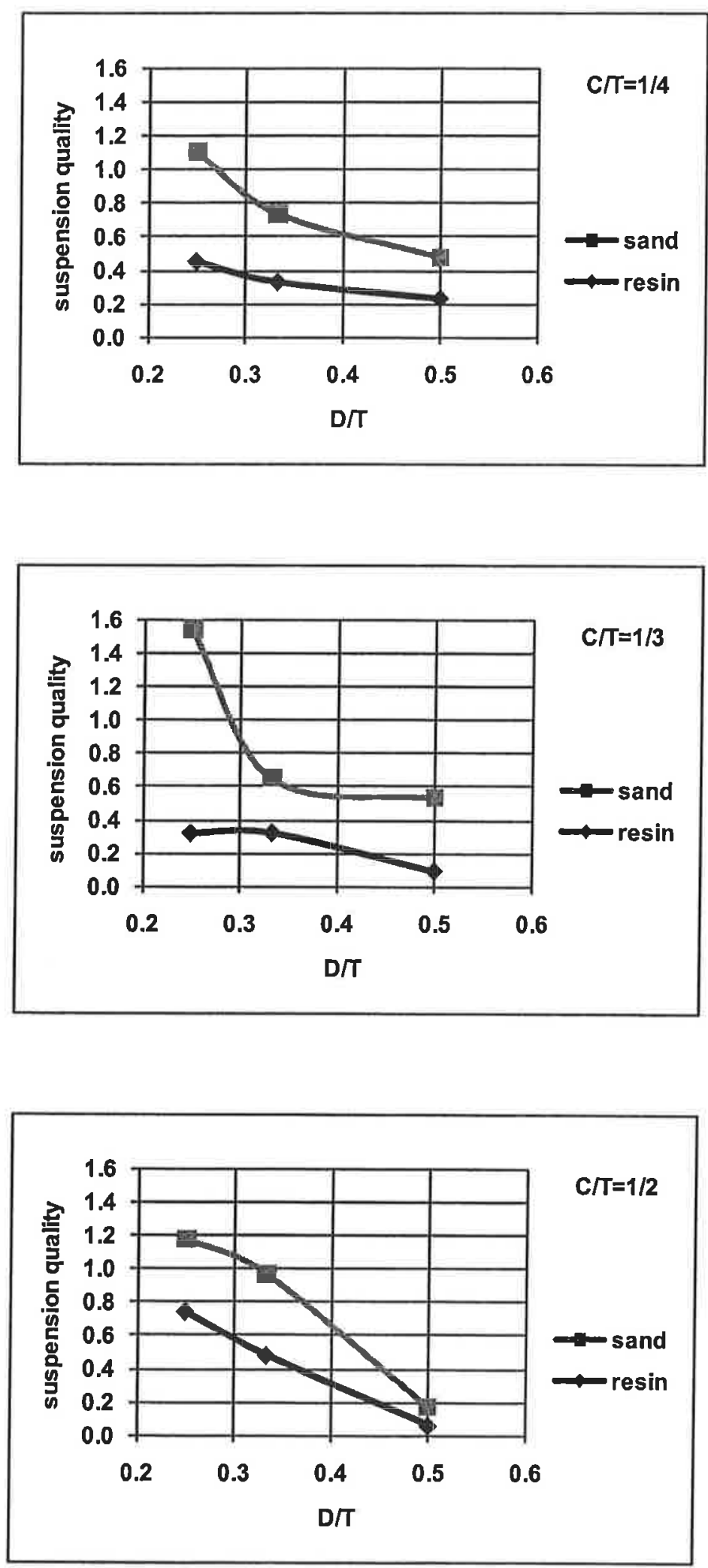

Figura 5-4. Influência do diâmetro do impelidor adimensional (D/T) e da sua distância ao fundo do tanque (C) sobre a qualidade da suspensão. Diâmetro da partícula $\mathrm{dp}=\mathbf{5 0} \mu \mathrm{m}$, diâmetro do tanque $\mathrm{T}=1 \mathrm{~m}$ e rotaçāo $\mathrm{N}=100 \mathrm{rpm}$. 


\subsubsection{DISTÂNCIA ENTRE O IMPELIDOR E O FUNDO DO TANQUE}

A Figura 5-4 mostra como $C / T$ afeta a qualidade da suspensão. Para pequenos valores de $D / T(1 / 3$ e 1/4), posicionar o impelidor junto ao fundo do tanque geralmente resulta numa melhor mistura. Se $D / T$ é grande, entretanto, o impelidor a meia altura é preferível. Isto pode ser explicado em termos da distribuição espacial da dissipação de energia em torno do tanque. No primeiro caso ( $D / T$ 1/3 e $1 / 4)$, a energia dissipada é relativamente baixa, logo a gravidade age sobre as partículas no sentido de trazê-las para a parte inferior do tanque. Portanto, colocar o agitador nesta região (C/T $1 / 3$ ou 1/4) é o mais efetivo para dispersar as partículas. Por outro lado, se a dissipação de energia é suficientemente elevada ( $D / T$ 1/2), a ação da gravidade torna-se menos importante, de modo que o agitador posicionado no centro do tanque $(C / T 1 / 2)$ é suficiente para suspender as partículas. Uma vez que esta configuração oferece a distribuição de dissipação de energia mais uniforme (ver Figura 5-5), ela também oferece o menor valor de $\sigma$.
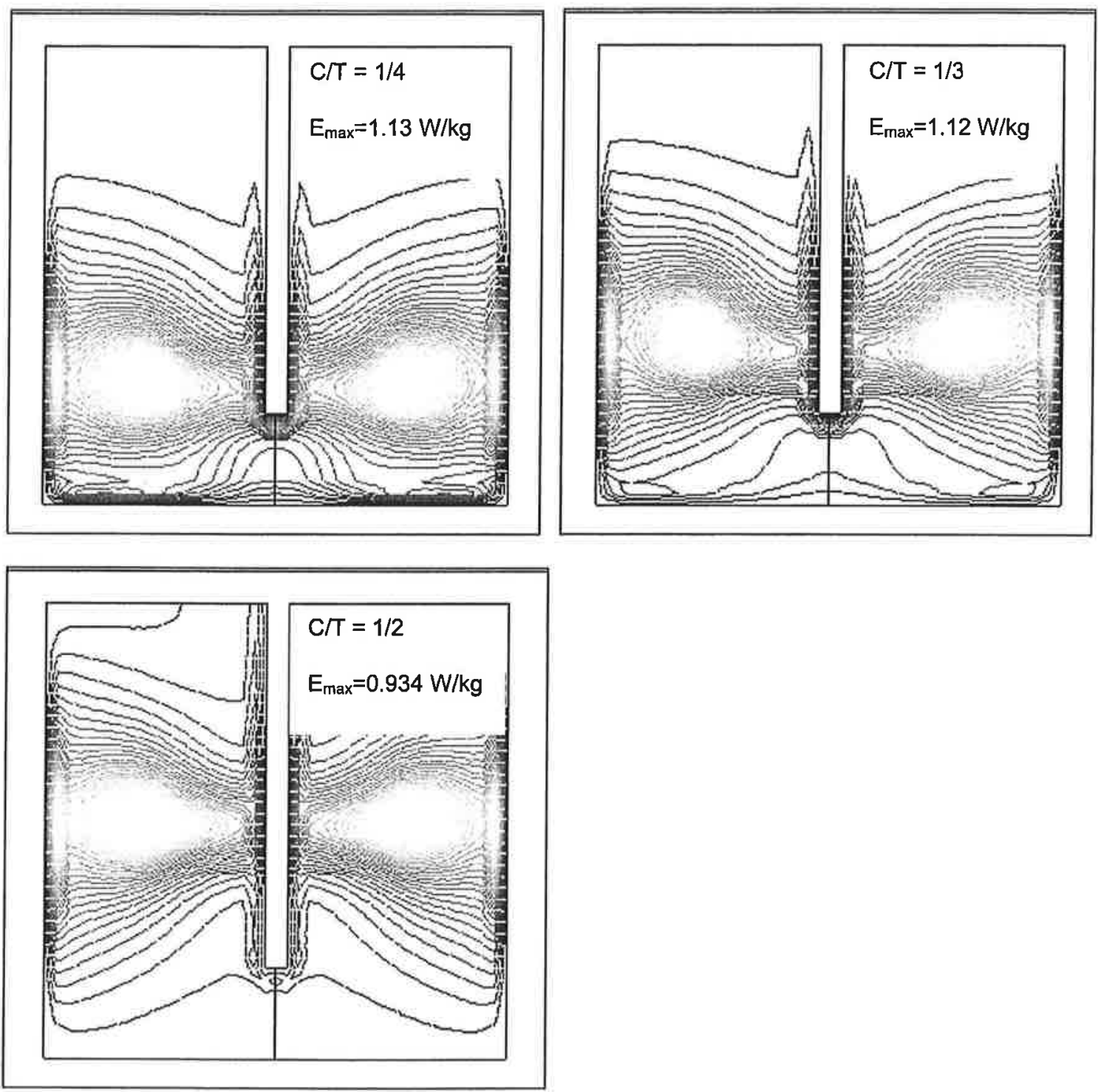

Figura 5-5. Distribuição espacial de energia dissipada (E) no fluido para três valores de $C / T$, para $D / T=1 / 2, T=1 \mathrm{~m}$. Linhas mais claras indicam valores superiores de $E$. $O$ valor máximo de $E$, Emax, e o valor de C/T são indicados no canto superior direito da figura. 


\subsection{Um modelo matemático para a suspensão de partículas}

Procura-se desenvolver um modelo matemático baseado em parâmetros adimensionais que correlacione os valores simulados de $\sigma$ com as condições de mistura e com as propriedades dos sólidos e dos fluidos. Alguns parâmetros adimensionais possiveis para esta correlação são inspirados em trabalhos anteriores sobre teorias para tanques agitados na condição de suspensão minima (Musil and Vlk, 1978; Wichterle, 1988; Rieger and Ditl, 1994; Rieger, 2000; Murugesan, 2001; Rieger, 2002). Estas teorias freqüentemente prevêem que a suspensão de partículas depende de certos números adimensionais, tais como os números de Froude ( $\left.F r^{\prime}\right)$, Froude modificado ( $\mathrm{Fr}^{*}$ ), Arquimedes (Ar), Reynolds (Re), Reynolds para a partícula, além de outras relações adimensionais tais como $d_{p} / T, D / d_{p}, C^{2} / T^{3}, \rho / \Delta \rho, D / T$ e o teor de sólidos, com as seguintes definições:

$$
\begin{aligned}
& \operatorname{Fr}^{\prime}=\left(N^{2} D / g\right) \cdot\left(\rho_{L} / \Delta \rho\right) \\
& \operatorname{Fr}^{*}=F^{\prime} \cdot\left(\frac{D}{d_{p}}\right) \\
& \operatorname{Re}=N \cdot D^{2} \cdot \rho_{L} / \mu_{L} \\
& \operatorname{Ar}=d_{p}^{3} \cdot g \rho_{L} \Delta \rho / \mu_{L}^{2}
\end{aligned}
$$

Foi considerada uma estrutura matemática simples para o modelo, com a seguinte forma geral:

$$
\sigma=a_{0} \cdot \pi_{1}^{a_{1}} \cdot \pi_{2}^{a_{2}} \cdot \ldots
$$

Onde $\pi_{1}, \pi_{2}, \ldots$ são variáveis adimensionais e $a_{0}, a_{1}, \ldots$ são parâmetros que minimizam a diferença entre valores da qualidade de suspensão obtidos com o modelo $\left(\sigma_{\text {calc }}\right)$ e valores determinados por simulações com CFD $\left(\sigma_{\text {sim }}\right)$. Minimização foi alcançada por linearização logarítmica da equação acima seguida de regressão multilinear.

Diversas combinações de variáveis adimensionais foram investigadas. Uma correlação adequada foi selecionada com base em três critérios. Primeiro, o modelo deve se ajustar bem aos resultados previstos pelas simulações de CFD. Em segundo lugar, os parâmetros do modelo devem ser consistentes com o fenômeno físico sendo descrito (por exemplo, um modelo que prevê melhores qualidades de suspensão com partículas mais densas seria rejeitado). Em terceiro, o modelo deve ser simples, isto é, números adimensionais excessivos ou redundantes são evitados. Uma correlação que preenche estes três requisitos é a seguinte:

$$
\sigma=a_{0} \cdot \operatorname{Fr}^{\prime-0,446} \cdot \operatorname{Ar}^{0,132} \cdot\left(d_{p} / T\right)^{0,382}
$$

Com $a_{0}=6.127 .0$ coeficiente de correlação ( $R$ múltiplo) para a correlação linearizada com o logaritmo natural é de 0,81 , considerando-se 94 simulações por CFD. Valores da qualidade da suspensão determinados com esta correlação $\left(\sigma_{\text {calc }}\right)$ em função de nossos dados de simulação 
$\left(\sigma_{\text {sim }}\right)$ são mostrados na Figura 5-6. A linha pontilhada fornece a condição $\sigma_{\text {sim }}=\sigma_{\text {calc }}$. A correlação prevê razoavelmente bem a qualidade da suspensão para toda a faixa de condições investigada.

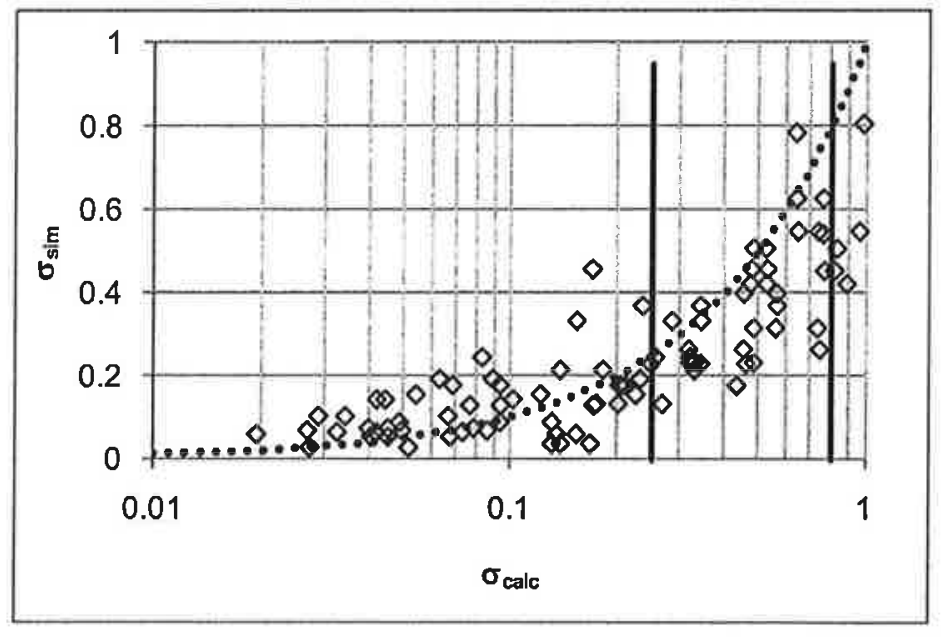

Figura 5-6. Qualidade da suspensão obtida por simulações de CFD $\left(\sigma_{\text {sim }}\right)$ contra valores calculados com a correlação (5-5) $\left(\sigma_{\text {calc }}\right)$. A linha pontilhada representa $\sigma_{\text {sim }}=\sigma_{\text {calc. }}$. As linhas verticais indicam os limites para suspensão completa $\left(0,25<\sigma_{\text {calc }}<0,80\right)$ e para suspensão homogênea $\left(0<\sigma_{c a l c}<0,25\right)$.

\subsection{Validação do modelo com dados experimentais}

Até aqui foi mostrado como a modelagem por CFD pode ser aplicada para apoiar o desenvolvimento de uma correlação que descreve a suspensão de partículas para uma ampla faixa de condições. Para validar este procedimento, a correlação proposta foi aplicada a dados experimentais em escala de laboratório obtidos da literatura (Bohnet and Niesmak, 1980).

Como os dados experimentais foram realizados em condições distintas, particularmente quanto ao tipo de impelidor, tamanho e densidade das partículas (Tabela 5-2), o modelo foi adaptado ajustando-se o termo pré-exponencial $a_{0}$ da equação (5-5) para o valor 1.102 , e mantendo os mesmos valores para os demais parâmetros e potências. Um bom ajuste foi obtido, conforme mostra a Figura 5-7, mostrando a generalidade do modelo proposto.

Tabela 5-2. Faixa de validade das correlações desenvolvidas por CFD neste trabalho e dos dados experimentais de Buurman (1986).

\begin{tabular}{|l|l|l|l|}
\hline Variável & Unidades & Este trabalho & Buurman, 1986 \\
\hline Impelidor & & Pás planas & 4 pás inclinadas \\
$\mathrm{N}$ & $1 /$ min & $20-100$ & $60-1000$ \\
$\mathrm{~T}$ & $\mathrm{M}$ & $1-5$ & 0,39 \\
$\mathrm{D} / \mathrm{C}$ & - & $1 / 2-1 / 4$ & $1 / 3$ \\
$\mathrm{C} / \mathrm{T}$ & - & $1 / 2-1 / 4$ & 0,17 \\
$\mathrm{H} / \mathrm{T}$ & - & 1 & 1 \\
$\mathrm{~d}_{\mathrm{p}}$ & $\mu \mathrm{m}$ & $10-500$ & $70-1150$ \\
$\rho_{\text {solid }}$ & $\mathrm{kg} / \mathrm{m}^{3}$ & $1375-2750$ & $1050-8850$ \\
$\rho_{L}$ & $\mathrm{~kg} / \mathrm{m}^{3}$ & 1000 & 1000 \\
$\mathrm{C}$ & vol\% & $5 \%$ & $5 \%$ \\
\hline
\end{tabular}




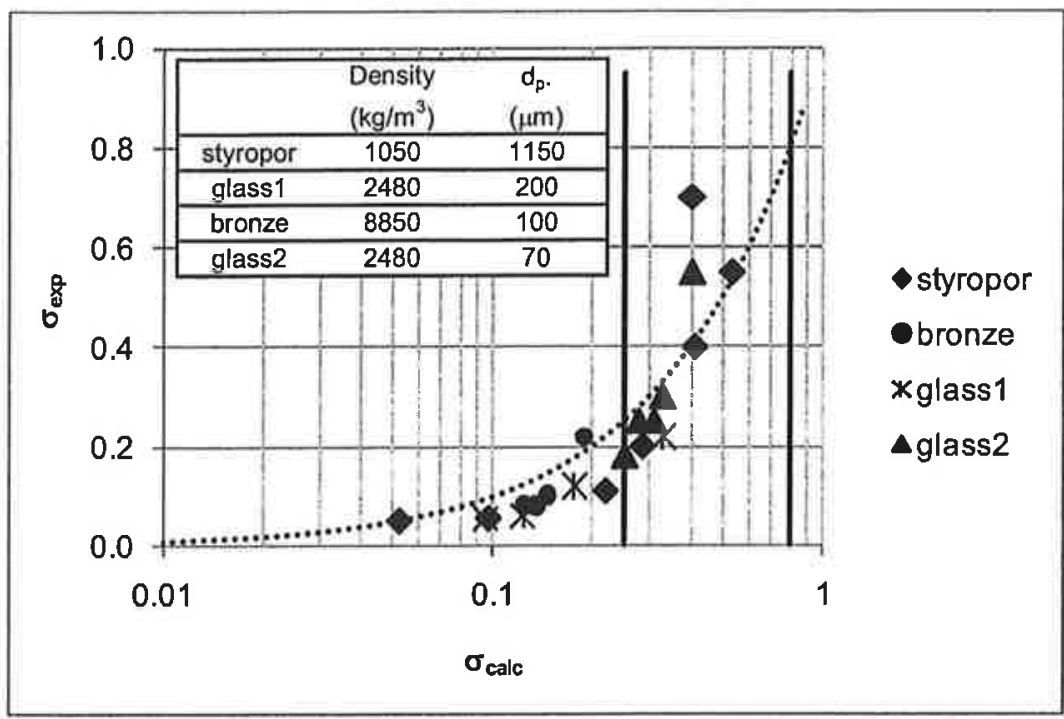

Figura 5-7. Qualidade da suspensão obtida experimentalmente por Bohnet e Niesmak (1980) contra valores calculados com a correlaçăo (5-5) e $a_{0}=1.102$. As linhas verticais indicam os limites para suspensão completa $\left(0,25<\sigma_{\text {calc }}<0,80\right)$ e para suspensão homogênea $(0<$ $\sigma_{\text {calc }}<0,25$ ).

\subsection{Projeto de misturadores sólido-líquido com base na qualidade da suspensão.}

A equação (5-5) pode ser rearranjada para um formato mais adequado para o projetista de processos. Isolando-se $\mathrm{Fr}^{\circ}$ se obtém:

$\mathrm{Fr}^{\prime}=\mathrm{a}_{0}^{\prime} \cdot \sigma^{-0,446} \cdot \operatorname{Ar}^{0,296} \cdot\left(\mathrm{d}_{\mathrm{p}} / \mathrm{T}\right)^{0,856}$

Com $a_{0}^{\prime}=2,244$ para impelidor de pás planas e $a_{0}{ }_{0}=1,044$ para turbina de pás inclinadas. Para uma dada geometria de tanque, propriedades da partícula e do fluido, o valor apropriado da qualidade da suspensão $\sigma$ pode ser obtido, dependendo de se desejar suspensão homogênea ( $\sigma=$ $0,25)$ ou completa $(0,25<\sigma<0,8)$. Usando-se o valor escolhido de $\sigma$ na equação $(5-6)$, o número de Froude ( $\left.\mathrm{Fr}^{\prime}\right)$ é calculado. A partir dele, a rotação requerida para o impelidor é calculada.

\subsection{Conclusões}

Simulações de fluidodinâmica foram aplicadas para desenvolver uma correlação semi-empírica simples para a qualidade da suspensão de partículas em tanques agitados providos de impelidores de pás planas. O modelo correlaciona a qualidade da suspensão à geometria do tanque, bem como às propriedades do sólido e do fluido para uma ampla faixa de condições, tais como diâmetro do impelidor e sua distancia do fundo do tanque, rotação do agitador, densidade e tamanho de partículas. Ajustando-se apenas um parâmetro do modelo, ele representou dados experimentais de Bohnet and Niesmak (1980), indicando que a sua estrutura é adequada para 
descrever sistemas com diferentes tipos de impelidores e propriedades materiais. O modelo pode ser empregado no projeto de tanques agitados para a determinação da rotação necessária para promover uma qualidade de suspensão especificada.

\subsection{Lista de símbolos}

\begin{tabular}{|c|c|c|}
\hline B & Largura da chicana & $(\mathrm{m})$ \\
\hline $\mathrm{C}$ & Distancia entre impelidor e fundo do tanque & $(\mathrm{m})$ \\
\hline $\mathrm{c}$ & Fração volumétrica de sólidos & $\left(\mathrm{m}^{3} / \mathrm{m}^{3}\right.$ mistura $)$ \\
\hline $\mathrm{c}_{\mathrm{AV}}$ & Fração volumétrica média de sólidos & $\left(\mathrm{m}^{3} / \mathrm{m}^{3}\right.$ mistura $)$ \\
\hline $\mathrm{D}$ & Diâmetro do impelidor & $(m)$ \\
\hline$d_{p}$ & Tamanho a partícula & $(\mathrm{m})$ \\
\hline Fr* & Número de Froude modificado & $(-)$ \\
\hline $\mathrm{g}$ & Aceleração da gravidade & $\left(\mathrm{m} / \mathrm{s}^{2}\right)$ \\
\hline $\mathrm{H}$ & Altura to tanque & $(\mathrm{m})$ \\
\hline $\mathrm{N}$ & Velocidade de rotação do impelidor & $(1 / s)$ \\
\hline $\mathrm{N}_{J S}$ & Rotação mínima do impelidor & $(1 / s)$ \\
\hline $\mathrm{Pe}$ & Número de Péclet para o sólido & $(-)$ \\
\hline$S$ & $\begin{array}{l}\text { Constante que depende da geometria do } \\
\text { sistema }\end{array}$ & $(-)$ \\
\hline $\mathrm{T}$ & Diâmetro do tanque & $(\mathrm{m})$ \\
\hline $\mathrm{W}$ & Largura do impelidor & $(\mathrm{m})$ \\
\hline $\mathrm{X}$ & Massa de sólido por massa de líquido & $(\mathrm{kg} / 100 \mathrm{~kg})$ \\
\hline
\end{tabular}

\section{Letras gregas}

$\begin{array}{lll}v & \text { Viscosidade cinemática } & \left(\mathrm{m}^{2} / \mathrm{s}\right) \\ \sigma & \text { Qualidade da suspensão } & (-) \\ \rho & \text { Densidade da partícula } & \left(\mathrm{kg} / \mathrm{m}^{3}\right) \\ \rho_{\mathrm{L}} & \text { Densidade do líquido } & \left(\mathrm{kg} / \mathrm{m}^{3}\right)\end{array}$




\subsection{Referências}

Angst, R. and Kraume, M., Experimental investigations of stirred solid/liquid systems in three different scales: Particle distribution and power consumption. Chemical Engineering Science 61, 2864 (2006).

Bohnet, M. and Niesmak, G., Distribution of solids in stirred suspensions. Ger. Chem. Eng. 3, 57 (1980).

Murugesan, T., Critical impeller speed for solid suspension in mechanically agitated contactors. Journal of Chemical Engineering of Japan 34, 423 (2001).

Musil, L. and Vlk, J., Suspending solid particles in an agitated conical-bottom tank. Chemical Engineering Science 33, 1123 (1978).

Ochieng, A. and Lewis, A. E., Cfd simulation of solids off-bottom suspension and cloud height. Hydrometallurgy 82, 1 (2006).

Ochieng, A. and Onyango, M. S., Drag models, solids concentration and velocity distribution in a stirred tank, Powder Technology 181, 1 (2008).

Ranade, V. V., Cfd simulation of liquid-phase mixing in solid-liquid stirred reactor. Chemical Engineering Science 64, 2273 (2009).

Rieger, F., Effect of particle content on agitator speed for off-bottom suspension. Chemical Engineering Journal (Lausanne) 79, 171 (2000).

Rieger, F., Effect of particle content on agitator speed for off-bottom suspension. Chemical Engineering and Processing 41, 381 (2002).

Rieger, F. and Ditl, P., Suspension of solid particles, Chemical Engineering Science 49. 2219 (1994).

Spogis, N. and Nunhez, J. R., Design of a high-efficiency hydrofoil through the use of computational fluid dynamics and multiobjective optimization. AlChE Journal 55, 1723 (2009).

Srinivasa, T. and Jayanti, S., An eulerian/lagrangian study of solid suspension in stirred tanks. AIChE Journal 53, 2461 (2007).

Van den Akker, H. E. A., The details of turbulent mixing process and their simulation. Adv. Chem. Eng. 31, 151 (2006).

Wichterle, K., Conditions for suspension of solids in agitated vessels. Chemical Engineering Science 43, 467 (1988).

Zwietering, T. N., Suspending of solid particles in liquid by agitators. Chemical Engineering Science 8,244 (1958). 